Portland State University

PDXScholar

$1-1-2010$

\title{
War, Peace, and Principled Action: A Study of Veterans and the Peace Movement
}

Laura Kay Wegener

Portland State University

Follow this and additional works at: https://pdxscholar.library.pdx.edu/open_access_etds Let us know how access to this document benefits you.

\section{Recommended Citation}

Wegener, Laura Kay, "War, Peace, and Principled Action: A Study of Veterans and the Peace Movement" (2010). Dissertations and Theses. Paper 392.

https://doi.org/10.15760/etd.392

This Thesis is brought to you for free and open access. It has been accepted for inclusion in Dissertations and Theses by an authorized administrator of PDXScholar. Please contact us if we can make this document more accessible: pdxscholar@pdx.edu. 
War, Peace, \& Principled Action: A Study

of Veterans and the Peace Movement

by

Laura Kay Wegener

A thesis submitted in partial fulfillment of the requirements for the degree of

Master of Science

in Sociology

Thesis Committee:

Peter Collier, Chair

Johanna Brenner

Martha Balshem

Portland State University

(C) 2010 


\begin{abstract}
Throughout the history of the United States (U.S.), there have been service members who, upon leaving the service, have spoken out against U.S. involvement in wars. The current conflicts in Afghanistan and Iraq, and their increasing unpopularity, have contributed to this trend. Recently veterans have begun to come forward in larger numbers to speak out against the current wars and have self-identified as members of peace movements.
\end{abstract}

The purpose of this research project was to explore veterans' understandings of the peace movement and their involvement in veterans’ peace movement organizations. This study hoped to answer the following questions: 1) How does a veteran understand the current peace movement? 2) Which, if any, parts of the current peace movement does a veteran find to be in line with his or her own values? 3) What do veterans feel it means to be a veteran for peace? 4) How do veterans come to identify with the current peace movement? 5) How do veterans take a stand against the current peace movement? 6) What do veterans feel is gained by involvement in the peace movement?

The study was conducted using a qualitative approach, and 27 interviews were conducted either face-to-face or over the phone with U.S. veterans from across the country, who have served since the Vietnam War. Veterans who were no longer serving in an active duty capacity were selected via a snowball sample of the researcher's circle of military colleagues and friends around the U.S. 
The identity of "veteran in the peace movement" is a complicated one, and the result of a long, complex, series of lived experiences. This study let participants describe the process of identity acquisition, or rejection in their own words in order to create a realistic and honest narrative about the emotional and mental processes, and life events that trigger or influence these, that influenced identification or not with a veterans' peace movement organization. 


\section{ACKNOWLEDGEMENTS}

I would like to thank all of my incredible friends and families. Even when you didn’t understand what I was doing, or I why I was subjecting myself to the "thesis torture,” you offered support, love, and encouragement. Most importantly, you kept me grounded and sane - when I had lost my motivation and my mood was low, you brought me back to earth with laughter and love. You restored my commitment and my passion for the research. I could not have done it without each one of you.

Thank you to my committee for your wonderful input and support. To my Chair, I offer my most heartfelt gratitude for your patience and guidance during this process. You kept me focused and on task when we both know I would have gone off into the Land of Literature, never to be heard from or seen again. Thank you so very much, all of you.

Finally, I would also like to offer my thanks and gratitude to the amazing veterans who agreed to let me interview them. I am humbled and honored that you were willing to share your stories of pain and joy, failure and triumph, with me. It is my hope that this work will reflect the honor you all so richly deserve, and the respect I feel for you and all that you have done, and continue to do, for this country. 


\section{Table of Contents}

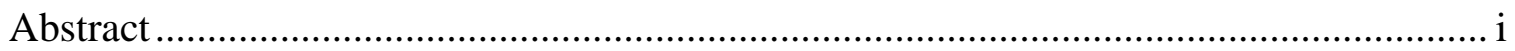

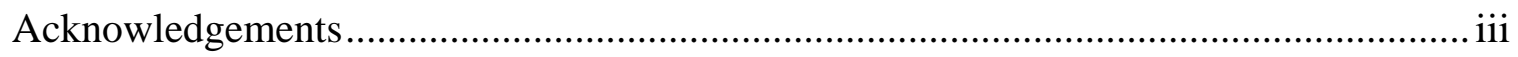

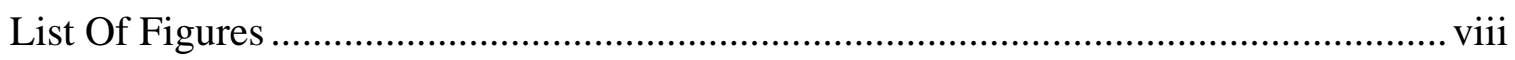

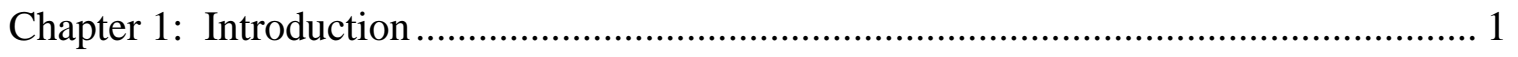

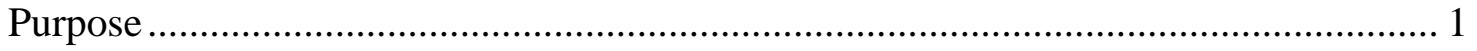

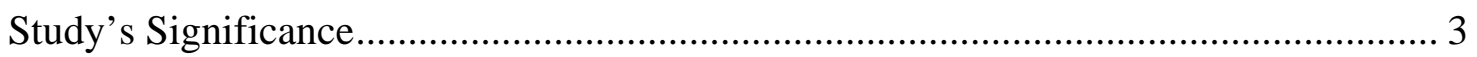

Research Questions .......................................................................................... 4

Historical Background.................................................................................... 5

Chapter 2: Literature Review And Theoretical Framework ........................................ 13

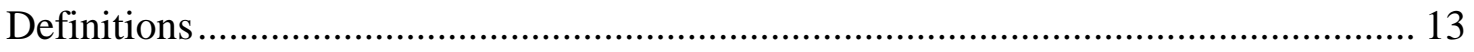

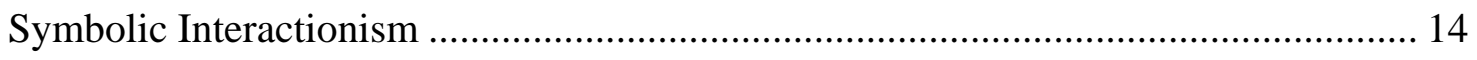

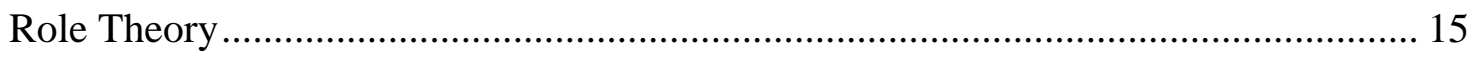

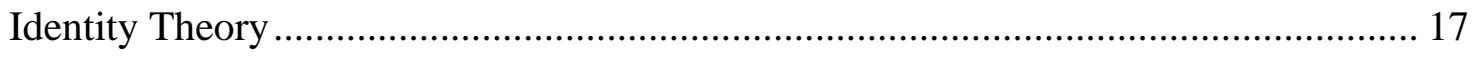

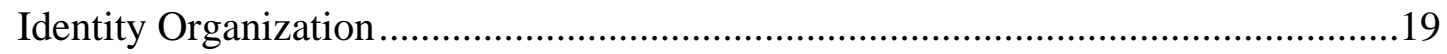

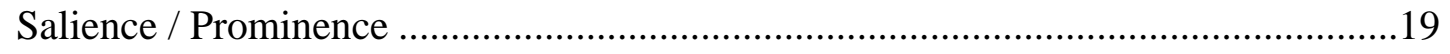

Role Mastery: Learning A New Role …..........................................................23

Meadian Concept Of Role............................................................................... 24

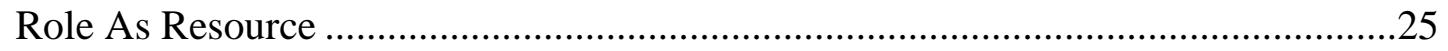




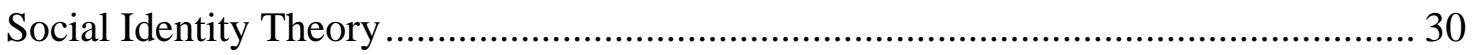

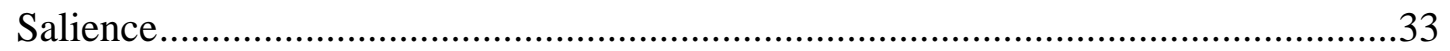

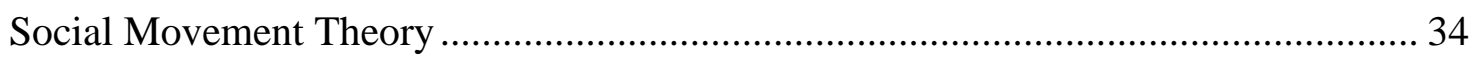

Theoretical Approaches.........................................................................................

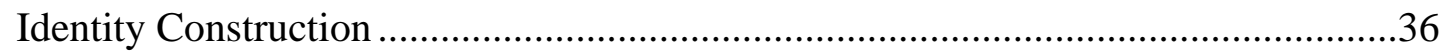

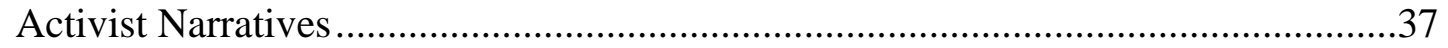

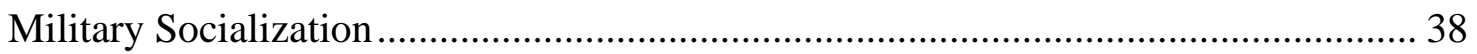

Integrating The Literature .................................................................................... 42

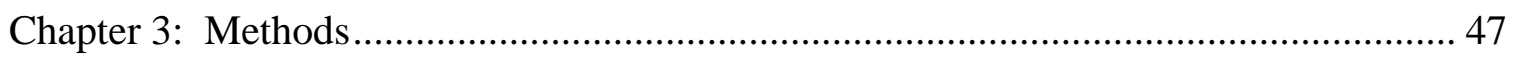

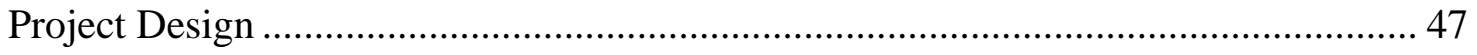

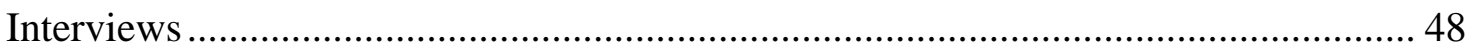

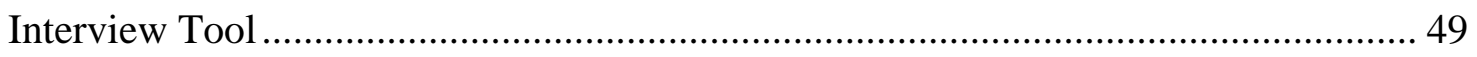

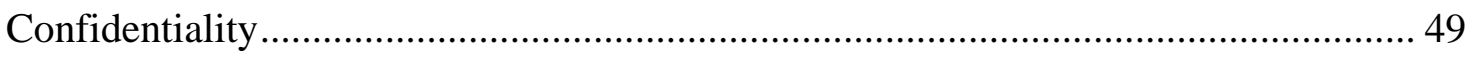

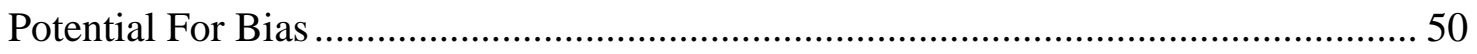

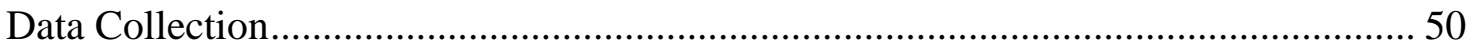

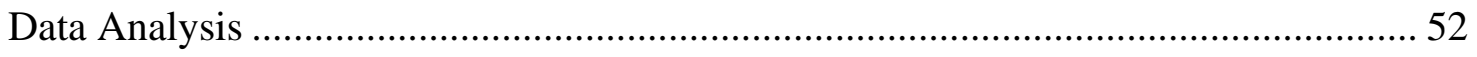

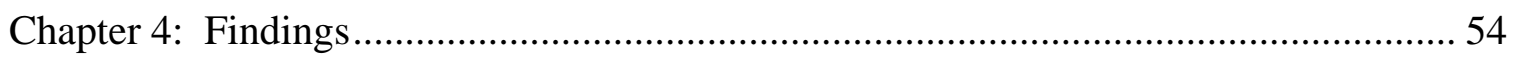

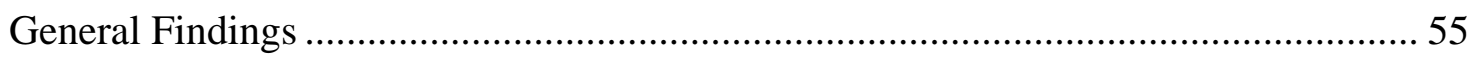


Interaction Of Veterans’ Demographic Information And Experiences.

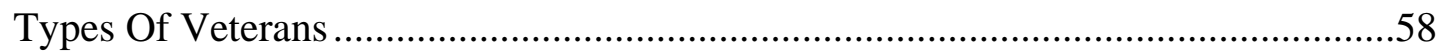

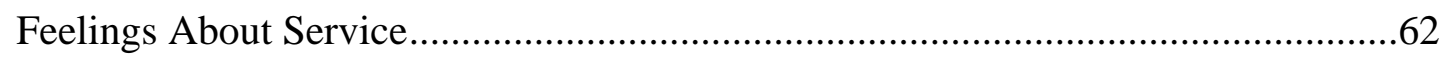

The Peace Movement \& Getting Involved.................................................................... 67

Views On The Peace Movement ................................................................................67

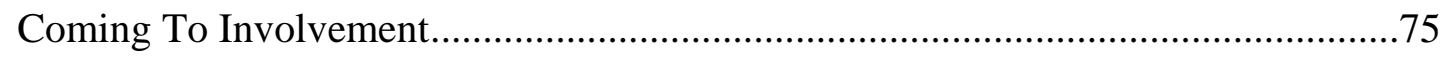

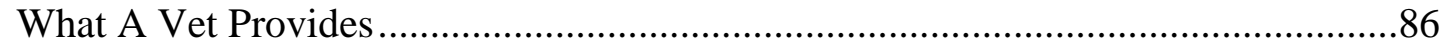

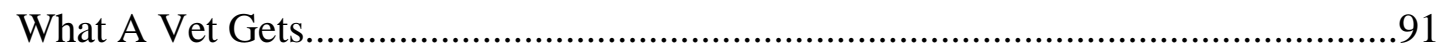

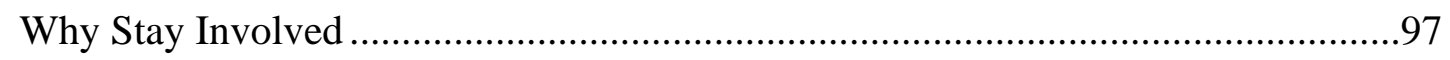

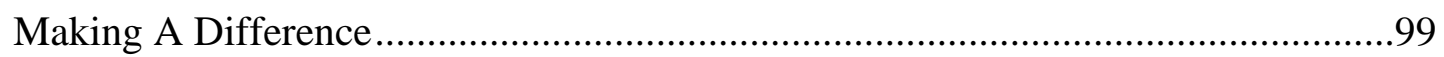

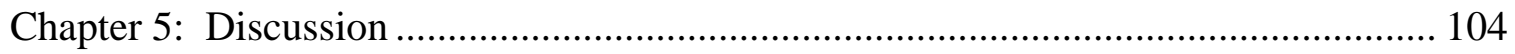

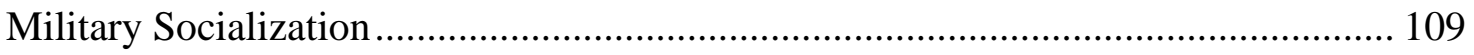

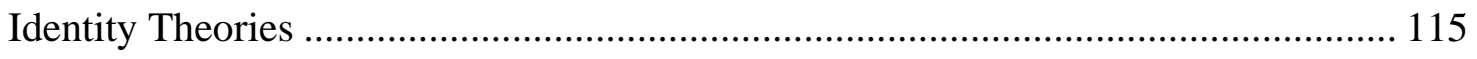

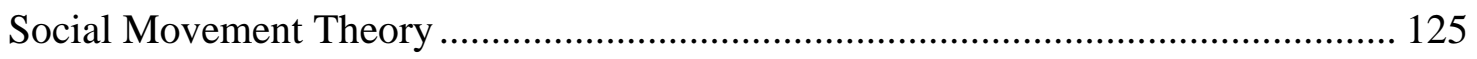

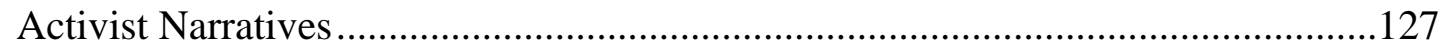

Identity Construction ..........................................................................................129

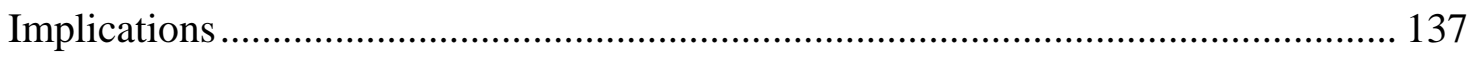

Implications For The Veteran Peace Movement .......................................................137

Implications For The Veteran Peace Movement Members ........................................138 
Implications For The Veterans

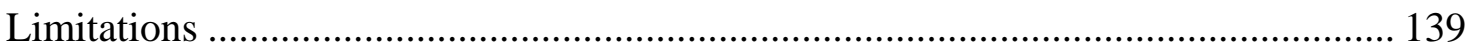

Suggestions For Future Research ........................................................................ 140

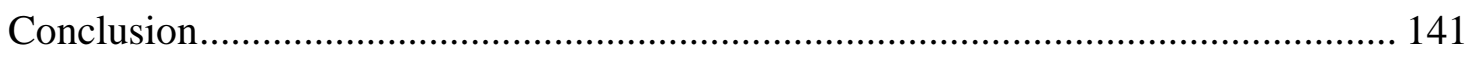

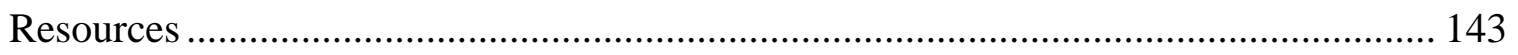

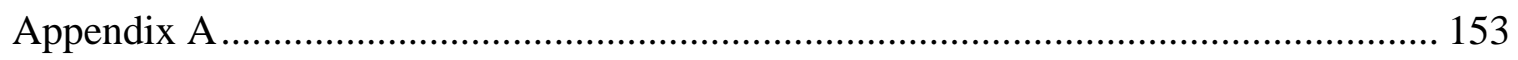

Interview Recruitment Poster.................................................................................... 153

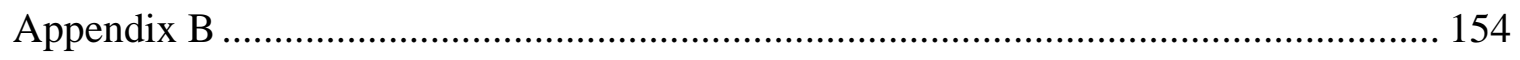

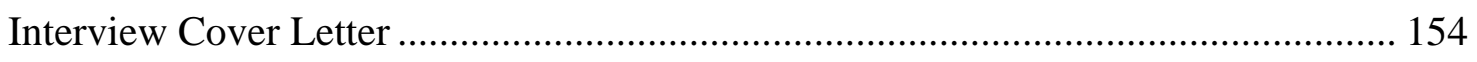

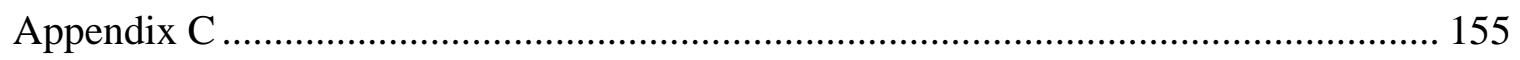

Letter Of Consent ............................................................................................. 155

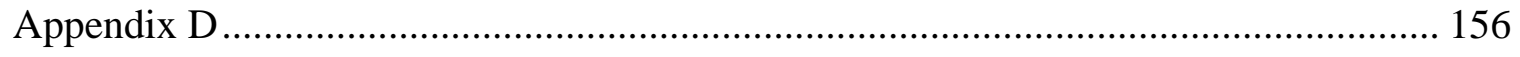

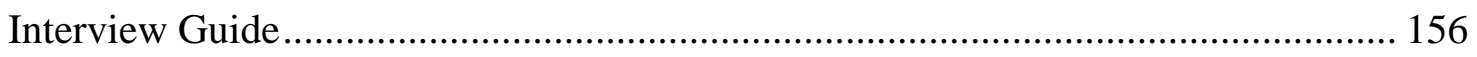

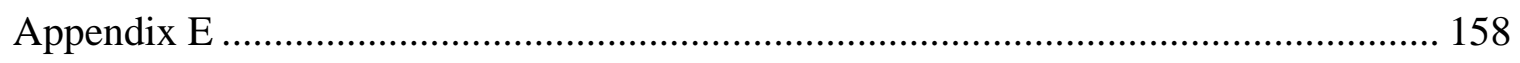

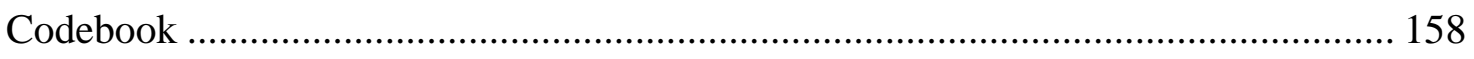




\section{LIST OF FIGURES}

FIGURE

1 Participant Demographics

2 Being the Same and Different
PAGE

51

101 


\section{CHAPTER 1: Introduction}

What is it that leads one veteran to leave military service and then internalize ideologies like those of peace movements, while another veteran holds onto ideologies of patriotism that are based on the honor of war and military action? Throughout the history of the United States (U.S.), there have been service members who, upon leaving the service, have spoken out against U.S. involvement in subsequent wars. However, it is only recently that some veterans have begun to shift from an idea of patriotism equated with honorable military service, to one that also includes the possibility of participation in efforts for peace and conflict resolution without violence or military intervention. The Vietnam War triggered protests and polarized civilian citizens of the U.S. Veterans of that war, and the wars that followed, were no exception. Many veterans have come forward to speak out against the current wars and have self-identified as members of peace movements. The current conflict in Iraq, with its increasing unpopularity, has resulted in a continuation of this trend; what is particularly interesting is the increase in the number of veterans in anti-war and pro-peace organizations.

\section{Purpose}

The purpose of this in-depth interview research project will be to explore a national sample of U.S. veterans' understandings of the peace movement and their contact with, or involvement in, peace movements. For this study, U.S. veteran is understood to refer to both males and females who served in an active duty capacity in any branch of the military service since the Vietnam War. This time period was selected because many of the leaders of today's veteran peace movement are veterans from that 
conflict. Additionally, only veterans who are no longer serving in an active duty capacity were selected in order to reduce the possibility of negative consequences, such as being ostracized from their units or finding themselves slandered or mistreated by others with whom the veteran serves but who do not share her views. Respondents were selected via a snowball sample of the researcher's circle of military colleagues and friends around the U.S. Additionally, flyers were posted around the Portland State University campus to increase the number of participants. While this is a convenience sample, the regional diversity provided richer data, due to a greater range of political and social perspectives. Finally, for this study, peace movements are defined as efforts based on beliefs centered around prevention, de-escalation, and conflict resolution via non-violent means such as demonstrations, boycotts, lobbying, or diplomacy.

The study was conducted using a qualitative approach. The identity of "veteran in the peace movement" is a complicated one, and the result of a long, complex, series of lived experiences. This study lets participants describe the process of identity acquisition, or rejection in their own words in order to create a realistic and honest narrative. This level of detail and depth can best be accomplished via qualitative research methods, as opposed to surveys or other quantitative methods.

As a result, in depth interviews were utilized for this study. This method of data collection allowed a deeper look into veterans' stories and moved beyond demographic similarities such as race, service, or gender. While demographic factors may indeed have an influence and be important, it is the aim of this study to look specifically at the 
emotional and mental processes, as well as any life events that trigger or influence these, that lead a veteran to identify or not with a peace movement.

\section{Study’s Significance}

This study adds to the knowledge of peace movements and might, hopefully, be useful to veterans who are encountering issues in their own lives, specific to both their identities as veterans and the peace movement. For example, a veteran may be attempting to negotiate evolving ideas about the value of military action versus diplomatic action; or, may be seeking an answer to the question: Is it more patriotic to follow the orders of your Commander in Chief, or to take a stand for something other than military intervention/action? In light of the changing face of politics in the U.S. with the election of Barack Obama, the time has come to take a deeper look at the involvement of veterans in peace movements. Perhaps it is reasonable to ask if the changing face of foreign policy and the changes in the military climate - the possibility of ending a U.S. military presence in Iraq and escalation of U.S. involvement in Afghanistan, and a new President who prefers and encourages diplomacy rather than immediate and swift military intervention - might encourage more veterans to begin considering involvement in peace movements.

A better understanding of veterans’ personal military experiences might be useful in appreciating ways of resolving conflict without violence. A deeper understanding of the meaning of peace movement for veterans might also aid in awareness about the range of understanding and emotional commitment, as well as the types and extents of involvement, available to veterans in peace movements. Finally, this study sheds light on 
the variety of opportunities for peace movement involvement for veterans who might otherwise shy away due to more traditionally understood definitions of what it means to be in the peace movement. Many veterans still equate peace activists with veteran-haters, and so are unlikely to be willing to openly associate with activists.

Shedding light on the lived experiences and personal beliefs of these veterans may serve to inspire peace movement involvement by others. Likewise, giving a voice to these veterans may also provide validation for veterans not only unsure if they have a place in peace movements, but also, what they can offer and what they might gain.

\section{Research Questions}

This research is about role understanding and identity development. The overarching research question is "How do post Vietnam-war era U.S. veterans understand, and in some cases come to identify with, the role "veteran in a peace movement?" This research seeks to understand the identity processes involved in veterans answering the question "can a person like me be part of the peace movement?” Some will decide they can be a part of it. Some will decide to reject it. As a result, this research will provide an idea of shared identity and common meaning among veterans in relation to the peace movement. There are several specific questions to address. These are:

1. How does a veteran understand the current peace movement?

2. Which, if any, parts of the current peace movement does a veteran find to be in line with his or her own values?

3. What do veterans feel it means to be a veteran for peace?

4. How do veterans come to identify with the current peace movement? 
5. How do veterans take a stand against the current peace movement?

6. What do veterans feel is gained by involvement in the peace movement?

\section{Historical Background}

"We have been taught to ring our bells, and illuminate our windows and let off fireworks as manifestations of our joy, when we have heard of great ruin and devastation, and misery, and death, inflicted by our troops upon a people who never injured us, who never fired a shot on our soil, and who were utterly incapable of acting on the offensive against us." - William Jay, A Review of the Causes and Consequences of the Mexican War (1849)

In 1812, the United States was still a newly formed nation, on the brink of war with what was, at the time, the reigning empire. The new nation had been pulled into the conflict between France and England against its will. In spite of the fact that England's Navy was pressing Americans into service, many in New England considered policy decisions that had led many to the poorhouse and were severely damaging commerce to be the main cause of the war. Still others saw this as a war of conquest and cited the U.S. government’s desire to annex Canada for the Unites States (Polner \& Woods 2008). There followed protests and statewide militias refusing to serve, even while others were drawn into the fight. As the war dragged on, and the U.S. began to suffer some serious land-based losses, support for the war became scarcer, the anti-war movement pressed forward, and volunteers to fight dwindled (Polner \& Woods 2008).

However, for many, opposition to the war was seen as treasonous and unpatriotic. As was famously stated, "He who is not for us is against us" (Hoey 2010, www.earlyamerica.com). Newspaper office buildings were destroyed by mobs and Baltimore, in particular, was a hotbed of anti-war protestor backlash. Riots broke out 
there against protestors at the beginning of the war, but the backlash faded as the war became increasingly unpopular.

While there is little direct connection between the protest efforts of the war of 1812 and later anti-war movements, those movements that came later can trace their roots to this first movement. Several peace societies formed and died afterward, and others continued to form as the nation grew and became involved in more wars (Hickey 1990). In addition, governmental spending during this war led to a financial crisis, which came to be known as the "Panic of 1819” (Polner \& Woods 2008).

While there was opposition to the Mexican War, most Americans believed in their “manifest destiny” and were eager to annex Texas (Andreas 2010; Polner \& Woods 2008, p. 23). President Polk hoped for an act of aggression by the Mexican government so that he might have an excuse to attack. As a result, he placed U.S. troops in the disputed area and waited for the Mexicans to take action against them. When they did, Polk declared, "Mexico has passed the boundary of the United States, has invaded our territory and shed American blood upon the American soil. She has proclaimed that hostilities have commenced, and that the two nations are now at war” (Polner \& Woods 2008, p. 22; www.yale.edu 2010). Abraham Lincoln, at the time a Congressman, spoke out against the war as he believed, rightly so, that the conflict has been set up. As before, protesting was seen as unpatriotic. For example, Henry David Thoreau was jailed due to his protests.

Protests began in earnest again with the coming of the Civil War. This pre-war protest effort peaked with the candidacy, and subsequent failure, of George McClellan for 
President as the “Peace Democrat” (although he didn’t agree with the party’s platform) (Dudley 1932). The basis of the movement was not so different from those stated today the cost-benefit deficiency, the horrors of war that veterans and their families face, and the disgrace of war for profit. In addition, many believed that slavery would die if the North simply stopped supporting it, and no war was necessary (Polner \& Woods 2008). Once the Civil War was in full swing, the peace movement suffered and fell apart because many of them were pacifists, and others protested on a platform of keeping the Union together. Once the war began, pacifism seemed pointless, as did efforts to keep the Union, now split, whole. During the war, there were protests in New York City against the draft; mostly due to the fact that the wealthy could pay someone else to serve in their stead (Harris 2003; Murdock 1967). This too, is not so different from people who speak out against the military today, stating that it targets those who are poor or have no other options.

The Civil War brought forth, for the first time in the nation's history, government suspension of people's legal rights, censorship of the media, jailing of editors who spoke out, citizens arrested and jailed with no trial, and the use of troops to break up strikes and protests (Polner \& Woods 2008, p. 57). President Lincoln, as those before and after him, in an effort to justify his actions, spoke of the U.S. government as an "instrument of God's will” (Polner \& Woods 2008, p. 58).

The Spanish-American war brought the U.S. into international politics in a way it had not previously been, that lasted into the $20^{\text {th }}$ century (Stromberg 1998; Zakaria 1999). However, here again, many Americans were concerned over the colonialist nature of the 
Spanish-American war and spoke out against the U.S. becoming another imperialist power. Mark Twain and many others, including veterans from the Civil War, spoke out because they believed that the U.S. went to war, not for the noble cause of freeing the people under Spain, but rather, to expand its territories and control (Andreas 2010; Greenberg 2003; Polner \& Woods 2008; Zwick 1992).

World War I introduced a new wave of anti-war and peace movement efforts. In June of 1918, Eugene Debs stated:

"And here let me emphasize the fact - and it cannot be repeated too often - that the working class who fight all the battles, the working class who make the supreme sacrifices, the working class who freely shed their blood and furnish the corpses, have never yet had a voice in either declaring war or making peace. It is the ruling class that invariably does both. They alone declare war and they alone make peace" (Polner \& Woods 2008, p. 115).

However, by and large, these protest efforts were post-war. While President Wilson told the American people that the "world must be made safe for Democracy" (Polner \& Woods 2008, p. 117), and U.S. Ambassador to the United Kingdom (U.K.) stated, "the only way of maintaining our present pre-eminent trade status" was to declare war on Germany (Andreas 2010). As a result, this is a time when the peace movement began to really focus on the corporate interests of war, the maintaining of the status quo at the cost of young lives, and drafts that targeted the poor but gave them no voice in decisions regarding military action (Polner \& Woods 2008, p. 118). It is also during this time that the peace movement began to see another surge of veteran involvement. Similar to what occurred at the outbreak of the Spanish-American war, veterans from the Civil War once often again spoke out against U.S. involvement in the war. 
As before, opposition to the war was seen as unpatriotic. People who spoke out against the war found themselves arrested and sentenced to long prison terms due to the Espionage Act of 1917 and the Sedition Act of 1918 (Davis 2004; Karp 1979; Polner \& Woods 2008). President Wilson supported these measures, and as late as 1933, some people who had spoken out against the war were still waiting to be released from prison for speaking out against the war (Polner \& Woods 2008, p. 118).

World War II introduced a new generation of protestors, and the final step in producing a movement with a focus of shared common goals. However, the war resistance was almost entirely focused to the beginning of the war, and faded to a few dedicated pacifists as it progressed (Romero 2009; www.alba-valb.org 2010). Peace movement efforts picked up again as the Cold War began as nuclear armament became more and more prolific, and more young men and women were put into harm's way (Brown \& Brutoco 1997; Davis 2004). During this time, protestors were seen with suspicion and might find themselves labeled a communist, or under government surveillance (Peace III 1991; Wittner 1984). The Cold War boosted the power and position of the military-industrial complex, and the policymaking ideals that came from this time have come to dominate even into today (Polner \& Woods 2008, p. 197).

When one considers the peace movement, Vietnam era protests are the most likely to come to mind. This movement began in the early 1960s, although opposition to any involvement in Vietnam had been brewing since the 1950s when the U.S. stepped in after the French left (Barringer 1998; Zaroulis \& Sullivan 1964). Media coverage of antiwar street protests, and the shooting at Kent State, both served to make the movement 
more available and real to the public at large, and cemented the resolve of protestors (Fink 2010). As happened during the Civil War, the wealthy and elite were able to avoid the draft (Polner \& Woods 2008, p 230-231). At the same time, increasing numbers of Vietnam veterans returning from the war began to get involved in the anti-war movement.

Many of those involved in the peace movement from the Vietnam era, and many veterans who served in that war, are now the foundation of today's movements against the Iraq and Afghanistan wars. This paper focuses on the involvement of Vietnam and post-Viet Nam era veterans in the current peace movement in the U.S.

In looking back, it is eerie to see the parallels between the wars and struggles of the past with those of today. As Polner and Woods (2008, p. 231) point out, today's government uses the same tactics of spotlighting "dubious and exaggerated incidents” to garner support for going to war that President Lyndon Johnson used to support U.S. involvement in Viet Nam in the 1960s. The speeches of supporters and non-supporters have changed very little, and the arguments made are virtually identical. What is different today is that there are a variety of peace and anti-war organizations for veterans. For example, Veterans for Peace (VFP) is an organization compromised of male and female veterans of World War II, the Korean War, the Vietnam War, the Gulf War, and other conflicts, as well as peacetime veterans. Founded in 1986, VFP is a national organization with chapters in 44 states, and works to promote alternatives to war. According to the organization's website (http://www.veteransforpeace.org/), VFP draws upon the "personal experiences and perspectives gained as veterans to raise public 
awareness of the true costs and consequences of militarism and war - and to seek peaceful, effective alternatives.”

A similar organization is Iraq Veterans Against the War (IVAW). This particular organization was founded by Iraq War veterans in July 2004 and is an affiliate to VFP. The stated aim of IVAW is to give a voice to the large number of active duty service people and veterans who are against the war, but feel pressured to remain silent (http://ivaw.org/about). Further, IVAW is working to achieve an immediate withdrawal from Iraq, as well as reparations for damages that Iraq and its people have endured. Along with this, IVAW seeks to stop the commercial looting of Iraq so that the citizens of Iraq are allowed to control their own lives and future. Finally, IVAW hopes to garner full benefits, adequate healthcare (including mental health), and other supports for returning servicemen and women (http://ivaw.org/about). Membership is a conglomeration of veterans from all branches of the armed forces, including the National Guard and reservists who have served since September 11, 2001. IVAW is a national organization with chapters in 48 states, DC, and Canada, as well as several U.S. military bases located overseas

Of course, it is not necessary for an individual to affiliate with an organization in order to see herself as a part of a peace movement. Often, simply identifying with the aims and goals, or having an ideology that is similar to, a larger organization is enough for an individual to have a feeling of being a part of a peace movement. Unfortunately, there is very little research to illuminate the reasons why some veterans would openly identify with a peace movement's aims and goals, or a specific peace movement 
organization, while others would not. And there is even less research that provides insights into what a veteran involved in or identifying with a peace movement organization might hope to accomplish on a more personal and individual level.

In this chapter, an introduction of the research being done, and the study's significance were provided. Additionally, the research questions were presented, as was a discussion of the historical background of veterans and peace movement activities that relate to this project. The following chapter will provide an overview of the literature and theoretical framework that guided this research. 


\section{CHAPTER 2: Literature Review and Theoretical Framework}

While there is very little literature that specifically focuses on the topic of veterans and their attitudes toward and involvement with the peace movement, insights into this topic can be gained through examining literature from related areas - e.g. identity development, adult socialization, and social movement participation, Therefore, this literature review is divided into five parts: definitions, identity theories, social movement theory, military socialization, and a discussion of how the different theories inform the current research.

The first section of this chapter will lay out and define the key terms used in this study. The second section will examine identity theories - i.e. symbolic interactionism, role theory, identity theory, and social identity theory. The third section of this chapter will explore the reciprocal relationship between participating in social movements and the development of personal and collective identities. More specifically, how does involvement in a social movement influence personal and collective identities, as well as how do personal and collective identities influence involvement in a movement? The fourth section, military socialization, will help in understanding how a veteran comes to identify as a service member via socialization, and the impact this has on political and personal beliefs. The final section will explain how the different theoretical perspectives inform and complement each other in regards to the current thesis project.

\section{Definitions}

This study focuses exclusively on U.S. veterans, and their identity development and transformation as it relates to their opinions of, and possible involvement with, the 
peace movement in the U.S. In this study, the term "U.S. veteran" refers to both males and females who served in an active duty capacity in any branch of the military service since the Vietnam War, but are no longer active duty. A veteran can self-identify several ways. In general, however, they are identified by the war they fought. As such, there are Vietnam veterans, Iraq veterans, Iraq II veterans - identified as such due to the combats in progress during their service; more generally, there are combat veterans, and noncombat veterans - so identified by if they were involved in combat or not. Finally, "peace movement" is defined as beliefs of non-violence, anti-war, or pro-peace that result in actions or efforts centered around prevention, de-escalation, and conflict resolution via non-violent means such as demonstrations, boycotts, lobbying, or diplomacy.

\section{Symbolic Interactionism}

All of the identity theories discussed in this section build upon a foundation of symbolic interactionism Symbolic interactionism, linked to the work of George Herbert Mead (1934) developed in part as a response to William James’ (1890) description and classification of the self as material, social, and spiritual. While Mead saw the self as exclusively social, he did agree with James that the social self existed in relation to others, and was reliant on social interaction (James 1890; Mead 1934), "for it is from the social process that mind, self, and society derive” (Stryker \& Serpe 1982, p. 202).

Mead's view of the self was that it is reflexive, and both subject and object (1934, p. 291). There are three basic premises in a symbolic interaction perspective (Blumer 1969; Howard 2000; Mead 1934; Stryker \& Serpe 1982). These are: 1) Human beings act toward things on the basis of the meanings they ascribe to those things; 2) meaning is 
derived from, or arises out of, the social interaction that one has with others and the society; 3) these meanings are handled and modified through an interpretive process used by the person in dealing with the things he/she encounters. Building upon these foundational premises, Mead argues that the self is multi-faceted because society is multi-faceted (Mead 1934). Role theory, identity theory, and social identity theory are all efforts to explain both the development and organization of the multi-faceted self as described by Mead.

\section{Role Theory}

Within Sociology, the concept of "role" provides a useful way to explain the selfsociety relationship described by Mead (Callero 1994). Role theory focuses on how individuals determine what is the socially expected, "correct," and/or most appropriate action by referring to a range of roles available to them.

Initially, there were two distinct perspectives in role theory - a structuralist perspective that focused on how the organization of society directed and constrained individual behavior, and, an interactionalist perspective that emphasized individual agency and the creation of the larger social structure through patterns of individual interactions. According to a structuralist interpretation, the way a society is "set-up" influences the development of the self (Parsons 1951). Society is made up of institutions that address specific societal "functions" (e.g. the institution of "family” meets society's need for new members, the institution of "education" meets society's need for an informed workforce). Each institution, in turn, is made up of many statuses or positions (e.g. statuses within the institution of education include teacher, student, principal). 
Statuses are socially defined positions that an individual occupies within a given institution. Individuals who occupy specific statuses internalize a "role" -- a set of expectations for how someone of that particular status should act. Parsons (1951, p. 29) notes that when individuals interact with others, each conforms to a set of "mutual expectations [that are] definite and durable [and called] standards.” Standards are sets of mutual expectations that guide role enactment and individuals expect that others will act according to those standards. Because individuals can occupy more than one status, they can have more than one role. When a role is enacted, the person enacting it will develop a role-identity and in these various roles the expectations will vary (Parsons 1951).

Finally, it is important to understand that individuals are not born into these roles and statuses, but rather they are learned in a process of involvement in society. A female is not born knowing how to "do" Mother or Daughter anymore than a male is born knowing how to "do" Father or Son. These are roles an individual learns from the larger society; whether an individual is born into them (son/daughter) or achieves them (mother/father), they must be learned. Additionally, not all statuses are available to all people as the structure of society limits the legitimacy of certain statuses to certain people. For example one must be, in most cases, not only male, but also Catholic and ordained by an approved authority, to be a Catholic priest.

The work of McCall \& Simmons (1966) exemplifies the interactionist role theory perspective. According to McCall \& Simmons, a personal identity is a set of categories that describe a unique person and, "serve as the pegs upon which social identities and personal biographies can be hung” (1966, p. 65), while a social identity is pulled from 
broader social groups/positions (p. 64). A role identity is a form of social identity in that it is an individual's idealized and imagined view of "how he likes to see himself being and acting” (p. 67) as an individual within a particular social position.

While structuralist role theory is a top-down model, McCall \& Simmons' is a bottom-up perspective that focuses on how individuals construct the meaning of social roles through interaction. For McCall \& Simmons, society develops through interaction between people, and over time, repeated patterns of interaction create the meanings of roles and social positions. For them, structure exists in the moment and is only possible if there are participants to take part in and witness each other's actions (p. 65-66). Several ideas from the interactionist approach have been incorporated into identity theory.

\section{Identity Theory}

Identity theory builds upon symbolic interactionism. Identity is defined as individuals' understandings and labeling of themselves in terms of relationships and particular social roles, and is an answer to the question, “Who am I?” (Howard 2000; Mead 1934; Stryker \& Serpe 1982). Symbolic interactionism assumes that behaviors are organized in response to social factors, and that "structured role relationships impact on self and through self on social behavior, and that there is reciprocity in the direction of impact” (Stryker \& Serpe 1982, p. 200) in terms of the individual's relationship with others (Mead 1934). Identity theory examines the choices an individual makes when several rational role-related options exist. Specifically, this theory focuses on the consistency/inconsistency of choices made, any conflict of role-related expectations experienced by an individual, and the allocation of resources, such as cultural capital, to 
that individual (Stryker \& Serpe 1982, p. 205). The key for identity theory is to explain why an individual, with multiple courses of role-related action available, will pick a particular one (Stryker \& Serpe 1982, p. 207).

From an identity theory perspective, the self-concept is seen as multi-faceted because "persons may have as many identities as the number of distinct sets of structured relationships in which they are involved” (Stryker \& Serpe 1982, p. 206). For example, a man can simultaneously be a Marine, father, son, best friend, or pet owner; likewise, a woman can be a soldier, mother, daughter, soccer player, or hiker. Each of these is a different identity, in conjunction with different roles these individuals enact in their everyday life and relationships, and each requires a set of behaviors based on a different set of expectations for each identity.

Finally, it is important to note that an individual's total number of identities is not fixed. Individuals have agency, and this provides opportunity for the development of new identities and ways of seeing the world or behaving to achieve a desired goal (Burke 1991) because “individuals are not merely passive objects of socialization but agents who act to create contexts in which their identities are verified [and] the self is formulated, is maintained, and is subject to change in an ongoing interpersonal context” (Cast, Stets, \& Burke 1999, p. 78).

The following sections of the literature review will elaborate on identity organization, identity verification, and role mastery. The first section, identity organization, will examine hierarchy, salience, context and personality, and commitment. The identity verification section will explore Burke’s (1995, 2005) feedback loop as a 
mechanism used by individuals to determine how to best enact an identity based on a desire for self-verification from others. The final section, role mastery, will elaborate on the process of learning a new role and developing "role mastery" through the process of what Turner (1978) called "role playing” and "role making."

\section{Identity Organization}

Although an individual may have multiple identities, the likelihood of different identities being enacted in a given situation is not the same. Each role-identity is not equally important to the individual. Identities are organized into a hierarchy based on their relative importance, or salience, to the individual (Burke 1991; Stryker 2000). In addition, commitment -- the degree to which a given identity is important in maintaining key social relationships - affects that identity's relative salience (Burke 1991; Stryker 2000).

\section{Salience / Prominence}

Salience in identity theory is similar to the interactionist concept of prominence because both refer to an identity's relative location in the individual's role-identity hierarchy (Stryker \& Serpe 1982, p. 206). The more important the identity, the more likely the person is to enact that identity in interactions with others (Stryker \& Serpe 1982, p. 206-207). Several factors have been identified as influencing the importance of a given identity within the identity hierarchy, and these are: 1) self-support, 2) othersupport, 3) self-investment, 4) material investment, 5) extrinsic rewards, and 6) intrinsic rewards (McCall \& Simmons 1966, p. 80-81). 
Self-support is the support for an identity that a person gives to him or herself that "supports his own imaginative view of his qualities and performances as an occupant of a given position” (McCall \& Simmons 1966, p. 77) and helps to guide actions and behaviors to ensure alignment with an identity. Other-support comes from "people whose evaluations and appraisals of this role could be expected to count” (McCall \& Simmons 1966, p. 77), such as bosses, professors, parents, and friends.

For McCall \& Simmons (1966), self-investment is dependent on how much an individual has "gambled his regard for himself on living up to certain imaginations of self” (p. 78). Material investment relates to what an individual is willing to dedicate to an identity, for "if one stakes his entire fortune or Life's work on fulfilling a particular view of himself, that identity will be more prominent in the hierarchy, for one does not live by imagination alone” (McCall \& Simmons 1966, p. 78). Extrinsic rewards are what is gained from an identity in the form of "goods, favors, prestige, and the necessities of life" (McCall \& Simmons 1966, p. 78). Finally, intrinsic rewards do not rely on performance of an identity, but rather, relates to the pride an individual feels about the identity.

In the end, salience alone will not account for whether an identity is enacted or not. Stryker \& Serpe (1982) note that enactment also depends upon the characteristics of the situation and personal characteristics such as self-esteem or level of satisfaction (p. 209). Some situations make enactment of certain specific identities either easier or harder (e.g. enacting a nudist identity in a college classroom). Similarly, an identity that is a major source of an individual's self-esteem, regardless of its placement in the 
hierarchy or support from others, will more likely be enacted than one that is not so personally valued.

\section{Commitment}

Consistent with identity theory's symbolic interaction foundation, the nature of an individual's role-based interactions with others affects the salience of that identity. Commitment is defined as the degree to which an individual's interactions with important other people in her life depend upon that individual being a "particular kind of person" or enacting a particular identity (Stryker 2000, p. 32). The relative importance of an identity is dependent on the actor's commitment to the identity (Burke 1991, Stryker 2000). In short, commitment is dependent on how much an individual has "gambled his regard for himself on living up to certain imaginations of self” (McCall \& Simmons 1966, p. 78). Burke and Reitzes propose that (1991), there are "two dimensions of commitment: 1) extensiveness, the sheer number of relationships to others entered by virtue of having an identity, and 2) intensiveness, the depth of the relationships entered by virtue of an identity” ( $\mathrm{p} 241$ ). Salience is likely to be greater when commitment is greater, and the more salient the identity the more likely behavior will coincide to expectations (Stryker 1982, p. 208).

\section{Identity Verification}

Burke (1991) examines how individuals decide how to best enact an identity based on a desire for self-verification from others. He explains this process of identity verification through a feedback loop that is continually activated when a particular identity is enacted (Burke 1991, p. 837). There are multiple parts of the feedback loop: an 
internalized role standard, input from others about the person's current state of role enactment, output, a cognitive comparison process, and output, in the form of role related actions (Burke 1991, p. 837). Through the cognitive comparator process, the person compares the internalized role standard with self-referent feedback from others in an effort to minimize the 'gap' between the standard and the enacted behavior, and to gain positive feedback, or limit or eliminate negative feedback from others. This continues until the individual is enacting the role 'correctly' and feedback received is consistently positive and affirming.

When there is a disconnect between how an individual sees herself and how others see her an identity discordance can arise causing strong emotions that will need to be resolved via a shift in the understanding and definition of the self. Social stressors can also interrupt the identity process and lead to changes in identity. According to Burke (1991), there are four types of identity interruption: broken loop, interferences from other identities, over-controlled identities, and episodic identities (p. 841-844).

A broken loop exists when "the loop of the identity control process is broken by external events [that interrupt] the normal, continuous, automatic adjustment process” (Burke 1991, p. 841). Breaks can occur at either the input location (where the identity receives input from the environment) or the output location (where the behavior enters the environment) of the identity loop (p. 841-842). Additionally, depending on where the break occurs, an individual will be faced with different problems.

If a break occurs at the input, the actor/individual does not recognize or understand the response of others to her behaviors, but if a break occurs at the output, the actor's 
behavior does not have the intended influence on others (Burke 1991, p. 843).

Interference from other identities occurs when there is a "negative connection between (among) two (or more) identities [such that] increasing congruence with respect to one identity, decreases the congruence for another” (Burke 1991, p. 842).

Over-controlled identities are "'tightly" controlled identities [that] attempt to match the reflected appraisals to the actual identity almost exactly” (Burke 1991, p. 843). In other words, they are identities that are perfectionist in nature and prone to higher levels and occurrences of distress. Because it is nearly impossible to perform an identity perfectly, the individual will invariably feel the failure on many occasions and be forced to constantly "monitor and adjust [the] identity process" (Burke 1991, p. 843). A person with a less tightly controlled identity is more likely to "laugh it off" or "roll with the punches” when identity performance in not perfect.

Finally, episodic identities are identities that lack practice or feedback because they are used only occasionally and this is why an interruption occurs (Burke 1991, p. 844). These identities tend to be rehearsed mentally via "what-if" scenarios, but are likely not "learned well enough that the behavior required is automatic... [resulting in] true interruption of the identity process” (Burke 1991, p. 844).

\section{Role Mastery: Learning a New Role}

Within identity theory, the process of learning a new role, or gaining a deeper understanding of a role, is referred to as the development of "role mastery." Turner (1978) explains role mastery through the concepts of "role playing” and "role making."

According to Turner, role playing is when an individual utilizes what she perceives to be 
the standard version of a role when she is unsure of the role situation (p. 6). At this stage, the individual's role enactment is compartmentalized and completely context-specific. During this phase, the person's behavior is dependent on what seems easiest, safest, and most effective (p. 6). On the other hand, role making begins to occur when a level of familiarity with the role exists that allows the individual to develop and then enact her own version of the role (Turner 1978, p. 13, 17-18). At this point, the role is crosssituational. This is an iterative process and as she learns more, and her understanding of the role increases, so will her ability to make the role what she wants it to be and to use it across varied situations. The concept of role mastery will be developed in greater detail in the sections on the Meadian concept of role and role as resource.

\section{Meadian Concept of Role}

Meadian role theory is an effort to reconcile and unite the two role theory perspectives. Initial work from this perspective argues that roles can be used for purposes other than defining one's self and others. Roles are also used in thinking by operating as schemas to perceive and think about the world, and in acting by serving as guides that direct role-appropriate action (Callero 1994, p. 234). In addition, this perspective would argue that a role could be used as a "resource" in the process of completing valued goals (Baker \& Faulkner 1991; Callero 1994). Role as Resource theory, initially proposed by Baker and Falkner (1991) and subsequently developed in greater detail by Callero (1994), will be discussed in detail in a subsequent section of this literature review. Later developments in Meadian role theory posit that there is more than one version of a role depending on the context of a given situation and the multiple 
reference groups that an individual might look to (Collier 2004). By acknowledging that individuals do not simply master specific roles, but in some cases multiple versions of the same role, Meadian role theory also expands understandings of role mastery. This expansion of role mastery will be explored in a subsequent section of this chapter.

\section{Role as Resource}

Swidler (1986) explains the impact of culture on individual action through the analogy of a "toolkit" that an individual has access to, and can make use of. As part of the process of determining paths of action, this cultural toolkit consists of the "habits, skills, and styles" that an individual has acquired that he or she can pull from and then use as a resource when strategizing about the best course of action for a given situation, and to achieve a given end (Swidler 1986, p. 273). As stated previously, an individual's level of commitment to an identity affects that identity's relative level of salience in the individual's identity hierarchy, and relative salience - along with situational and personality characteristics - determine the likelihood of the enactment of a given identity (Stryker \& Serpe 1982).

Further, while it is true that in many ways culture shapes and defines what a person wants, this is not the whole story and does not take into account both what is achievable or that there might be multiple ways to achieve the same goal. This is where the toolkit comes into play, because "people may share common aspirations, while remaining profoundly different in the way their culture organizes their overall pattern of behavior” (Swidler 1986, p. 275). In short, action and goals cannot be explained in a vacuum of one or the other, i.e. behavior vs. want. This is because it is easier to take 
action in the direction where a person already has existing "cultural equipment." In this way, want and action can, and are, used together. Callero’s $(1986,1994)$ elaboration of “role as resource” builds upon Swidler’s work by suggesting that roles and identities are also elements in an individual's cultural tool kit as they serve as resources people use in determining which paths of action to follow. \#

Identities, then, are resources or tools that individuals put into action in order to accomplish valued goals and gain access to other resources, such as material, social, and cultural capital (Callero 1994, p. 238-240). In keeping with Mead's original vision of symbolic interaction, a role is only "real" for the members of a group to the degree that it can be used to accomplish pragmatic goals that are valued by both the individual and the larger group (Callero 1994, p. 232). \#

While earlier versions of role theory share the view that all roles are not the same e.g. task versus status (Bales 1958), instrumental versus expressive (Parsons \& Shils 1951) - those structural-based typologies are not useful in understanding role as a resource. Therefore, Callero proposes a new, more relevant typology of role types. He states that, "roles vary in terms of cultural endorsement...cultural evaluation... social accessibility... and situational contingency” (Callero 1994, p. 235-238), and each type should be thought of as existing on a continuum.

Cultural endorsement is the degree that a given role is "accepted and recognized as legitimate” (Callero 1994, p. 235) within a particular group. The cultural evaluation of a role can vary from being accepted as legitimate by all communities (Callero 1994, p. 
235), accepted as legitimate by one particular group and not many others, or accepted as legitimate at one time in history but not at other times.

Cultural evaluation refers to how the role is evaluated by society as positive or negative, normal or deviant, rather than the degree that it is recognized or accepted as legitimate (Callero 1994, p. 237). Those roles that are evaluated the most positively also "tend to be more powerful” (Callero 1994, p. 237). A lower prestige role is less likely to be as useable for "gain[ing] access to cultural, social, and material resources," while a higher prestige role will provide its holder with more access to resources, as well as the wherewithal to "achieve and maintain power" (Callero 1994, p. 237).

Social accessibility has to do with the degree to which a specific role is available for use "by all members of the community of endorsement" (Callero 1994, p. 237). The level of accessibility is a result of a "collective understanding or acceptance of a particular meaning and definition of the cultural role” (Callero 1994, p. 237). The limits can be physical or social.

Situational contingency refers to the context in which a role claim is made. More specifically, it is "concerned with the "how" and "when" of role use" (Callero 1994, p. 238). While it is possible that some roles, such as male or female, are "situationindependent” (Callero 1994, p. 238) and can be used across contexts and situations, others are "situation-dependent” (Callero 1994, p. 238), such as water polo player or stripper, and rely upon a specific context for enactment circumstance. While situational contingency is tied to the other three role types, it is most closely linked with social 
accessibility because those roles that are more independent are also more accessible (Callero 1994, p. 238).

Callero points out that, while society consists of independent individuals with their own identity hierarchies, these individuals' choices of lines of identity-related action are often constrained by an over-arching social structure. The reciprocal influence of structure and agency in Callero’s model has implications for both the individual and the structure of the larger society.

In terms of individual agency, while a person has the ability to determine how they will enact the roles available to them, her or his chosen line of action would not even be possible without that role being culturally endorsed as legitimate in that society . Similarly, all lines of action associated with culturally endorsed roles are not simultaneously available to an individual; in claiming one role, others may become inaccessible or denied (p. 234-238).

In terms of social structure, while society may limit which roles are available to certain individuals, those individuals do get to choose how they enact the roles available to them. The result is that the structure of the larger society can be changed as individuals enact culturally endorsed roles in novel ways. This can be one of the underlying processes in successful social movements (Howard 1994) that will be discussed in a subsequent section of this literature review.

\section{Differentiated Model \& Role Mastery}

Building upon a Meadian conceptualization of role, Collier’s (2001) differentiated model proposes that more than one version of a particular role exists because there are 
multiple reference groups of individuals using that role to accomplish slightly different valued interactional goals. Reference groups are groups that an individual uses as evaluative standards when assessing the quality of her own characteristics, circumstances, attitudes, values, and behaviors. In addition, these reference groups serve as criteria that the individual utilizes in determining which aspects of the role standard need to be accentuated in interactions within that group in order for the person's role performance to be viewed as legitimate. Because this model proposes that more than one version of a role exists at any time due to the presence of multiple reference groups, there now exists an additional possibility of identity interruption. This can occur when an individual enacts a version of a role in a group that does not recognize that version of the role as legitimate.

The process of identity verification follows Burke’s feedback loop model, with the individual using a cognitive process to compare self-referential feedback from others about her current role performance with an internalized role standard based on the interactive goals she is trying to realize. If she notes a discrepancy, she enacts roleassociated behaviors in her interactions with others in hopes of eliciting feedback on her role performance that verifies that she is enacting the role properly. Only when she finds a reference group that shares the same version of the role in question will she find the legitimation or identity verification described in the Burke model.

The differentiated role model's discussion of role mastery mirrors Turner's (1978) role playing-role making distinction, but expands Turner's model through the concept of differentiated role mastery. Collier (2004) notes that, "differentiated role mastery occurs when individuals successfully learn how to recognize and respond to different standards 
for a role... and this increased expertise gives them more options for subsequent performances of that role” (p. 5). This, in turn, increases the odds of an individual's success. Collier \& Morgan (2007) examine role mastery and role identity acquisition, through an exploration of the ways in which identity achievement will vary with ease of understanding, social location, and repetitive teaching or instruction about the role (Collier \& Morgan 2007). Specifically, differentiated role mastery is "the mastery of multiple versions of the role [that] serves as a resource enabling people to accomplish their desired goals” and includes both implicit and explicit knowledge (Collier \& Morgan 2007, p. 4). Differentiated role mastery is fundamentally tied to the individual's knowledge of the range of possible reference groups available to that person at that time. The ability to enact behaviors that match each reference group's particular role standard results in additional tools being added to that individual's cultural toolkit.

\section{Social Identity Theory}

Social identity theory attempts to "forge a non-reductionist social psychology... able to deal with the dynamic relationship between individual and society without sociologizing or individualizing it: that is, to explore the social dimension of human behavior” (Hogg \& Abrams 1988, p.13). While Americans see social identities tied to self-esteem and "tend to think of social identities as aspects of individual self-concept part of internal differentiation... the European conceptualization is one involving extension of the self beyond the level of the individual” (Brewer 1991, p. 476).

In social identity theory, an individual's identity is seen within the context of the group he or she is part of. As such, "social identity, and group belongingness are 
inextricably linked in the sense that one's conception or definition of who one is (one's identity) is largely composed of self-descriptions in terms of the defining characteristics of social groups to which one belongs” (Hogg \& Abrams 1988, p. 7). This perspective focuses on understanding the mental processes that lead an individual to think of herself as a member of a group, and to make choices about how inclusive a group she identifies with, which group among the many at the same level of inclusiveness she identifies with, and how she must act in order to be seen as a good group member.

Social identity theory looks at psychological processes involved with "seeing oneself as a member of a group (Hogg et. al 1995; Stets \& Burke 2000). Social identity theory views an individual's actions as a result of group membership, and group membership is based on the twin processes of self categorization and social comparison with the ultimate goal of maximizing self esteem.

The material on social identity theory will be divided into two sections: selfrepresentations and salience. The section on self representations will explore the manner in which a person thinks about herself in relation to other people or groups, moving from the more micro level self-representations ("I am Jane the smart student") up to the more macro level self-representation ("I am a human being”). The section on salience will elaborate on in-group out-group influences on self-categorization and situational context.

\section{Self-Representations}

Social Identity theory proposes that an individual has both a personal identity and a set of social identities. The personal identity is the "individuated self," while the social identity is the "categorizations of the self into more inclusive social units that 
depersonalize the self-concept, where I becomes we" (Brewer 1991, p. 476). The boundaries of these "more inclusive social units" can be understood as the distinction between the "in-group" - the group the person is a member of - and an "out-group" of others. In addition, this theory points out that there are different levels of social identities, and these identities vary in inclusiveness (Brewer 1991, p. 476). Social identity theory posits three "general" levels of identity, and that

"the distinction between personal and social identity is not a dichotomy, but a hierarchical continuum ranging from unique individual identity at one extreme to identification with the entire human race at the other, with many levels of social differentiation in between. At any one level in the hierarchy, the next level up provides the frame of reference for relevant social comparisons [from the] three levels of self-categorization: the superordinate level of self as human being...the intermediate level of ingroup out-group categorizations... and the subordinate level of personal identification” (Brewer \& Schneider 1999, p. 171).

What is most important about this is the ability for the self-concept to be "expandable and contractable" and open to changes in self-definition, self-interest, and motivation (Brewer 1991, p. 476). The individual can chose to move among possible self-representations, from one self-representation to another (e.g. student to worker) or even from one level of inclusiveness to another (e.g. PSU student to PSU Sociology student in a specific class), based on the demands of the current situation and the goals the individual is trying to accomplish.

These levels of inclusiveness, and their connection to the goals of an individual, relate to Brewer's (1991) concept of “optimal distinctiveness.” Optimal distinctiveness is "a reconciliation [by an individual] of opposing needs for assimilation and differentiation among others. According to this model, individuals avoid self-construals that are either 
too personalized or too inclusive and instead define themselves in terms of distinctive category memberships” (p. 475).

However, it is not just the situation or goals to be accomplished, or the desire for optimal distinctiveness, that determines which self-representation a person employs. The out-group that is immediately present can also serve to make a particular selfrepresentation salient. This is discussed below.

\section{Salience}

In social identity theory, salience is the self-categorization that the individual believes best 'fits' the situational requirement based on available contextual information (Stets \& Burke 2000). As mentioned previously, the presence of a particular out-group (e.g. an evangelistic street preacher) can almost force an individual to call-up a specific self-representation (e.g. atheist), thus making that self-representation salient. Because an individual is more likely to "behave in concert [with the] group [he identifies with, he is] more likely than not to participate in the group's culture, to distinguish [himself] from the out-group” (Stets \& Burke 2000, p. 226). For example, an individual who is a member of an organization (i.e. the Democratic Party) is more likely to attend events, agree with policy, and vote in a manner that is in line with the leadership and "models" of Democratic Party membership, than with those of the Republican Party, Green Party, etc. In addition, he will identify as a Democrat in a variety of ways - U.S. Democrat, Oregon Democrat, Portland Democrat, SE Portland Democrat - in an effort to individuate and differentiate himself from others - from the “out-group.” 


\section{Social Movement Theory}

\section{Theoretical Approaches}

According to Peterson (1989) there are the two dominant contemporary approaches to social movement analysis - resource mobilization theory and the European structural approach. Resource mobilization theory is an American approach, which concentrates upon the mechanisms by which movements recruit participants, while the European structural approach "focuses on how social problems are transformed into social movements” (Peterson 1989, p. 419). Eyerman and Jamison (1989), addressing both perspectives, posit that, like an individual, "a social movement develops a sense of itself and its mission... which both unites it and distinguishes it from others and which is an alternative to the established political culture” (Peterson 1989, p. 423).

Similarly, Melucci et. al (1989) propose that, “contemporary movements are unique in that they operate as signs, in the sense that they translate their actions into symbolic challenges to the dominant codes” (Peterson 1989, p. 424; Melucci et. al 1989, p. 12). While Melucci et. al recognize the value of resource mobilization theory in explaining how social action is formed in contemporary social movements, he argues that the theory fails to properly examine this process (Melucci et. al 1989).

A third approach, the collective identity perspective, (Polletta \& Jasper 2001) may prove useful in filling in this relatively underdeveloped area in both of the dominant perspectives, i.e. understanding the processes underlying social movement participation from the perspective of both the movement and the individual movement participant. A collective identity perspective has been utilized to answer four types of process-related 
questions (Polletta \& Jasper 2001, p. 284-285).

What is going on in society at a particular time that serves to rally collective action among individuals?

Corrigal-Brown (2008), in a study that attempted to address this question, examined how "individuals can develop different identities in social movements as a result of their previous social movement experience, personal political ideology, and the organizational context in which they engage” (p. 4) with an eye to understanding the potential for a movement's long-term continuity.

Why do people decide to join a movement? What kinds of motivations lead individuals to join a social movement, particularly when material incentives may be lacking?

Howard (1994) addressed this question by tying identity and social movement theories together. She stated that the passage in and out of social roles lead to changes in the networks of social relationships and interactions, as well as commitment to particular identities. A person may seek out a social movement in an effort to find a community of like-minded others, but then may consciously avoid a second social movement, as those involved in the movement may be a much different kind of community than she sought.

What factors influence a social movement's organizational form and subsequent strategic choices?

In a study that addressed this question, Stavro (2007) examined the power of collective action to contribute to coalition building based on a shared reality. Similarly, Kutz-Flamenbaum (2007) noted that the in-depth exploration of movement members', or 
potential members', ideologies is the best way to uncover and understand the "significant and meaningful divisions” within a movement (p. 21-22).

What impact does a social movement have on and individuals' collective identities and as a consequence, the broader culture?

In an effort to understand the relationships among social movements, collective identities, and the broader culture, Meithe (2002) examined how movement participation leads to the construction of both individual and collective identities. This study spotlighted how social movements can influence and change both the individual, and the social norms and expectations of the society she is part of.

\section{Identity Construction}

Hunt \& Benford (1994) provide a more detailed discussion of how activists construct and align personal and collective identities. They propose that movement identity development is interactional and is constructed, interpreted, and communicated via words, deeds, and images. Identity talk is based on group-specific guidelines. It tends to be iterative and is continually being redefined over time. In short, identity talk "stories" reflect an activist's perceptions of movement experiences based on her interpretation of current situations, herself, and others.

For an activist, there are four moments of identity construction included in their stories. These are: 1) becoming aware, 2) becoming active, 3) becoming committed, and 4) becoming weary and leaving the movement (Hunt \& Benford 1994, p. 492). Becoming aware stories reflect the individual's "discovering” or understanding some injustice, and are associated with how the activist comes to frame the issue and to attribute blame in 
regards to the perceived injustice. Becoming active stories focus on recruitment into and participation in the social movement, while becoming committed stories relate to increased participation in and identification with a particular social movement. Finally, becoming weary and leaving the movement stories relate to the event or series of events that lead an individual to leave the movement. Relating these moments through stories allows the individual to both solidify and demonstrate a personal identity as an activist, while also creating a collective identity that bridges the individual and the movement (Hunt \& Benford 1994, p. 493).

\section{Activist Narratives}

In addition to identity construction "tales," there are six additional types of stories in these activist narratives: associational declarations, disillusionment anecdotes, atrocity tales, personal is political accounts, guide narratives, and war stories (Hunt \& Benford 1994, p. 493-494). Associational declarations are "in-group/out-group claims (p. 494). For instance, an individual will state that she picked group A over Group B because Group A has goals and a structure more in line with her personal beliefs about inclusion and diversity than Group B. Disillusionment anecdotes are accounts of entry into, and then exit out, of a movement (p. 497), while atrocity tales relate to negative experiences that serve to "indentify victims and villains" (p. 499). Personal is political stories relates to “mundane aspects of everyday life...considered part of an individual’s political discourse” (p. 501). This is the area most focused on the alignment between the personal, individual, identity and the larger collective identity. Hunt \& Benford note that when these stories are told, it becomes clear that "to be 'pc' is to present a personal 
identity that is consistent with understandings of the movement's...collective identity" (p. 501). Guide narratives are stories about "how participants became aware, active, and committed with the guidance of others” (p. 504). Finally, war stories are about "becoming committed" and "provide activists with verbal demonstrations of how a “model” peacemaker becomes committed” (p. 506).

All of these different types of accounts contribute to a deeper understanding of how an individual comes to be part of a social movement. The present study utilizes all of these perspectives as a bridge because identities are resources that can be used by groups or movements to further their agenda, as well as by individuals to achieve personal aims.

\section{Military Socialization}

Jennings and Markus (1977) point out that socialization efforts, and interest in understanding them, is more likely to occur during, and be focused on, childhood. As people progress through life, experiences may occur "which may either reinforce or alter pre-existing values” and behaviors (Jennings \& Markus 1977, p.131). Institutions also can affect both individual behavior and value structures. These authors note that while there are millions of people in this nation who are veterans, there is a significant lack of research on veterans' individual-level experiences (p. 132). Jennings and Markus point out that the military is an interesting institution to study because individuals often considered military service a short-term option, rather than one for long-term success or personal goals. In addition, several other components of military service deserve greater study, including duration of service, recency of experiences, intensity of experiences, the 
affective dimension of service and person, and finally, the salience of the experience to the attitudinal and behavioral domains in the person (Jennings \& Markus 1977, p. 133134).

In their study of Vietnam veterans, Jennings \& Markus (1977) hypothesize that an increase in, or broader, political interest may be tied to the recency of the military experience while longer service was clearly equated with more rigid social views (p. 140142). But, when the service time is short, there is a positive relationship between tolerance of divergent political views and separation from the military, and later returnees were more politically outspoken about the government and military than the early returnees.

Finally, they found that even though veterans might not be certain about the worthiness of the war, they found ways to justify their presence via “dissonance reduction” (1977, p. 144). In other words, they either vilified the opponents, or clung to whatever rationalizations they could find. However, as the war continued veteran opposition to it increased, as did disillusionment with the government. Additionally, the longer a veteran served in Vietnam, the more likely he was to state the war as a reason for losing faith in his government (1977, p. 145).

Franke $(1997,1999,2000,2001)$ has looked extensively at multiple facets of service member identities and identity tensions, recognizing that resolving the tensions that can develop between identities must be addressed as a regular part of lived experience. He further points out that looking at a person's unique perception of his or 
her self-conception can help the researcher to become aware of the motivations behind a person's decision about how to resolve those tensions (1999, p. 14).

Franke is clearly critical of social psychological approaches of identity research. He believes that social scientists tend to link behavior, values, and attitudes to group membership in a rather linear way that oversimplifies the uniqueness of each person and does not adequately explore the association of life interests and identity salience within a specific context (1999, p. 26). Like Collier (2004), Franke proposes that identifying with a given group (e.g. soldier) is an important piece of self, although a person may be aware of several different versions of that identity (e.g. solider as warrior, soldier as peacekeeper) (1999, p. 16, p. 26).

Franke notes that core identities, those that the person views as central to who she is, hold more sway on decision-making processes than those on the periphery, which may only come into play in very specific circumstances (1999, p. 31). In order to work through inconsistencies among different individuals' understandings of the same identity, people engage in negotiation where the group reaches a "working consensus." This then allows the individual to stay consistent with her self-conception and yet still be part of helping the group realize its goals. Franke proposes that this working consensus may vary depending on the context of the situation, and the salience of the involved subidentities (1999, p. 17).

He also discusses the ways in which group members create collective products such as norms, values, attitudes, and scripts for behavior through social action. These are then internalized and employed to guide the decisions of an individual. In addition, the 
person's perception, evaluation, and judgment become frames of reference for her identity, and shape her self-conception (Franke 1997, p. 31-34).

As service members are exposed to an increasing range of military roles, there is an increased opportunity for the development of a wider range of associated military identities. For example, the active participation of Vietnam soldiers in pro-peace and anti-war movements during the '60s, '70s, and ' 80 s, and the increased acceptance of those actions by both veterans and civilians, changed what it means to be a veteran in U.S. society.

Franke's 1997 study $^{1}$ of officers in training during the period between the first Iraqi conflict and the 9/11 terrorist attacks, examines the changing face of the U.S. military and the increase in military peacekeeping missions (p. 34). This reflects an important shift in how service people are socialized, from "soldier as warrior" - where the goal is preparing for war, violence, and victory - to "soldier as peacekeeper," with the goal of preventing violence and protecting civilian noncombatants (p. 36). In addition, Franke discusses the identity-based tensions that result as service members attempt to reconcile beliefs in sacrifice and engagement in clearly laid-out and dangerous service, with that of non-violent, malleable, and "constabulary force” type of service (p. 36-38).

Even though the goal of the socialization process was the development of “soldier-as-peacekeeper” identities, Franke found that the longer his subjects attended military training, the more they exhibited a "willingness to battle and win," while their "attitudes towards noncombat operations grew more negative" (p. 44). Also, the more experienced the service member, the more likely he was to feel he had the right to

\footnotetext{
${ }^{1}$ Warriors for Peace: The Next Generation of U.S. Military Leaders
} 
challenge a direct order from a superior if that order went against his ${ }^{2}$ personal sense of right or wrong (p. 45). It is important to note that while this study provides a compelling look into the effects of military socialization during the time period in question, it does not illuminate the realities of current military service, or the post-9/11training of service members.

Although the Jennings and Markus research was conducted during the 1970s and the Franke research in the 1990s, both are relevant to issues being experienced by today's service people. Currently, many veterans are becoming disillusioned with the war, and with the U.S. government. Evidence of this can be found in reports of veterans who would rather go to prison than serve, veterans who come home and tell about the horrors of war, or stories of veterans who feel their country, upon return, has abandoned them. As recent developments around the world and in the peace movement are polarizing veterans on both sides of the issue, it is important to explore how both groups of individuals understand what it means to be a veteran. This is where integrating perspectives from Identity and Social Movement theories might provide particularly beneficial.

\section{Integrating the Literature}

The three literatures that are the foundation for this research - identity theory, military socialization, and social movement theory - inform and complement each other in ways that explain how in veterans with common goals are able to come together for engagement in collective action. Identity theories, with their common background in

\footnotetext{
${ }^{2}$ The research focused almost entirely on males.
} 
Symbolic Interactionism, all maintain that it is through interactions with others that shared meaning develops. Some of the most important "shared meanings" have to do with how people come to self-identity with particular social roles, and how these selfidentifications influence their actions.

This research explores the development of shared self-meanings in regards to a specific version of the veteran role, "veteran for peace," and how this identity affects individual actions, in this case participation in a social movement. A veteran, when considering the peace movement, is engaging in a journey of self-discovery. A veteran who comes to the peace movement must first decide that she believes there is an incongruency between the government's declarations of wanting peace, and a long history of military action, along with the continuation of sending troops into combat zones. A veteran, even one not directly exposed to combat, is well aware of the traumas and difficulties faced by veterans who have seen 'action.' As a result, many veterans come home with an appreciation for the value of non-violent efforts in negotiation when faced with the possible horrors of warfare. Numerous veterans have known or seen friends killed in action, or been forced to take a life themselves - all terrible, life-altering, consequences of war. These events may lead a veteran to begin to question the validity of military action if other avenues exist, or can be created, to prevent war or violence. Identity theory, more specifically social identity theory, informs the military socialization literature in regards to understanding the different criteria that veterans might use in distinguishing different in-group level veteran self-categorizations from other out-group ones (e.g. “combatant” vs. “non-combatant” or “officer” vs. “enlisted”). 
Through Brewer’s Model of Optimal Distinctiveness (1991), social identity theory also helps explain how a single veteran, who self-categorizes in terms of two different groups (e.g. the relatively smaller "Veterans for Peace" or the more inclusive "Veterans of Foreign Wars"), chooses to participate in one group or the other. The key to this choice is the fit between the groups goals and what the veteran is trying to achieve, and degree to which the veteran can balance her competing needs for "being the same as" (i.e. assimilation) and "not getting lost in the crowd" (i.e. differentiation).

Interestingly, while military socialization draws many concepts from identity theory, the focus is all on how the military trains an individual to "be" a service person. For example, all of Franke's (1997, 1999, 2000, 2001) research focuses on the socialization of male officers, primarily during the Vietnam era. An under-explored area of this literature has to do with differences in the socialization experiences between enlisted and officers, and how these differences relate to veterans' post-service beliefs, attitudes, and actions. However, the military socialization literature is useful in informing the social movement literature due to its focus on how individuals are trained into action (or inaction). Several of the veterans interviewed in this study spoke of how their military training enabled their current movement activities by preparing them to anticipate situations, accurately assess the potential for confrontation, and, if needed, engage in defensive action if movement members face a possible confrontation with authorities. The social movement and identity theory literatures combine to address how identity and participation are linked. Does movement participation lead to identity, or does identity lead to movement participation? Howard (2000) notes that social 
movements mean nothing until people interact in them and "identity struggles may...generate explicit social movements [as] this identity requires a perception of membership in a bounded group, consciousness about that group's ideologies, and direct opposition to a dominant order” (p. 384).

By combining the three literatures discussed in this chapter, one can begin to understand the ways in which veterans with common goals are able to come together for engagement in collective action. As a result, this literature is also useful when trying to answer the six research questions of this study:

1. How does a veteran understand the current peace movement?

2. Which, if any, parts of the current peace movement do a veteran find to be in line with his or her own values?

3. What do veterans feel it means to be a veteran for peace?

4. How do veterans come to identify with the current peace movement?

5. How do veterans take a stand against the current peace movement?

6. What do veterans feel is gained by involvement in the peace movement?

It is important to note that veterans, like other groups, are not likely to have a shared understanding of the peace movement. In addition, where the veteran peace movement will fit into personal values may vary. For example, some veterans may feel that involvement in the peace movement is not only unpatriotic, but also potentially dangerous and might open the U.S. to another terrorist attack due to prevailing stereotypes of peace movement activists. During bootcamp (for enlisted personnel), and Officer Training School (for officers), veterans are trained to take orders, and to value a 
particular role standard that put country above all else. It then follows that whether veterans see the veteran for peace role as legitimate will likely to be tied to how deeply ingrained that training and associated role standard have become. Whether a veteran comes to identify with or take a stand against the veterans peace movement, as well as what she sees can be gained from being involved, will depend to a large part on the effectiveness and persistence of her military socialization experiences.

In this chapter the literatures being used to inform this study were discussed in four sections. The first section of this chapter defined key terms used in this study. The second section examined identity theories - i.e. symbolic interactionism, role theory, identity theory, and social identity theory, while the third section explored the reciprocal relationship between participating in social movements and the development of personal and collective identities via a review of the social movement literature. The fourth section of this chapter focused on military socialization and the impact this has on political and personal beliefs. The final section demonstrated how the different theoretical perspectives inform and complement each other when looking at veteran involvement in the peace movement. The next chapter will discuss the methodology used in this research. 


\section{CHAPTER 3: Methods}

This Methods chapter provides a description of the research design and project participants, outlines the interview tool and enumerates the steps involved in participant recruitment. This chapter also provides a description of both how participant confidentiality was maintained, as well as the method of analysis.

\section{Project Design}

The purpose of this research was to explore veterans' understandings of the peace movement and their contact with, or involvement in, peace movements. The overarching research question was "How do U.S. veterans who have served since the Vietnam War, understand, and in some cases come to identify with, the role 'veteran in a peace movement?'" This research sought to understand the identity processes involved in veterans answering the question 'can a person like me be part of the peace movement?' This research provides an idea of shared identity and common meaning among veterans in relation to the peace movement. As a result, several more focused questions were addressed: 1) How does a veteran understand the current peace movement? 2) Which, if any, parts of the current peace movement does a veteran find to be in line with his or her own values? 3) What do veterans feel it means to be a veteran for peace? 4) How do veterans come to identify with the current peace movement? 5) How do veterans take a stand against the current peace movement? 6) What do veterans feel is gained by involvement in the peace movement?

As discussed previously, most literature as it relates to veterans is focused on military socialization, or the personal life biographies of a select few. As a result, this 
study is exploratory in nature. A qualitative method was utilized in an effort to move deeper into the issues being discussed. A quantitative study would be insufficient for achieving the level of nuance needed when discussing issues of such personal value and biography.

Methodologically, (Berg 2007) a qualitative approach allows the researcher to locate and explore the "what, how, when, and where of a thing - its essence and ambience” (p. 3). In addition, with a qualitative approach, the research is able to prompt the respondent in a manner that allows for a fuller description and understanding of the subject. Finally, a qualitative study allows the researcher to understand the life experience of the individual out of the symbolism and meaning of the individual herself.

\section{Interviews}

Data were collected via interviews utilizing an approved interview guide. This interview guide directed the topics to be covered during the conversation. The data used in this study are based on interviews conducted with U.S. veterans who have served in the military during and since the Vietnam War.

Because the goal is to understand the veteran's perceptions and understanding about participation and support of the peace movement, no effort was made to strictly adhere to the ordering of questions asked. Instead, using a semi-structured approach, the researcher would, when possible, allow the respondent to guide the direction and order of the interview. 


\section{Interview Tool}

The interview guide was designed so that broad questions were asked at the beginning and the questions became increasingly more specific. For example, the interview began with questions about service and service dates, then progressed into questions focused on determining specific life events that led the participant to join the peace movement. The final question provided respondents the opportunity to add anything that had not been covered by the questions previously asked.

There were two interview guides. The first was for self-identified members of the “veterans’ peace movement,” the second was for self-identified non-members. The first and last portion of the guides was identical. The middle portion differed because for nonmembers the focus was on why the respondent did not participate in peace movement activities. On the other hand, for members, the focus was on how and why the respondents came to be involved in the movement. The guide was fairly stable, and the questions did not change during the interview process. However, the ordering of questions was often adjusted based on how participants were responding to them, or in an effort to probe for more information when needed.

\section{Confidentiality}

Respondents received and signed a copy of an informed consent that indicated their participation was voluntary and that their responses would be held in confidence, and pseudonyms would be used in the final product. While most respondents expressed no concern over their identity being known, because excerpts from the interviews are included in this thesis, participant names have been changed to provide confidentiality. 
In addition, any otherwise identifying information has been removed. The interviews were recorded on tape and the completed interviews were later transcribed and numbered by the researcher.

\section{Potential for Bias}

It is important to note that the researcher herself is a veteran, and a veteran who has come to embrace the peace movement. As a result, a potential for bias does exist. However, because the researcher has experienced much of what the respondents discussed, she is able to provide an insight and was seen as "legitimate" in a way that another researcher would not. In recognition of this potential bias, the interview guide was reviewed and approved by three veterans, who were not part of the study population, prior to the beginning of data collection.

\section{Data Collection}

Twenty-seven interviews were conducted between May 2009 and December 2009. Fifteen interviews were done face-to-face, while twelve were done via telephone. Two interviews were with pairs or couples, totaling four interviews. Interviews ranged in duration from less than 10 minutes to over an hour, depending on how much the respondent was willing to share and the strength of his or her opinions. Interviews took place at the respondent's suggested location, an office on the PSU campus, or via the telephone. Participants came from a range of racial backgrounds, as well as ages, Services, and military campaigns. Demographic information about the respondent population is provided in Figure 1 below. 
Figure 1

\begin{tabular}{|c|c|c|c|c|c|}
\hline \multicolumn{2}{|c|}{ Respondent Demographics } & Total & \multicolumn{2}{|c|}{ Respondent Demographics } & Total \\
\hline \multicolumn{2}{|c|}{ Race } & \multirow{6}{*}{27} & \multicolumn{2}{|c|}{ Overseas Tours } & \multirow{3}{*}{27} \\
\hline White & 24 & & Yes & 23 & \\
\hline Latino & 1 & & No & 4 & \\
\hline Black & 1 & & Combat & & \\
\hline Asian & 0 & & Yes & 13 & 27 \\
\hline Other & 1 & & No & 14 & \\
\hline \multicolumn{2}{|c|}{ Gender } & \multirow{3}{*}{27} & \multicolumn{2}{|c|}{ Campaign } & \multirow{5}{*}{27} \\
\hline Male & 20 & & Vietnam & 4 & \\
\hline Female & 7 & & Pre 9/11 & 3 & \\
\hline \multicolumn{2}{|c|}{ Service } & \multirow{6}{*}{27} & Post 9/11 & 8 & \\
\hline Army & 12 & & None & 12 & \\
\hline Navy & 7 & & Sup & & \multirow{4}{*}{27} \\
\hline Air Force & 4 & & Yes & 16 & \\
\hline Marines & 1 & & No & 7 & \\
\hline Dual Services & 3 & & Undecided & 4 & \\
\hline \multicolumn{2}{|c|}{ Service Type } & \multirow{3}{*}{27} & \multicolumn{2}{|c|}{ Membership } & \\
\hline Enlisted & 20 & & Yes & 11 & 27 \\
\hline Officer & 7 & & No & 16 & \\
\hline \multicolumn{2}{|c|}{ \# of Years } & & \multicolumn{2}{|c|}{ Interview } & \\
\hline 4 or less & 12 & 27 & By Phone & 12 & 27 \\
\hline 5 or more & 15 & & In Person & 15 & \\
\hline
\end{tabular}

Unfortunately, the participants are not entirely representative of the current military. For example, according to a study done in 2004, the Latino population in the military is about 10\% (http://www.prb.org/pdf04/59.4AmericanMilitary.pdf, p 21), but make up only about 3.7\% of the participants in this study. Additionally, blacks are 
overrepresented in the military, making up "about $22 \%$ of enlisted personnel in the armed forces (20\% of men and 34\% of women)... [but only] 13\% of civilians ages 18 to 44” (p. 20) they only represent $3.7 \%$ of the participants in this study ${ }^{3}$. Finally, while women only make up about $15 \%-20 \%$ of the military services, in this study they represent nearly $30 \%$ of this study’s participants.

\section{Data Analysis}

Each interview was read several times from beginning to end before any coding was done. This allowed the researcher to gain a general feeling for themes and concepts that would later guide the more focused coding effort. A standard coding technique that allows the researcher to utilize "textual accounts to document themes and patterns" (Berg 2007, p. 205) was then used. As a result of this process, a set of over-arching encompassing terms was developed and noted (e.g. "loyalty vs. disloyalty” “camaraderie vs. healing”).To ensure reliability, as much as possible, the derived coding terms and themes reflected the actual terms used by respondents (Berg 2007, p. 307).

In the next step, transcripts were divided for code analysis based on categories of peace movement member or non-member. The final step consisted of dividing the collected data for analysis based on the veteran's exposure to combat. Due to the small representation of women compared to men, respondents of color compared to white respondents, and officers compared to enlisted only a rudimentary analysis was done on these comparison groups.

\footnotetext{
${ }^{3}$ Regrettably, in spite of the researcher's efforts to achieve a level of representation commiserate with the general military population, very often, when a person of color was contacted, they insisted they had nothing of value to add, were unresponsive to my requests, or were consistently unavailable when the time came for the interview.
} 
An inductive grounded theory approach was taken. This allowed the researcher to "identify the dimensions or themes that seem meaningful to the producers of each message) (Berg 2007, p. 311). To achieve this, coding was first done line-by-line, working up to broader levels of specificity to determine the larger themes in the transcripts. Due to the exploratory nature of this research, these themes and concepts were then compared to the research questions to establish both how they align with and answer them, and to determine if there were other topic areas that stood out as deserving of more analysis and discussion.

The following outlines, briefly, the steps involved in the analysis:

- Transcripts were coded by hand by the researcher, then read and re-read to begin discovery of themes and concepts.

- The themes and concepts were developed into categories and codes, with an aim to meet the goals of the research while also respecting the evolutionary nature of the interviews.

- Codes were then examined by both their relevance to the research questions and their frequency of usage by the participants by category.

The coding and analysis process created a great deal of data regarding opinions on the peace movement, as well as several other topics.

In this chapter, the particulars of the research design were detailed, a description was provided for the project participant recruitment process, the interview tool was outlined, and a discussion of issues of confidentiality and potential researcher bias was provided. In addition, the coding technique employed to facilitate analysis of the 
collected data was reviewed. This analysis plan included a description of the development of both themes from the codes, and categories from the respondents. The following chapter discusses the key findings related to the research questions, and the intersection between themes and categories.

\section{CHAPTER 4: Findings}

The findings of this study are organized into two sections. The first section, titled “General Findings” covers peace movement support and membership information about the entire participant population. This section is focuses on the interaction of participant demographics and their military experiences. It also provides a definition of the three types of veterans found in this study, and findings regarding their feelings towards not only the peace movement, but also their service. The second section, "The Peace Movement \& Getting Involved” focuses on findings directly related to participation or non-participation in the peace movement. This section is initially sub-divided into the three categories of veteran described in the second section, and each sub-category of veteran is further divided into veterans who have seen combat, and those who have not. .

Themes discussed within each category are pulled out and italicized at the subheading level. Each section is titled in boldface. Finally, quotes from participant responses have been pulled from the transcripts and are provided throughout because it is the respondents themselves who can best speak to their experiences and the reasons behind their actions and decisions. 


\section{General Findings}

"If the survivor is allowed to testify and tell his story uninterrupted, he eventually enters a zone of consciousness where the norms of his society no longer have the authority to censor. When this happens, the power of truth is born." - Vietnam Veteran

This portion of the Findings Chapter is divided into three sections. The first section, Interaction of Veterans’ Demographic Information and Experiences, covers material related to categorical differences between veterans as a result of gender, service rank, length of service, combat experience, and campaign. The second section, titled Three Types of Veterans, includes a range of veterans' responses to the peace movement, and to the idea of veterans participating in the peace movement. The final section, Feelings Towards Service, discusses findings related to the three types of veterans and the interaction that appears to exist between their feelings about service and their combat exposure.

\section{Interaction of Veterans’ Demographic Information and Experiences}

\section{Theme \#1: Demographics impact veterans' views of the peace movement}

\section{Gender-based differences}

Of the twenty-seven veterans interviewed, nearly $60 \%$ support the peace movement; while over $40 \%$ consider themselves to be members. Of the supporters, $75 \%$ are men, but only $25 \%$ are women. Among the members, $82 \%$ are men, while $18 \%$ are women. The extreme difference between the men and women, where there is a $50 \%$ higher percentage rate of involvement by men, might be attributable to the smaller number of women who participated in the study. It might also be a result of higher rates

of combat exposure for men than women. However, it should be noted that women, even 
those serving in supply or administrative roles in today's wars are often exposed to similar combat scenarios. For example, Kate ${ }^{4}$ was a dental tech in Kuwait who saw combat, and Brenda was a medical laboratory assistant who has more recently seen combat in Iraq.

\section{Service Rank-based Differences}

Of the seven officers, $43 \%$ support the peace movement and 29\% consider themselves to be veterans’ peace movement members. Of the twenty enlisted participants, 65\% support the peace movement, while 45\% consider themselves members.

\section{Length of Service}

Relative length of service seemed to be one clear difference between officers and enlisted personnel. Only 40\% of the twenty enlisted participants had served over four years, but all of the officers served over twenty years. The relatively lower levels of support for the peace movement among officers may be attributable to dissimilarity in length of service, as it should be noted that a period of service which ends in retirement (like that of the officers) equates to benefits from the military in the form of pay, medical, and dental services. However, this is not always the case. For example, Lauren, who is an active member of Veterans for Peace shared that, "it worked out okay for me, and now I'm able to be a fulltime peace activist and live on my retirement which I think is the ultimate irony!”

\footnotetext{
${ }^{4}$ All names have been changed by the researcher
} 


\section{Combatant and Non-Combatant Differences}

Of those thirteen veterans who have seen combat, 69\% support the movement, and $62 \%$ are members. Of the fourteen non-combatant veterans, only $50 \%$ support it, and only $21 \%$ are members. The differences in how a combatant veteran and a noncombatant veteran see a veteran's place in the peace movement are articulated below. Tony was in the Navy and never saw combat. Dave was in the Army during Vietnam.

“For me, I dunno. I don’t wanna sound like a, like I'm some hardass, but, they volunteered to do it... And to come back, and not necessarily whine about it. To me, it just kinda makes people think that they're kind of...They're whining about what they volunteered to do.” - Tony

"Well they have legitimacy. When you're talking with the mainstream people, they respect the idea that these guys have gone over and fought. The combat veterans especially. Combat vets come back, people know they deserve respect, at least to be heard.” - Dave

Fifty percent of the enlisted respondents had seen combat but only $20 \%$ of the officers had seen it. These 'exposure to combat' differences may contribute to the differences in levels of support and membership between enlisted service members and officers.

These numbers, along with the veterans’ responses, support claims that exposure to combat impacts the likelihood of peace movement support and participation.

\section{Campaign-based Differences}

There is also the possibility that campaign or recency of service, might also account for variability of differences in peace movement support and membership. For example, when looking at campaigns, all of the Vietnam veterans support the movement and are members. Of the eight Iraq II veterans, $88 \%$ support the movement, and $63 \%$ of them are members. This differs a great deal from twelve non-combatants, who were split 
into $42 \%$ who support, $33 \%$ who do not support, and $25 \%$ who are undecided. Of this group, only $17 \%$ are movement members In addition, discussions of trauma and coping were central to discussions with veterans who had seen combat in either Vietnam or Iraq II, while it was not the case for veterans involved in campaigns in Kuwait, Kosovo, and Afghanistan. Using these examples, there can be no direct correlation ascertained pertaining to recency.

Interestingly, both the Vietnam and Iraq II campaigns are generally not highly thought of by the American public, and the veterans who served in these campaigns are much more likely to support, and to be members of the veteran peace movement. Dave, a veteran from Vietnam, knew from the "get-go" that the military and the war were no good for him even though it took him years to come to the movement, and he put it like this:

"Well, I look at Vietnam as the most traumatic experience [that ever happened to me] and, I almost every day think about Vietnam. Almost every day. So, when I first came home, I tried to put that on the back shelf. I came home and I wanted to get back in and become integrated into society, and I fell in love, got married, and that kind of thing. The military wasn't the first thing on my mind at that time, although I was drinking very heavily and didn't know what that was all about... But, in general, even the minute I joined the service I knew that was not a place I want to be.”

These types of responses suggest that there might be a relationship between campaign and peace movement support or membership

\section{Types of Veterans}

Theme \#2: Different types of veterans express varied views on peace and the peace 
Veterans fell into three camps when it came to discussion about support and involvement in the peace movement. These veteran types are organized by the deepening levels of commitment expressed by the veterans themselves during the interviews. Type I veterans are those veterans who are non-peace movement supporters/non-veteran peace movement members. Type II veterans are peace movement supporters but not members of a veterans' peace group. Finally, Type III veterans are those who support the peace movement and have claimed for themselves the identity as veteran for peace.

Views on the Peace Movement

Not surprisingly, Type I veterans feel that the peace movement is either harmful, 'wrong-sided,' disloyal, or in some way unsupportive of the military and the U.S. They do not agree with the peace movement, do not see the role of 'veteran for peace' as legitimate, and will not participate in the veterans' peace movement. Type II veterans support the peace movement and recognize the legitimacy of the role veteran for peace, but do not self-identify as such. They are not involved in the veterans' peace movement for several different reasons. These reasons may range from simply "not knowing about the peace movement," to feelings of "having nothing to contribute," to feelings that "while the 'fight is a good one' there is no point in personally participating in the movement.” Type III veterans not only support the ideals and goals of the peace movement, but are also actively enacting the role of veteran for peace from within an organization. 
It became clear during the course of the interviews that support of the veterans' peace movement did not necessarily equate to participation. Pete, who, when asked if he supported the veterans' peace movement or not, stated:

"I think it's great. I think that we're in places and doing things that we probably shouldn't be... I think it's great that people are standing up for what they believe in. Especially... you tell me veterans are doing this, that even though we serve, that doesn't necessarily mean that we agree with the war or that we're doing all that we can do.”

However, Pete is not a veterans' peace movement member, and when asked about not being a member, he replied,

"I'm really feeling like I'm on the fence with this whole deal. I'm really thinking we should do some things, we also shouldn't be the world's police. I'm not a bleeding heart liberal... I guess I want a gun, but I'm not a gun toting republican, either...”

Statements like these can be seen as evidence of veterans' discomfort, and perhaps confusion, about how to be both a veteran who supports other service members and is proud of service given, and a citizen who does not support a current military action or policy.

Other veterans made statements indicating a fear that supporting the peace movement would indicate they were disloyal or betraying the troops. As Shelley put it, involvement in the movement means, "Protesting war and not necessarily not being for your country, but wishing that there everybody could just get along and have peace, I guess.” This ambiguity and confusion about the role a veteran would have to play in peace movement may be one reason that a veteran can support the movement but not the veterans' movement, and not be a member. When asked if she believed veterans have a place in the peace movement, Shelley stated, 
“That's a tough one, because I don't really think a veteran has anything to give to the peace movement. I think that when you make a choice to serve your country, you're making a choice to do whatever is asked of you. So, to make a choice to serve your country...but then, you all of a sudden want peace? I mean, that just doesn't make sense. Because being part of the military is knowing that you're going to have to fight at some point with other people.”

Another form of ambiguity can found among Type III veterans. A veteran might be part of an organization, but identify with only their local chapter, as opposed to the national organization it is part of. They might also choose to be part of one organization, while rejecting another. In these cases, participants were very clear about how and why they identified with their particular group and not others. This is demonstrated in comments made by Jesse:

"Generally I joined IVAW because IVAW is more along with my thinking, more so than I think a lot of the other organizations were. You know how peace movements are dominated by old '60s oriented (people), with like doves and stuff. Their position is they're against all wars, which I think is weird, cuz I'm not against all wars, like class wars or anything like that ... I'll give you an example. There's a chapter in Tacoma that, they're against civil disobedience. They don't believe in civil disobedience, which means that to them, Gandhi and Martin Luther King are too radical. And this is accepted in that group. There's a lot of Veterans For Peace people who are like that. They're so passive, and I think they're kind of the people who've gotten to a comfortable point in their life, too, cuz they're older and more settled in. They like the idea of being political activists, but they're kinda scared of change. So, I don't really like that. Now, IVAW can be like that, but VFP, that's the prevailing attitude, and I don't wanna be in an organization that thinks that Martin Luther King and Gandhi, are too militant. Every movement has civil disobedience, like laying in the street to block military equipment. It's not sit-ins. According to them, Rosa Parks shoulda just gotten off, you know, get off the bus! You can see how it doesn't make much of a dent.”

In summary, it is apparent that different types of veterans hold different views on the peace movement. Yet within type and across types of veterans, it is clear that there 
are ambiguous feelings about the peace movement and whether veterans' participation in this movement has value.

\section{Feelings about Service}

\section{Theme \#3: All veterans expressed mixed feelings about their service}

Veterans’ ambivalent feelings about the peace movement carry over in their discussions of their military service. Opinions about military service tended to range from "loved it" to apathy to something in between those extremes. Many of them spoke of the good people they worked with, the amazing experiences they were able to be part of, the value of the discipline in their later lives, and the honor and pride they have for what they did. Several spoke of their belief in the mission. Still others expressed pain and regret about what they saw as lies and abuse of the government that tainted the mission, and left them disillusioned. While in almost all cases, veterans shared a combination of both good and bad experiences, feelings, and memories, feelings of pain and regret seem to be the dividing line among the three veteran types.

\section{Type I Veterans}

Type I veterans, who are not supportive of either veteran involvement, or the veterans movement, on the whole tended to have more positive memories and feelings about their service than the Type III veterans. However, their responses were very similar to those of Type II veterans. This suggests a possible relationship between positive or negative military experiences, and the support or involvement of a veteran in peace movement organizations and activities. Even among Type I veterans, there are 
noticeable differences in how combat and non-combat veterans talked about their military

experiences.

Type I - Non-Combatant

John and Shelley are both Type I veterans without combat experience. John left the military because it was time to retire after serving over 20 years. Shelley left the service to be a mother.

"It was good and I really enjoyed it and if it wasn't for my son I would totally still be in. I don't know if I would have stayed in the Navy, but I would have definitely stayed in the military service.” - Shelley

"Most of my Naval career was real good times. There were a few bumps where things didn't go quite right. But, fortunately, they were pretty much temporary. And, I would say that the people that I worked for were, by and large, were exceptionally good people.” - John

\section{Type I - Combatant}

In addition to talking about their positive experiences, Type I combat veterans

framed their military service in terms of duty and obligation for all citizens of the U.S.

They felt good about having met their duty and done their part to 'pay it forward' for the veterans that came before. Ben, an officer who served part of his career during the Bosnian War, noted:

"I have always been of the belief that everyone should serve their country in some capacity or another. Whether that is as part of the uniform military service, or a police officer, or a fireman, or what have you. Everybody has a debt to pay for everyone who has gone before us and maintained this country as it is in a freedom kind of state. So, I looked upon it as an obligation for myself, and still look back on it, very, with fond memories of all the activities, although there were some jobs that I had that I didn't particularly care for, um, I look back on it with good thoughts." 


\section{Type II Veterans}

Predictably, Type II veterans were more ambiguous when discussing their feelings about their service in the military. Still, during the interviews, they were specific about what in their service had been good for them.

Type II - Non-Combatants

The non-members, particularly if they saw no combat, were less likely to have anything negative to say about their service, and spoke of something garnered from their service, regardless of if they supported the veteran peace movement or no. An example of this is Rachel, an African American who is a supporter/non-member, and whose family had uprooted her as a young woman and moved to a predominantly white neighborhood where she felt little or no connection with her new neighbors, but did feel a connection when she joined the military. She said it was "Time well spent. It matured me in a lot of ways. You know, uh, it also exposed me to a community that I haven't been around since my parents moved away from the African American community [where I grew up]... And put us, and our family, in a really minority area of African American culture, so... We didn’t really have any roots. I felt like I had no roots, until the military."

\section{Type II - Combatants}

The ambiguity about feelings about service when talking about combat veterans is illustrated nicely in the exchange below, between the researcher and Jeff, who has served in both Kosovo and Afghanistan. While he doesn't delve into the details of his service, it 
becomes clear during the discussion that there were events during his service that left him

uncomfortable, that he had to "come to terms with."

"I feel good about it... For a long time I didn’t feel all that good about it. But, I've come to terms with everything that I did or didn't do. I feel like it was my best choice for my life at that time... I would probably never go back, I can't because of my back anyway, but, I might of gone back in a moment of weakness if I didn't have my back problem. Realistically, I would have hated it then, cuz I'm a free spirit in an enclosed system basically, so I need to, I needed to do my four years and I need to get out afterwards.” - Jeff

\section{Type III Veterans}

These veterans were the most forthcoming during the interviews. Type III veterans articulated how they felt and provided clearly laid out and rational reasons for those feelings. They spoke most often about the government and military; specifically the lies they believed they were told, the betrayals they had felt, and propaganda used by the military as a sort of brainwashing technique. However, many of them still found their service to have been worthwhile and rewarding.

\section{Type III - Non-Combatants}

Non-combatants expressed less anger in their answers than combatants. It was obvious during the course of the interviews that they felt less "attacked," and more "fooled" or lied to. One example of this is Bob, who was an officer during the Cold War

era. When asked about his service, he stated:

"Well, I generally enjoyed my time in the service. There were some rather difficult times, but I generally supported the mission that we were tasked to accomplish. And looking back, we can probably get into that after, but, I have second thoughts about the things I did. But, at the time, I think I bought into all the propaganda about how valid the mission was. I was a Cold Warrior, and supposedly a tip of the spear deterrent against the Soviets, and I bought into all that. Never really thought about, expenditures, about the money we were burning up with what we were 
doing. But, I had other jobs that I thought were very rewarding. I'd say by and large it was a positive experience.”

Type III - Combatants

Others, primarily those who had seen combat, felt disillusioned from their experiences, and felt that their service to the country was tainted by an unworthy mission. These veterans often has an angrier tone when discussing their service, and felt the most betrayed and lied to of all the respondents. Like the others, they expressed some ambivalence about their service. As Jesse put it:

“Generally I'm really disappointed in it... Obviously I'm really against the wars now, but maybe I wouldn't be if I hadn't actually participated in it. At the same time, there's good things, like the discipline it gave me, but at other times... I dunno, it's kinda good not to be a "yes" man anymore all the time. All the shit that they give you, is just to make you become a disciplined yes man, and that's not necessarily a good thing for anyone. But, generally, I helped the U.S., and their objective of dominating the world, and do I think that's a worthy cause? Of course not."

Sam, who was an interrogator in Iraq, believes that, the U.S. should not be in Iraq and that his experience "was regrettable, I guess in reference to abuses of soldiers and detainees and just the Iraqi people in general. But, I think that overall I definitely had a negative effect in the world in supporting the U.S. occupying Iraq, and helping the fight against the insurgency there, which is essentially fighting for the sovereignty of their country against the imperialist occupying power.”

Still others found their service to be a crash course in self-realization. Bernie was an Air Force officer during the Vietnam War, and is now an active and very vocal member of the anti-war/pro-peace movement. Like the others, he articulated a level of ambiguity regarding the good and the bad of military service. As he put it, 
"Well, my Vietnam experience really changed my life. I discovered my soul... that I had a conscience. I discovered I had doubts, that I had questions I had to ask, I had a resilience I did not know I had... [It] was very difficult emotionally, did in some way prepare for, gave me a sense of who I was, some sense of who I am vis-à-vis authority structures. I didn't know anything about that, and didn't know about life, as far as reality is concerned. So, that Vietnam experience, including the training, before I got in trouble, it opened up a dimension in me I didn't know existed, which was more archetype. I discovered me as an archetype. I also learned that I could contest hierarchy. I really did not like having anything beneath me, or above me. I did not like it. I felt, I actually really experienced it in my body after about a year and a half, that I resented it. I mean that is the absolute truth. And I did not like the strata. And, of course, the military strives on and is dependent on it. So, that really was very markedly noticeable. And I did not want to be in the world of that. That was really a good lesson and I have not been in an hierarchy since. I learned to create my own world, and so that was another lesson throughout my military experience. I didn't like my experience on one level, but I appreciate that it could prepare me like perhaps no other experience could.”

Based on the responses of the veterans, it can easily be inferred that the less

"pleasant" the time in service and mission was for the veterans, and the less they believe in what they were expected to do, the more likely they were to seek out, and become part of, the peace movement.

\section{The Peace Movement \& Getting Involved}

\section{Views on the Peace Movement}

\section{Theme \#4: There is a range of opinions across veteran types about the veterans' peace}

\section{movement.}

When discussing the veterans’ peace movement with the participants there was a wide range of perspectives. Veterans tended to answer in a very effusive manner, as there was a great deal of personal feeling behind their thoughts and opinions. For Type IIIs (supporter-members) what became immediately clear was a level of frustration with 
the direction and ineffectiveness of the movement, but also a sense that the goals were important and achievable, and that the effort must continue because even, when it was not explicit, the positive impact was there.

While still seeing obstacles in the path to peace, many veterans expressed a belief that the movement will reach its goals, and that the effort must continue for this reason. However, they are frustrated by the sense of being pushed back on by media and other outside influences that are less about the war, and more about the American way of life, their view of American citizens as apathetic or lazy, and what the American people see as more immediate concerns.

\section{Type I Veterans}

Type I veterans expressed fears that the movement was pointless, even harmful. What was implied in the statements was a belief that pushing for peace equated to a passivism that would open the door for the U.S. to be attacked again. Either due to a failure to plan for 'reality' or a refusal to acknowledge that nothing really can be done. Type I - Non-Combatants

Type I non-combatants framed their responses to veterans in the peace movement differently that Type I combatants. When non-combatants answered the questions about veterans in the peace movement, they were likely to discuss the unrealistic nature of peace, and the dangers of passivism. Derek's answer provides a good example of this sort of response.

"Well, I think we have entered that war with open eyes. and, knew what we were getting into. We always want to be thinking towards peace, but how do you establish peace... Once we were attacked on our own soil, I think, we need to take up a strong hold against that type of terrorism or 
we'll just be inviting it here in our country. You have to draw a fine line there between a peace movement and protecting your country... We're aware of what the service people are trying to accomplish. It's their job. I do understand that we do need peace throughout the world, but, how do you accomplish that? That's the question. I don't feel like it should be put down your arms and be conquered. I think you have to fight for what is your own. Am I all out for total peace, lay down the arms and leave and let aggression take over a country? No.” - Derek

Other Type I veterans expressed a belief veterans "should know better”;

essentially that they were incorrect to align with the peace movement. These veterans also implied in their statements that a veteran's involvement might be tied less to feelings about the mission, and more to feelings of bitterness or anger about life events, unrelated to the military or the mission, that took place while they were serving. An instance of this is John, a retired Naval office.

"I always thought that most veterans should probably have the bigger picture, and would hopefully be more informed about current events and the job that we're doing there... Sometimes it's not missions, it might have been the way that they were treated, or be their perception about how things went while they were there, so that might be the other reason.” John

\section{Type I - Combatants}

Type I Combatants, on the other hand, tended to be much shorter in their responses, almost hostile about it because of what they felt could potentially be threats to the safety of the troops, or other reasons that could be inferred as the interviews progressed. Ben articulates this fear in the following example.

"Everybody's entitled to their opinion. When the opinion starts to affect the safety of soldiers, then I become very upset.” - Ben 


\section{Type II Veterans}

Like many of the veterans, the Type II veterans were not always certain that the peace movement was relevant and workable today. These veterans often expressed respect for what the Type III veterans are trying to accomplish, and recognition of the legitimacy of their efforts. The primary difference between Type III and Type IIs in this area really lay in the Type II belief that peace is nice, but unrealistic, and that peace through superior firepower was the only way.

\section{Type II - Non-Combatants}

Dan, a veteran who did not serve in a combat situation, had this to say:

"Although everyone strives for peace there's always conflict, and because of the conflict there are times that people need to either demonstrate their superiority or... Everyone does want peace, but unfortunately, not everyone strives for it the same way. Whether it be peace through friendship, whether it be peace through superior firepower, everyone does want peace... but there are different methods for receiving that peace. Unfortunately, we live in a society today where peace through superior firepower is the norm."

For other Type IIs there were very different responses. While these particular

Type II veterans were not a part of the movement, they were enthusiastic about it, and about what veterans have to offer it. Janet, a dual service veteran who felt she had nothing to offer the movement because she had never been in combat, had this to say:

"I think it's awesome. I think veterans have a really strong voice. I mean, they actually have seen combat and have seen the ugliness of war, and I think that what they have to say has a lot more legitimacy that someone serving in the Senate, or the House of Representatives, that have never worn the uniform and has never seen combat. I think veterans have a very strong voice, in the peace movement. I like to see it. I like to see veterans getting involved with military policy once they get out. I'm all for that. I haven't done it myself, but, I respect the veterans that are involved."

Type II - Combatants 
Jeff's statement (provided below) also sheds light on another common theme in the interviews - an effort to differentiate veterans in the peace movement from "long-haired hippies" who are seen through the lens of negative stereotypes. This was seen in various forms throughout the interviews, regardless of level of support for the peace movement. In addition to this is the interesting suggestion that, despite training to stand up and fight, veterans are, in fact, not trained to stand up and fight when the fight is in the form of protest.

"I believe a lot more in the veterans' peace movement than I do the hippies on the street, just cuz those guys have been there, they've seen a lot of that stuff, and I think they have every right to their feelings. Maybe they are making a lot more progress than I see. I'd look at the other side, not all civilian side, but people without that context, I think they take shit way too far, and I think half their ideas are pretty lame-brained. I think that might push in the other ones. A lot of vets that I know, even the ones that are against the war, which is, especially the thing in Iraq, which is generally most of them, even the ones that would go again but are against the purpose of it, I dunno, I just don't think their minds process in their manner to just say "I'll stand up in protest." It's just not really something the military gives you, stand up and protest, for one. For two, in this time period, like I said 30 times, it just doesn't seem feasible. But, maybe I'm wrong. Maybe they'll prove me wrong. I doubt it.”- Jeff

\section{Type III Veterans}

As the strongest supporters, and the self-proclaimed members of the movement, the Type III veterans had the most extensive responses regarding the veterans’ peace movement. The language used by these veterans reflected the sort of personal research and studying they had done prior to coming to the movement. They also tended to express great frustration with the U.S. people, the military, government, and what one called the "military media complex."

Type III - Non-Combatants 
Lauren, who began a chapter of Veterans for Peace in her local hometown after

her service ended, felt many of these concerns and frustrations, and put it like this:

"You know, a of people say 'what's wrong with the peace movement'... because the wars in Iraq and Afghanistan only affect, directly, a very small portion of our population, then it seems as though the people are not so concerned about it, they're more concerned about the economy and jobs, things that effect them. And, I think that's typical of the overall American value system. Until we can get Americans to value other people's lives the way they do their own, I mean, we've got to really change the psyche of the whole American society and the way we think about other people and other countries and not going to wars to spread the American way of life, and this is what really irritates. I think there is a strong peace and anti-war movement, which are not necessarily the same thing, but, I think also with the takeover of the media by a few corporations we also try to fight this battle with both hands tied behind our backs because we don't get media coverage... I call it the industrial military media complex, because they're all in cahoots, and it makes it very very difficult to be an effective movement. All that said, though, I think we are making a difference and I shudder to think where we'd be, what we'd be if there were not peace activists out there pushing and demonstrating and getting arrested and all that... but it's gonna take a major shift in our whole way of thinking from when you're growing up and you're told 'oh this is the best country in the world."”

\section{Type III - Combatants}

Brad is a Vietnam veteran, and is involved in the movement in spite of his fears

that it has little impact. His response when asked about the movement is an excellent

example of the layers of feeling about not just the movement, but also the U.S.

government and military, and the futility of peace movement efforts. When asked about

the movement, he replied:

"It's certainly not for every vet. It could really only be for those veterans who have had a shift in consciousness. And that could be whether from a result of their experiences as vets, or maybe as their upbringing. Kids are brainwashed, especially little boys... And now, we don't even have just the action toys, but they have video games. It's a whole 'nother layer of brainwashing coercion of... That's the dynamic, that you're up against. 
Then there's the whole profit motive... They know what they're doing, they're very smart people, and their goal is to perpetuate war. They just about got it. They got their global war on terrorism, and it's a war without end, against just concept. Not even against a nation. Not against a person, a leader, a dictator. It's against a concept. Well, that's like saying we're gonna have a global war on war! We'll have a global war on peace. It's just never gonna end because it's just a contest. It's an idea. They've just about got what they wanted. Perpetual war. Which is perpetual profit. And, anybody that's against that will be branded as either, a fairy or a faggot, or a weak-kneed liberal, or a traitor. Pick your epithet, and pin it right on you. If you come out saying that I am pro-peace. As a concept, not just as an end to this war. But, as for peace, as a means to an end. I'll be frank with you, I don't see what their worried about, you know? Because we're just bouncing off them. We're like a gnat flying around their head... I mean, they're the human beings, they're the corpus, they're the body of this war-making machine, and we're a gnat, buzzing around, we're a nuisance, but it's nothing that's going to stop the march towards war profits. It's pretty ridiculous."

There was also concern expressed about the fragmented and small nature of today's movement compared to that of the 1960s and 1970s. Mostly the combat veterans discussed this. But like the non-combatants, many of these fears are tied to feelings about the apathy of Americans who believed that President Obama's election would make 'everything better.' Jesse and Sam, both Iraq II veterans, and members of Iraq Veterans Against the War, had this to say:

"What do I think? Well, it's a lot smaller than it used to be. The thing is that, when Obama, basically the year that Obama [was running] a lot of people dropped out of the peace movement. They forgot that movements make change, not elections. And I think now that people are starting to see what a big mistake that was. At the same time, I'm kind of bitter because I was doing full-tilt organizing during that year, and people were off doing fucking whatever they could to get Obama elected. It's just a lot of wasted energy. In a way I think it's kinda good though, because, people see now wasted and stupid it was. Basically just helped an imperialist win the election. Another imperialist. . It's not even really different as far as foreign policy. If anything, I think there may be more troops put there than with George W. Bush's time. It's kind of interesting how that ended up working out. People voted for peace and they got escalation, that's kinda how it worked out.” - Jesse 
"I think it's fragmented and for a long time, it's been very ineffective. It's doing what it does largely because it continues to try to energize the American people who I honestly don't think can be energized. I believe that the way we're going to be bring about change is through destruction of the current and system and the construction of our own. There's a lot of people who say, if the American people saw what we were doing in Iraq, they'd be rioting in the streets. The fact is, they would probably just mumble a little something and then turn on the TV; watch some American Idol or the football game, or whatever. The American people have been trained, they've been to public school, they've been trained to be sheep, and to be accepting of whatever the U.S. government does. It's going to be the people who are involved in the peace movement now and whoever else they bring through that are going to bring about the change with their own two hands. Or it's not going to happen and we'll continue to be an imperialist power.” - Sam

Finally, there were veterans who felt that perhaps there was no more peace

movement; that the American people had essentially 'gone to sleep’ on the issue of the wars and that some sort of radical trigger would be needed to jumpstart the movement again. Bernie, a Vietnam veteran epitomizes this participant. Like Jesse and Sam above, Bernie did not seem to have faith in the voting system or the U.S government - a theme that repeated throughout the interviews. This is what he said:

"What peace movement? Well, the peace movement is dead. I think that what happened was that Bush II really provoked people because Bush unmasked the colonial nature of our U.S. society like nobody else has done. He really unmasked it, which is gruesome. The lives it kills are gruesome, the consequences are gruesome. The hope that is associated with Obama, the hope seemed to be like a tranquilizer. People assumed that with a different man the entire hierarchy would change. But, what we're seeing is that people still try to protect it, it's almost the opposite. What we are seeing is a tranquilizing effect. The movement has basically dissipated, because it doesn't have fire in the belly. It doesn't have it. I guess what I'm saying is, and if inarticulate Bush unmasked the U.S. empire like no one else, articulate Obama, just re-masked it. It may be quite a constructivist thought for a moment that perhaps people will see that perhaps it's the system, and it's not gonna be solved by working in the system. Because the way its constructed requires more, and our lifestyles require more. It may be that we're at the eve of an explosion of another, almost an epistemological break about life. It might be an evolutionary 
moment of recognizing that the system is us, and, it resides in all of us. That might be percolating all over the place, there's a process. And I wanna believe in Obama. I didn't support any of the Presidential candidates. I did not vote in the last election. I do think it's an incredible moment if we recognize that perhaps the cognitive dissidence in the way we've all been living, and what the hell the reality really is, and the lies that are masked and masked and masked and masked. I don't, I think the peace movement is in a state of block...”

The most striking differences, after all is said and done, between Type I, Type II, and Type III veterans lies in their fears and hopes when it comes to the safety of the U.S. and the use of firepower vs. peace. They all agree that, as the saying goes, "war is hell.” However, Type I and Type II veterans fear repercussions and national security threats if the U.S. fails to stay adequately armed against perceived threats, while Type III veterans are concerned about damages (emotional, financial, spiritual, etc.) that are done to the soldier, the civilian, the nation, and the planet when war is used as a means to achieve peace, or power, or whatever other goal is used as an explanation. Finally, Type I and Type II veterans appear to worry about the direction this country is headed far more than Type III veterans when discussing war, peace, and their implications politically for this country both nationally and internationally.

\section{Coming to Involvement}

"Fighting a war to fix something works about as good as going to a whorehouse to get rid of the clap." - Norman Mailer, as quoted by participant, "Janet”

\section{Theme \#5: There is a range of individual reasons for involvement or non-}

\section{involvement in the veterans' peace movement}

The veterans who have come to the movement have come from a variety of backgrounds, and for a variety of reasons. Nevertheless, in all cases, there was a sense of 
an injustice being done that must be righted, or lies that must exposed. Many of them were brought to the movement by specific life events that triggered the move many years after service, while others became involved immediately after separating.

\section{Type I Veterans}

Veterans who were not members, as mentioned previously, either felt they had nothing to add, felt they were too busy, or felt other people were 'taking care of it.' Additionally, they supported the war or were not necessarily opposed to it, and expressed trust in the government to do the right thing. They also shared a belief that peace was not feasible, and sometimes implied that peace movement involvement of veterans is not particularly patriotic.

Type I - Non-Combatants

When John was an officer in the Navy. When he was asked about his reasons for not getting involved, this was his response:

'I'm not against the policies. I can remember how I felt... I think I've told you before - if you give me information that turns out to be not true, but at the time that you gave it to me you thought it was true, then it's not a lie. And, if I look back several years ago before we went into Iraq, the things that Saddam was doing, the things that were going on with the UN Peacekeepers there, the refusal to do the inspections, the verbal talk that was coming out of a lot of his henchmen, would have indicated to me that there was something going on there that was a lot bigger than a dust storm... It seemed to have a certain amount of credibility there. I can remember also that there were highly credible people in the Clinton administration that felt like Saddam Hussein had WMD... What I'm saying is, at the time that we went into Iraq, I think it was largely justified... Even if it wasn't just WMD, if you look at it from a humanitarian side, I think the people are going to be better off with the next government than they were with the previous government... Now, at some point they're going to have to stand up and fight for themselves, and I think they're doing a pretty good job at this point... When I look at the whole big picture I don't have a problem with the policy of United States 
going into Iraq... I think when we went in, it was justifiable at the time... I can't adhere to 'Bush lied.' I just don't think that a lot of the people that were in office at the time wanted to lie, and I just remember the way things were, and the way things looked... So, I don't have a problem with the U.S. policy, foreign policy.”

\section{Type I - Combatants}

Barry is an Iraq II veteran who feels that, due to other obligations in his life right

now, he does not have time. Further, he trusts that the government will have a better understanding of what is needed and why, and how to get the things done that need it. As

with many of the veterans who do not believe peace is realistic, Barry expresses a level of fear and expectation that the U.S. is under a constant threat of being attacked.

"Between school and the hospital. I'm not exactly opposed to the war. I feel like, our Commander in Chief, whoever it is, will do the right thing. I believe that, yes, we should [stop] terrorism at its worst. My personal opinion, people are always going to try to kill Americans and if it's in their backyard, well, that's a lot better than being in my backyard. They're gonna come wherever they can, and do whatever it is their whacked out minds tell them to do."

Ben expressed a belief that the government is more aware of what is taking place, and is better able to make the decisions about whether war is "right" or not. In addition, he implies that it is not patriotic to be part of the peace movement.

“Because I don't think that I have all the information that I need to make a stand on an opinion against the government when they have more information about what is happening what is going on, the particular threats and so forth. I have to have faith in the leadership that they are doing what is necessary to combat whatever they feel is harmful to our national interests. Although I am no longer in service as a commissioned officer, the oath of office that I took to protect and defend the constitution against all enemies foreign and domestic is an important part that every American should be part of.” 


\section{Type II Veterans}

Veterans who recognized the role of veterans in the peace movement, but did not themselves take part (Type IIs) responded in ways that were similar to both the Type Is and the Type IIIs. Many of them felt the superior firepower was the only way to peace due to the constant threat to the U.S. Still others expressed a belief that the U.S. is perhaps not acting in a "good way" but that they were still unsure where they stood on the issues, or if they had anything of value to contribute to the movement. Several of them didn’t even realize there was a veteran's peace movement. Finally, some of these veterans had at one time been a part of the movement, and still supported it, but had ceased to be involved themselves, for a variety of personal reasons.

Type II - Non-Combatants

Dan, a Navy enlisted man, does not believe that peace without superior firepower is realistic. Dan's statement implies an inability of people to be peaceful. Like other veterans, his statements imply an opinion about peace and a "hippy-ish" stereotyping. As he puts it,

"I believe I said earlier that people strive for peace in different ways, and currently the norm is peace through superior firepower. Although I would love for everyone to be the touchy-feely hugger mother kind right now, with the current situation, whether it be an economic situation or a religious standpoint or whatever differences people have, we're not able to come together the way that we should. There are those outside the social norms that are willing to do whatever is necessary to harm someone else. And as long as there are those people that are willing to harm someone else there needs to be those who stand up and are willing to fight to protect the other people to keep them from harm so everyone can enjoy that peace.”-Dan 
Amanda had been involved in the peace movement. When she was called to duty in Iraq, she went AWOL (Absent without Leave) in protest of the orders. However, since then she has left the movement. She explained the decision to leave the movement in the following statement.

"I feel like it's just not as a big of an issue in my life anymore. I feel like I've moved away from that. I've got work and other personal things and I feel like I've moved on from that. It might sound. Thinking about it, it might sound selfish, but then at the same time, I just don't feel it as much anymore because I already went through it, and I've moved on, and then, there's always new people growing through some other things and I'm hoping that these other people, since I'm not there anymore, that those new people who have, who still stand up who are doing that, and they're talking."

Janet expressed another common theme, that she had nothing to contribute

because she hadn't seen "real” combat, and so she doubted what her value would

be to the veterans' peace movement.

"Probably the main reason is I feel that even though I'm a veteran I have not been involved at all during combat. I don't know if my value to it as an organization would be as strong as someone who's actually seen combat. But, if I was ever asked to do something on behalf of the veteran's group for peace I certainly would do it.”

Another opinion expressed, and along the lines of "having nothing to

offer,” was that of Joe who stated, “I guess it's never been one of those issues I

really believed in. Maybe I see that there are enough people doing that it hasn't

drawn me in to "the cause” or, I always, especially with the new administration

taking over, the emphasis is greater than the last administration, which is why I

didn’t feel doing anything, my part, doing anything would help.”

Type II - Combatants 
Combatants tended to answer the question indirectly, during the course of the interview, via responses to other questions. By and large, they believed the movement was a waste of time due to its ineffectiveness, and that there were better ways to help other veterans. Jeff had this to say about the veterans' peace movement, and his reasons for not being a part of it:

"I don't think it's not doing any good, it's doing good for the people involved in it, just as something to do, so I'm for it in that respect. And, I think that every little hint of awareness they can give the civilian public is definitely good, I definitely support that. I just don't know that their efforts, their efforts sometimes seem to be counteractive. I know people here on the really really far right, do what they do, and sometimes people take it to the really really far left, and they try to balance it out, but sometimes it just seems like they lack realism on both sides, and now we have to meet in the middle. That's probably why I'm not involved in it more than anything. That, and when I got back, I was back for a couple years and I was drinking and doing my thing, just being by myself, when I got my head halfway straight I wanted to do something. I never even thought about the peace movement, I just thought about helping other vets. So I went to a VFP meeting once, but not to be a part of it, but just to get money for a scholarship, actually. I listened to everybody talk, and I respect those guys a lot, I just don't see it make a huge impact, so I guess that would be the reason. I think there's other things I could do, maybe not for them, but for myself, there's other things I could do with my time helping other people.”

Brenda is an interesting case of the Type II veteran. There are no veterans' peace organizations where she is located, and she would rather be with other veterans in her action, but feels it is more important to speak out than to wait for the opportunity to act with other veterans. And, with school, she is very busy. As a result, she is peripheral member of a civilian peace movement. Brenda is the only Type II to be involved in any kind of peace organization. When asked about why she became involved, her comments were the most similar of all Type IIs to Type III responses. She stated: 
"Just my drive. I really wanted to find groups when I came back of people who had the same types of ideals as me. And, I'm all for peace, I'm all for non-violence, and I needed something, I needed to know that there were other people out there who were willing to listen to my story and not judge me just because I've involved in the military, and accept me, and listen to my side of the story."

\section{Type III Veterans}

Type III veterans, whether they had seen combat or not, related personal biographies, and life events that brought them to the movement. In almost all cases, these veterans mentioned a period of self-education - often about the history of this country, and of conflict in the world. Many of them studied various religious traditions, including Buddhism and the Judaic-Christian faiths. Many told of self-medicating, and the therapeutic results of getting involved in pro-peace and anti-war movements. Several of them began in another movement or effort, and upon seeing the impact they were able to have, moved on to the peace movement.

\section{Type III - Non-Combatants}

Lauren and Bob were interviewed together. They both served as officers in the Navy. Lauren stated that she was always a more liberal service member, having gotten her degree in the Liberal Arts, while Bob describes himself as a "newbie to the activist life" and a "Cold War warrior" who believed what he was told while her served. For them, coming to the movement was a reaction to the invasions of Iraq. Less by the first President Bush, as that seemed "abstract and unreal," and more due to the invasion by President G.W. Bush, which they found unjustified. They tell the story about their coming to the movement below. 
Lauren: Well, I felt sort of, I tell you, we really did not like the Iraq war, but when it started we were traveling, so we didn't really get involved with it much, and, then was a time when we didn't hear anything or get any news for weeks at a time, so it was kind of abstract. When the first Gulf War broke out I was stationed in Japan, and it was just something that happened on the other side of the world, and it didn't affect me, even though I was in the military! Here's kind of how we got into it. When we moved here, it was the Fall of 2004, just before the elections. And, we had our camp that we were living in, and we didn't have a car, we had our bicycles and the camper, and so, when we were here we were living at the campground at the other side of town and we were bicycling around and we saw the HQ for the county democrats, so we rode in there because we wanted to help get Kerry elected. So, um, so we got involved in the local democratic party. And, we got pretty heavily involved, both of us were committee people, and we went to the central committee meetings faithfully, every first Thursday. And, Bob was on a committee and it was just, but I'm really proud of this, so I tell the story all the time. Bob had the idea to start a petition...

Bob: Well, it started out as a resolution. We wanted to pass a resolution by the democrats to bring the guard and regular forces all home. Um, from Iraq. Bring the troops home. And, so, that passed, to make a long story short, and then that got kicked up to the state central committee, and they passed it, so we're all, 'Well, what do we do now?' we got this resolution it's posted on the state democratic party of Oregon website, and, uh, I got the idea to try to pass a resolution with the city council here. So, we, to demonstrate community support we started a petition drive, and, uh, collected over 1000 signatures. It was just kind of...

Lauren: But, that's what I was collecting signatures for when I was in Albany, so...

Bob: Yeah. So, we got that passed. And, I think we're the only city in Oregon, well we were the first...

Lauren: Yeah, now there's 3 or 4, but we were the first city in Oregon. So it kinda went from there...

Bob: And, I don't remember at what point we decided that, 'well, that's the organization for us."

Interviewer: Okay. So, now you said that you [Lauren], kind of already started out on the more liberal side of the spectrum, and you [Bob] were more conservative side. What changed that for you?... 
Bob: I really didn't turn around until we got into the Gulf war and then into the Iraq war. But, I, you know...

\section{Type III - Combatants}

Jack is an Iraq II veteran. His involvement was triggered by what he saw as the waste of life, the pursuit of oil, the lies he had been told and was encouraged to tell his troops, and the abuse of his service by the military. He believes that he is now serving in another capacity - one that saves the lives of others.

"I always believed in the military you do what you're told...I mean, it was my career, and sometimes you do things that go against the grain simply because you chose that profession, but it got the point where I was like, too many people are dying or getting injured over here and for what? That's both sides! For starters we're fighting to liberate oil fields. We didn't care about these people. I would bring this point up to my commanding officer, you know, if we're liberating these people, cuz he'd always tell me to tell that to my troops. They'd tell me to tell my people this, and I'd flat out tell them no, cuz then I'd be lying to them, we're here to liberate oil fields. He goes, your politics can't get in the way here. I'm like, no it's everything about politics. I said, why aren't we in Sudan liberating those people? I said, there's genocide that's been going on for years down there! There's no commodity that we can get from those countries, that's why we're not there. I got home, and I've got problems here with my unit because I got vocal. I'm very vocal, and if I see something that I can stand behind, and I'll stand behind, or I'll stand in front and fight. That's just who I am. I don't believe in it, I have nothing to do with it. There were health concerns, health issues, with the vets coming home, with more stress, and they were gonna send me back again. They had already had in my psych eval... that I was not to have another weapon in my hand, and yet they were going to send me back to Iraq! And I just laughed, I'm like, okay, let me see here, you're going to send me to Iraq but you're not going to let me have a weapon? I said, trust me, I will get one. Now, how I get it from and who I use it on, hm! You may want to think twice about sending me. It was getting towards the end, and I was getting out, and I'd just had enough of it. After that I decided that I'm gonna speak out, and I have. I've spoken several times, on the radio, on the television, I'm honest about it. I don't like the propaganda the media's throwing out there, because it really annoys me, because it's your life and other people's lives on the line.” 
Dave is a Vietnam veteran. He did not get involved in the peace movement until several years after his service was completed. As he put it, he came home, got married, self medicated with alcohol, and tried to put the war out of his mind. However, he and his wife had a son born with serious birth defects that Dave came to realize were likely the result of his exposure in Vietnam to Agent Orange. Dave's son was born with a cleft palate and congenital heart disease. As a result of this, Dave began to study and learn first learning about Agent Orange and working with refugees and studying various religious traditions. When his son was three, he went in for heart surgery. The surgery did not go well and the little boy died in Dave's arms after seven weeks in a coma.

Dave and his wife took a "mourning-vacation" to the beach, and it is here that Dave had his epiphany. The trigger that moved him to join the movement was his son's death. He tells the story in this way:

"Well, there was a real epiphany. That was something that really shook my world. If I didn't have my wife and a daughter, I would've killed myself. There was no doubt about it. And my wife felt the same way. She was devastated. But, we had a beautiful little girl, and relatives took my daughter, and we went down to the beach. We stayed down there for a day, and I was walking down the beach and my soul, or whatever it was, left my body and I traveled through time. Through time I was seeing all these wars, all this violence, all these kids with illnesses. Dying, dying, dying. And all of it until we came to the biblical story about Eve. And Eve was holding Abel in her arms, and Cain, his brother, had just killed him. And, she let out a scream, silent scream so terrible that it shook the entire universe, and even God trembled. And, I was, shooo, swooshed back and an ocean of tears started lapping at my feet and brought me back to reality. And, I knew at that moment that I could not understand I could understand that children are born, that there are things that happen in the world that we don't understand why, with disabilities, with diseases, and in natural ways. But, here we were, spending tax dollars and money to buy bullets and kill other people's children. And I just knew from then on I could never support that. So, from that point on, I was, got actively involved.” 
Other veterans did not discuss a specific life event that triggered their

involvement. They spoke in terms of something larger than themselves, something that compelled them to involvement and to speaking out. They also discussed the therapeutic nature of involvement. Mark's is an example of the former type of narrative, Brad's of the latter.

"I mainly got involved because I had an overwhelming desire and obsession to bear witness about the lies of the Vietnam War. So, what I do is I speak to the dead, and the other thing I do is I point the finger at those who are perpetrators of wars. Um, these wars of what you might call non-stop war crimes.” - Mark

"Well, what brought me to this organization was I think, part of it was therapeutic because I felt like if I didn't speak out and do something to stop the Iraq War from happening, then I was just gonna go crazy. I mean, all of those triggers were active again. Everything that I had tried to bury for 20 years, in terms of PTSD was all just really cracking. It was causing me a lot of problems. And so I felt like, well, I gotta do something. And then, maybe the hope was that maybe it would get better. You know, just knowing that I publicly against this, and actively fighting it." - Brad

Finally, several veterans, in addition to discussion about educating themselves and studying aspects of war, religion, and society, also spoke about finding vindication through the involvement of other veterans. They also expressed a sense of relief in knowing that they were 'not alone' in their feelings, and that they had the right to speak out.

"I got involved in the peace movement through Vietnam Veterans Against the War (VVAW) action in Washington in 1971 on the Mall. Activities like that, do you know about it, they threw their medals. I was just totally ecstatic that my feelings about the war were legitimized. I had witnessed stuff that I had not been able to access at that time, it took 10 years to be able to access it for the worst parts, but I knew that war was wrong, and I knew that what I witnessed was wrong, and I had a lot of guilt in my mind. That really helped steer almost the whole decade of the '70s, knowing that I wasn't alone in how I felt. I knew I wasn't alone, but, emotionally I needed that. That was my initial involvement in that with vets. That 
would have been about less than a year after I got out of the military. I was just so against the Vietnam War. Although I still think at that time I believed Vietnam was an aberration, I was beginning to wonder about the history of the United States and war and I had begun studying history and philosophy and biology and other stuff came later. But I really knew something was wrong with this kind of behavior. Even though I knew it was a pattern in some ways, but still wasn't clear about the overall context of it all. I was really really clear that this is not right. I was not confused about my identity. I was developing a new identity... But it was all extended back to that I knew something was really wrong, fundamentally wrong with my society that would allow, that would allow or initiate a war in Vietnam. That would allow the injustices that I was experiencing in the United States. Even though I was a privileged European, Eurocentric, white male, I was very, I was sensitive to what injustices there were in society.” - Bernie

It is clear that how a veteran feels about her military service, and why she

comes to be involved in the peace movement are intimately connected. When she discovers in herself a disappointment, a fear, or anger about something tied to her service, she finds herself, consciously or unconsciously seeking out something else, something to allow her to feel some new control in her life, and a new direction and purpose. As one veteran very clearly stated, there is vindication and a feeling of community, a sort of triumph, in discovering that other veterans share her views, her fears, and her aims.

\section{What a Vet Provides}

\section{Theme \#6: Veterans provide a range of benefits to the peace movement}

With only a couple of exceptions, all of the veterans who participated in this study agreed that veterans have a great deal to offer the peace movement. Some of that has been briefly touched on in previous statements. When discussing what veterans have to offer the peace movement, members were most likely to discuss the voice of the veteran, 
and the legitimacy and credibility a veteran, particularly one who has seen combat can lend to movement. The participants also mentioned the neutralizing effect a veteran might have on negative stereotypes and opinions of peace movement activists and members.

\section{Veteran Type I}

In most cases, the responses from non-movement members tended to mirror those of the members, even though they did not support the involvement of veterans in the peace movement. As expected, they were quick to point out their disagreement with veteran involvement. These reasons varied, but tended to center, again, on fears about safety of the troops, trust in the government, belief in the mission, and threats to the U.S.

\section{Type I - Non-Combatants}

Even though they had never been exposed to actual combat, non-combatants recognized the perspective that a veteran, especially one who has seen combat, has to offer those who have not, regardless of their veteran or civilian status.

“Perspective. It's definitely about perspective. I don’t personally believe that anyone that hasn't been in a war can have the same perspective as someone who's been fighting on the ground against an enemy they don't know, for whatever cause. Maybe a touch of reality of 'this is why I did it, this is why I believe...I choose peace instead of war,' if that's the polar opposite.” - Joe

\section{Type I-Combatants}

Type I combatants pointed out the insight and leadership aspects of service that might be useful in a movement. As a non-supporter, they also mentioned in some form or another, their disagreement with veteran involvement.

"Insight. There are probably some aspects of their service that they were leaders, and so on, in some form or fashion that they could, lend to 
something like that. But, in my opinion, I think they would be backing the wrong side.” - Ben

\section{Veterans Type II}

Type II veterans, while not involved in the movement, articulated opinions regarding the contribution veterans have to give the peace movement in much the same way as Type III and Type I veterans. However, unlike Type Is, they did not express disagreement with veterans being involved in the movement, or the threat they posed to other soldiers, in their answers.

\section{Type II - Non-Combatants}

The Type II responses, as demonstrated below, mirror those of the Type I veterans, minus the expression of fears about the legitimacy or "rightness" of veteran involvement.

"Insight. Experience. Insight. Knowledge of combat vets coming back and talking. I think recruiters should use them more often. You know, because then they could say, hey, you know, this is what it's like. And, not be such a numbers game." - Rachel

"I think that veterans can provide a voice of sanity in a sea of insanities, as far as our government officials, because, especially with reference with the recent announcement of more troops in Afghanistan. I think that's a major mistake. Afghanistan has major issues with poverty, and illiteracy, and infrastructure, and sending more troops to Afghanistan is not going to solve those problems. I think that the more veterans can speak out about what they've experienced in Afghanistan, and Iraq, and just lend some more on the ground been there done that reporting vs. a lot of people in the media who have no idea what's going on over there.” - Janet

\section{Type II - Combatants}

Type II veterans also mentioned the impact that a veteran's involvement might have on the perception of the movement, and opinions of those outside the military. 
"I think that it paints a more complete picture for people who see it from the outside. I think that more people are willing to listen to veterans who are against it. More so, at least, than in the Vietnam era when people were spit on. Even if they were part of the peace movement. But, I think civilians have no idea really what war is like, and especially if they've had relatives go there, are a lot more likely to sympathize, I think, with people who have been through that experience, and having known that experience, still choose to be part of the peace movement.” - Brenda

\section{Veterans Type III}

Type III veteran responses were similar to those of the Type I and Type II veterans. They simply provided further elaboration and clarification on the influences provided by veterans involved in the peace movement.

Type III - Non-Combatants

Below is a response from Jake, who further details elements mentioned by the other veteran types above. The first is that of public perception of veterans. The second is one of political impact that is possible for veterans, but not for civilians. This impact was, as he put it, scaring the "crap out of politicians.” Again, even as a member of the peace movement, Jake made an effort to distance veterans in the peace movement from the stereotype of peace activists as "long-haired hippies.” His complete statement is provided below.

"People often think that veterans are entitled to things... and so, if we can get enough of them in a room together it seems a lot more respectable than a room of a bunch of pot-smoking hippies who are just kind of like, 'hey bro, wage peace not war.' It's not an argument that's effective. Throughout the past, veterans have been a more violent side of the peace movement... and Washington sees them as a threat, so they finally react. That's what veterans do, they scare the crap out of politicians because they know that they're poor and trained and armed. And angry. And they want things, and they're persistent. It all depends on how you look at it. If you're a civilian you hold veterans in high esteem, if you're a politician you fear the shit out of veterans. So, it all depends on what you bring, what side of the peace movement you look at it from.” - Jake 
Type III - Combatants

Unsurprisingly, combat members were far more talkative about what a veteran has to offer the movement. And, they articulated an additional set of ideas about what a veteran is able to bring to the movement. These veterans were more likely to focus on the voice of experience of veterans. What was also discussed in these interviews, in a much more pointed manner than with noncombatants, were the tactical and strategic, as well as organizational, skills of veterans. As with Jake above, these combat veterans also mentioned the firearms training of veterans.

"I think one thing that's good is, they have experienced different things. They understand that people that we would be fighting against, and they could probably talk about, sometimes the peace movement is disorganized, and kind of sloppy, so it's kind of good to have people who aren't. But, at the same time, there's people who think strategically, tactically. That's always a good thing. Not even just in a war situations, but people who are always thinking two steps ahead, and, we're trained to kinda think about the enemy, about the situation, whether it's the cops or whether it's politicians... they think ahead about what their likely acts are going to be. At the same time, I think it's good because, and this might sound bad, but I think it's good to have people in this movement who have been trained to fire weapons cuz I think a lot of people on the left have decided they're too good for guns, and that's great thinking. I mean, I don't like guns either, but, to have two good guns might be good when all these fucking crazy right-wingers rise up. I mean, they love guns, and they don't give a fuck about Gandhi, so, you know. I don't wanna sound like a gun not or anything, but it's just kinda one of those things where you're kinda like, people are odd. It's pretty much like people think of liberals, it's people who raise their nose at guns, or shooting. Like, I'm too good for that, you know? Yeah, that's why people fucking think you're a pompous asshole, and it's like, well, you know, Gandhi's not going to do you any good, you know? For them it's like a revolution, like today, Capitalism is failing, we're stuck in two stupid wars, they're just fucking run around with their heads cut off cuz they don't know what to do. “Oh, but I voted for Obama." I don’t know." - Jesse 
"I think that they can add the voice of experience, and also, on a tactical level, most veterans have been trained in crowd control and, when the police are lined up on the streets in riot gear, they can more or less say what's going to happen next. I think that's something that's valuable as well.” - Sam

Well, number one is the garden-variety critique of a peace activist's patriotism is neutralized. They can't throw that in our faces. Related to that is the issue of credibility where, you say that war is the enemy. Where we say that war is evil. Where we say that war is terrorism with a bigger budget. When we say that it embodies everything else that is evil, which is basically what matters in the end. We're speaking from experience first-hand, you know. We know it. Or, at least, some of us do. - Brad

This is one of two areas where all veteran type agreed on more than they disagreed. Almost of them saw the value a veteran has to offer the peace movement, even if they didn't know, or didn't like, the idea of "veteran in the peace movement.” It's very interesting that, whether a veteran sees this role as valid or not, he is still able to see the value in it.

\section{What a Vet Gets}

\section{Theme \#7: There are benefits to be gained by veterans in the peace movement}

Veterans also, by and large, agreed that there was something to be gained by the veterans who were involved. This was true in all the interviews except one. Shelley understood that a veteran might feel something is gained, but did not see how involvement in the peace movement would provide something legitimate to a veteran. She saw it like this:

“Get from it? I don’t know. I don’t know what you would get from being a veteran and being involved in the peace movement. I mean, there's that line of, you want to serve your country, but, and your proud to serve your country, but, you know, I don't know what you get out of [involvement].” 
For those veterans who did see something legitimate for the veterans involved in the movement, the gains ranged from healing to a sense of purpose. A sampling of these responses is provided below.

\section{Type I Veterans}

It was clear that for the Type I non-members and non-supporters there was sometimes a 'problem' with veteran peace movement involvement. There was often an underlying belief that their involvement is not a 'valuable' use of the veteran's time. Some of the non-member veterans expressed views that implied that veterans were involved in an effort to 'undo' something that they felt badly about on a personal level. Type I - Non-Combatants

Tony was in the Navy, and while he does not necessarily agree with veterans being in the peace movement, he stated that he believed that a veteran would gain "an awareness of whatever wronged them, like during the war. Whether it be something they saw or were exposed to.” And that, in doing that, veterans would have success in "getting their word out." While he does not state is specifically, it can be inferred that on some level he recognizes a therapeutic or cathartic element to being a veteran in the peace movement.

John had a different opinion about veteran involvement. He recognized that there might be something gained in having others around who can "relate” and his language use suggests an understanding of something that triggers a veteran to seek out and then join the peace movement.

"I guess it would depend on what they're background was, why they were there, and what it was that was making them unhappy to begin with... 
They might get some camaraderie. Or, a shoulder to cry on... people that have other similar stories to tell... You know, it depends. I guess if I knew somebody that was actively involved in the movement, then I would have maybe some other insights to give. You know, what was it that drove them to be the way they were. I dunno."

Derek expressed an opinion that came up in other ways, and with other inquiries. That opinion is one concerned with the security of the U.S. against attack from an adversary. In his statement he implies that peace is tantamount to a sort of anarchy that would lead the country open for rampant violence. He did not address what a veteran might gain, but instead focused on his fears about what "peace" would mean for the U.S.

"I think they have to keep an open mind and understand that it's not peace at all costs. It's peace, and keep your country safe. It's not throwing away all the weapons away and then let everyone else do whatever they want to do. I don't think you can do peace with that.”

Type I-Combatants

Type I combatants were more likely to discuss a veteran's purpose of desire in becoming involved in the peace movement as a means to an end. For example, seeking closure and achieving what the veteran feels the wars cannot, as Barry stated below.

“Closure. To a point. I'm assuming they don't feel honorable about their service. I know going to Iraq, a lot of us, really, are irritated, because it wasn't like it was war. We just drove around in a truck for hours risk being blown up by mines. So, you know going to peace, working with the peace movement, that's a way of accomplishing something. 'I can't do it, I can't get them one way, maybe I can this way.” - Barry

Worth noting is Barry's almost casual dismissal of his time in Iraq as not being 'real' war. While it is not the focus of this chapter, or this research, it is still a finding worth making note of. A statement like this further suggests that there may, in fact, be some differences between veterans by campaign. On the other hand, the difference may 
be less about the war fought in, and more about the type of combat engaged in during service in the war.

Other veterans reiterated the fear that involvement in the peace movement could be a dangerous thing. As Kate put it, "What do they get? Um, well it depends on how they're involved. It can be destructive depending on how they go about it." On the other hand, Ben talked about the ugliness of war, and efforts to keep others from having to endure it.

"Well, one of the things that a lot of people don't understand about war is how ugly it is. And, there's a lot of glamour that goes along with how things are going and so on. Nowadays with the transmission of pictures, photographs, images and such, more instantaneous, people have more of a feel of the ferocity and veracity of war than they used to. Before you would get it in news reels or just in letters and so on, and you couldn't really tell. Nowadays you can tell how bad it is, more easily. I think a lot of veterans feel that they would rather not have anybody go through the same kinds of things they went through. They're trying to probably stop it, or tone it down, or you know, cut back, because they know what it's like. They understand that there are bad things out there that could happen to people, and, a lot of it, they might see, as a waste... Just trying to make a difference."

\section{Type II Veterans}

Like the Type I veterans, Type II veterans saw the satisfaction a veteran might find in fighting a social injustice or in helping other veterans. These veterans also mentioned directly the potentially therapeutic nature of involvement in the peace movement.

Type II - Non-Combatants

Rachel and Pete's statements, given below, touch on the theme regarding satisfaction in fighting an injustice. They also add to this the idea of fighting something 
that is worthy, rather than something 'frivolous,' and doing something good for their

country.

"I can definitely see where they're looking at it, and probably getting some satisfaction from fighting social injustice, and all that's going on. Especially with recruiting of minority and low-income status youths. Or, just adults, too. As far as the war going on... I can see where you can get satisfaction in knowing that the next group of soldiers that are in the service, whether they're friends or they're family or their children following in their footsteps, will not be just fighting because some President's just wanting to get revenge for his father's error, or something. So it's a good cause that we're actually going to war. And that America actually values life...That's what you run your colors for. You can be absolutely proud of it.” - Rachel

"I think they get some...some satisfaction out of doing what they feel is right. You can support war or not support the war and still support your defense system, right? So, I'm sure that they feel like they're doing what they think is right for the country, and for them and themselves and their beliefs." - Pete

Janet directly addresses the repeated assumption of the aid veterans in the

peace movement might feel is achieved by their involvement in it. As she states:

"I would think that they may be able to prevent other military members having to possibly go through what they've gone through... I think they get the... Knowing that they might be able to stop other people from having to experience war and combat. Which, I don't know, the statistics are pretty high on post-traumatic stress disorder, and other afflictions of veterans. So, if they think they can help prevent that from happening to other people in uniform, I guessing they feel like it's a good reason to be involved." - Janet

Finally, Amanda, recounted the story of a friend who joined the movement

in an effort to heal himself and stay alive:

"I guess I can talk about one veteran in particular who I got to know very well who was very involved. I know that he told me that the reason he did it was because he knew that that was the only that was protecting him from committing suicide. He knew that if he wasn't out there, telling people, giving speeches, so he had to do what he thought or he probably 
wouldn't be here today. So that was his motivation for doing that.”Amanda

Type II - Combatants

As mentioned previously, some of the Type II veterans felt that a veteran in the peace movement might be trying to atone for something done or seen during service. Some of these veterans also expressed a view that the efforts of the peace movement, and the veterans in it, were futile. An example of this is provided below.

"Honestly? I think it helps them with their conscience. I honestly think it's outdated. I'd like to believe that it could do some good. And, sure, it's done some for some people, at least done good for them, but I don't see it making a lot of progress anywhere, and I've always thought there were better ways to spend my time as far as helping people. Maybe that's kind of a defeatist attitude, some people would say it is, but I'm just dealing with the consequences, cuz I've worked, like in a social work capacity, out at the VA when I was doing my work study, advocate and such. To me, that would be the more realistic work that could get done in the moment. Whereas protesting, and yeah, it did a lot during the Vietnam era, I know it did, but realistically that war still dragged out for a while from what I know of it. And, now, with the number of people that serve, and since it's such a small military, I don't see an impact.” - Jeff

\section{Type III Veterans}

The Type III veterans were not directly asked what they felt a veteran got from the peace movement, as this question was directed non-members' understanding. However, in the process of conducting the interviews, it became clear what the veterans involved in the peace movement felt was gained personally. In all cases, the gains can be boiled down to: healing, affecting change to the political system, ending the wars, and bringing the troops home. The only difference between combatant and non-combatant

Type III veterans was that the non-combatant often provided a caveat to their statements that recognized the difference in service experiences between combatants and non- 
combatants. What they saw was gained, is directly tied to why they choose to stay involved. These conversations are discussed in the next section.

\section{Why Stay Involved}

\section{Theme \#8: Veterans in the peace movement develop a shared identity}

As previously suggested, veterans who are involved in the peace movement, when asked about their reasons, gave a variety of explanations. On the whole, these reasons could be tied back to their reasons for joining, and their belief in the potential of the movement to achieve its goals, in some form or another. Many of them discussed the fact that the U.S. government was still sending troops over, that "lies” were still being told, and that the U.S. government was corrupt and needed changing. In the end, whatever the reason, what became evident was a shared idea that something was broken and needed to be fixed. In the case of these veterans, the broken thing is the U.S. government, which they saw as imperialistic, and its policies, which lead this country to wars for oil and profit. All the type III veterans had shared experiences that convinced them that they had a duty to take an active role in ending these conflicts in order to counterbalance the wrongs they had witnessed. Therefore, as they became aware of the role veteran for peace, they internalized it and started enacting it - claiming that identity.

Due to the nature of this question, the responses gathered were exclusively from Type III veterans. The examples below are from veterans quoted previously in other sections of this chapter, and they illustrate three aspects of a veteran for peace identity: fixing something that is "broken" in U.S. values and policies, bearing witness, and making a difference. 


\section{Need to Fix Something}

Lauren, who is very extensively involved in the peace movement, expressed

frustration with it, but stays involved because she believes in the movement, and what it is trying to accomplish. She put it like this:

"The more you get involved in it, the more you see the work that needs to be done, and since I'm retired I can devote all my waking hours to this, and, and sometimes [my husband]gets uneasy cuz he thinks I do too much, that I should rest, that I take on too many things, and...There's just so much work to be done! It's just not hard to see where there's a need. It's also possible to get burned out, and feel like, 'I'm not making any difference, it's too hard, it just pushing the boulder up the hill and we have too many forces working against us, and the money problems,' and that, and it does get discouraging. But, it's not hard for me."

Jake had an entirely different reason for staying in, but the same end goal

of "fixing" what is broken. He also mentions that his military service may have

had an impact on him that has left him feeling this sense of duty.

Jake: It'd be guilt if I didn't get involved, I think. So, if I wasn't participating in the community, or trying to make the world a better place, I wouldn't be able to go to sleep at night.

Researcher: So, is that because of your military experience, or because of what you believed before?

Jake: I don't know. Maybe just empathy with humanity. It could be part of the military that changed that in me. But, I think I experienced empathy long before the military. When I was younger. And it's just kind of been intellectualized more in my mind, as far as how empathy plays out as a characteristic.

\section{Bearing Witness}

Another aspect of the veteran for peace identity discussed by Type III combatant veterans was the need to bear witness for those who have come and gone before in opposition to the actions of what they viewed as a corrupt government. Several of the Type 
III veterans expressed the belief that there was still the possibility of success of the movement so long as veterans for peace, like themselves, continued the effort. Jack and

Sam are veterans of Iraq II, and Mark is a Vietnam veteran.

"We're still in Iraq, and they keep fabricating the lies and every time we turn around it's "watch this." When support for the war goes down, all of a sudden bin Laden puts out another tape. It's like on cue... it's just seems like it's some great big cover-up. It's all this big money... Obama's been brought along. The whole government's been bought out... A lot of people feel this is just paranoia, but you have a lot of power brokers that are behind the scenes, that call the shots, and they're very powerful wealthy people. Just look at people, look at history. Look at the Kennedys... You say something 'they” don't like, you're gonna disappear, you’re gonna be discredited. - Jack

"I believe we can meet that threshold of success. But, I think that that threshold is a lot larger than most people consider it to be. If we can't reform the government that engages in torture as a matter of policy, and that has continued under Obama's administration, if we can't reform a government that drops bombs on children in Afghanistan, Pakistan, just so that they can build a pipeline across that land, to the Caspian Sea, it just doesn't matter who you elect, because the people who are being presented, doing these choices are, company men, well, men and women, they're all bought and paid for by the people who profit off these wars. So, Barack Obama has taken more money from the defense industry than John McCain did! To think that we're going to change things through voting, through things like that is really Pollyannaish, and it's going to take some really dedicated and motivated people to the very important things that are required to bring about real change." - Sam

"[I have] the overwhelming obsession to bear witness, to speak for the dead. And to point my fingers at the perpetrators. -- those who are responsible for the wars. I speak for the countries we invade. I speak for the civilian populations who are being killed with our tax dollars. That's what I do. That's the reason I get up in the morning. The reason why I'm here." - Mark

\section{Making a Difference}

A third aspect of the veteran for peace identity emerges from Type III veterans discussion of their shared belief that, no matter how little they may be able to quantifiably 
measure their influence, without their efforts and presence, things would likely be much worse in this country in regards to unquestioned support for the war efforts. In addition, these veterans expressed a belief that their activism as veterans for peace is helping and supporting other veterans, as well as current and future active duty service personnel. Several made a point of mentioning that they do not see themselves as pacifists; they are ready and more than willing to stand up and fight for what they believe in. These comments from Type III veterans directly contradict the view of veterans for peace that many of the Type I veterans suggested - that being an activist is equal to being a complete pacifist who would leave open the door for another terrorist attack rather than fight.

"This is a very common question. People ask me that, and, people say, 'how do you know you're making any difference?', and I always say... you don't know the answer to that question because we don't know what would have happened if we had [not] done this work. I will tell you, I have had many people contact me, or write me, or tell me face to face, 'when I saw that you did this, or you said that, or you got arrested, or whatever, that motivated me to do this.' You never know when you're affecting somebody; you never know when you make an impression. You don't know when that tipping point is going to be. There's several people who -- I know Helen Keller is one of them, Margaret Mead is one -- I've heard them say, "I'm only one person, I can only do what I can do, but it's so important that I do it.” It takes many drops in the bucket to fill it up...I think it's very important that we keep working, and yeah, I think we are making a difference!” - Lauren

"I think it helps the vets see this, because, especially those that know me, I'm proud to say that I will fight for my people if I'm for it, if I believe in it, without hesitation. But when to comes to acting for odious ugly people back here in the states to increase their bank account, no. As far as I'm concerned send your sons and daughters to get that pipeline, not mine, not nobody else's!” - Jack

"Yes. Mainly because of the work I do in my writing, my photography. I send my images to an electronic newsletter out of New York called Military Resistance. My stuff, my photographs and the writing that I do for the photographs get exposure all over the world. I talk to vets who are in Iraq who reviewed my stuff when they were in Iraq, so I get a lot of 
exposure through that. Mainly because the electronic newsletter called, like I said, GI Resistance gets a lot of circulation, so, I mean, it's not just me, it's a lot of people who contribute to that." - Mark

\section{Being the Same and Different}

As suggested previously, it became clear that there are differences between the veterans that allow them to be divided into three types of veteran. These three veteran types are described in Figure 2 below.

Figure 2

\section{SIMILARITIES AND DIFFERENCES BETWEEN VETERAN PEACE MOVEMENT MEMBERS AND NON-MEMBERS}

\section{- War is bad}

SIMILARITIES

-Mixed feelings about military service

-Veterans have something to offer

-Veterans have something to gain

- Demographics affected peace movement support and membership

Type I
-Peace movement is possibly
detrimental to national
security \& vets should know
better
-Service good ontweighs
service bad
-Service is honorable duty
-Goverminent can be trusted
-Mostly non-combatant
officers
-Recognize the role,
negatively evaluate it, and
reject the identity

\begin{tabular}{|c|}
\hline $\begin{array}{l}\text { Type II } \\
\text {-Peace movement is a good } \\
\text { idea but not realistic } \\
\text {-Ambivalent about service } \\
\text {-Government may be doing } \\
\text { "bad" things } \\
\text {-More likely to have been } \\
\text { enlisted } \\
\text {-Recogniva the role, } \\
\text { fuvorably evaluste it, but } \\
\text { reject the identity }\end{array}$ \\
\hline
\end{tabular}

\begin{tabular}{|c|}
\hline $\begin{array}{l}\text { Type III } \\
\text {-Peace movement is necessary } \\
\text {-Service bad outweighs service } \\
\text { good } \\
\text {-Trigger event compels joining } \\
\text {-Government is corrupt } \\
\text {-More likely to be enlisted } \\
\text { combattant men } \\
\text {-Recogniwe the role, favorably } \\
\text { evaluate it, ond embrace the } \\
\text { identity }\end{array}$ \\
\hline
\end{tabular}

There are notable differences between the three veteran types. The biggest differences existed in their feelings about the peace movement and their service, their attitudes towards the U.S. government, and their evaluation and acceptance of the veteran 
for peace identity. Their combat exposure and military rank also varied consistently across group type.

Type I veterans were more likely to worry about the detriment the peace movement poses to national security, feel that their service good outweighed the bad, and that government could be trusted. Further, while the recognized the role veteran for peace, they evaluated it negatively and did not accept the identity as legitimate. The majority of these veterans were non-combatant officers.

Type IIs, on the other hand, expressed a shared belief that peace was unrealistic, were most likely to be ambivalent about their military service, and wondered if perhaps the U.S. government was behaving in a questionable way, but did not feel they had a voice for speaking out. Unlike the Type I veterans, Type II veterans favorably evaluated and recognized the veteran for peace role, but like Type I veterans, they rejected the identity. These veterans were primarily enlisted.

Type III veterans agreed that the peace movement was essential to the U.S., reflected more negatively on their service. They were also consistent in their shared belief in the corrupt nature of the U.S. government. All of these veterans recognized the veteran for peace identity, favorably evaluated it, and embraced it as their own. These veterans tended to be enlisted combatant men..

What became obvious over the course of the interviews was that what the veterans' experiences, was directly tied to their current sense of self and their veteran identity. All of the Type III veterans expressed a discrepancy between the standard applied for a service member (noble patriot warrior), the feedback they received in their 
execution (it is good to lie to their people, and bad to refuse) of that standard, and the values they held dear (dedication to honor, courage, and commitment). While all of the participants shared the identity of veteran, Type III veterans developed a secondary identity as veteran for peace with several shared elements including fixing something that is broken in the U.S., bearing witness (for other veterans and service people), and making a difference. This identity is based on shared experiences as soldiers that led them to feel anger and frustration at what the military and government asked them to do. What they were told they "should do" did not coincide with what the veterans felt was the true, and more noble, standard.

All of these veterans believe they are fighting for their country, but they disagree with U.S. foreign and military policy, and believe that they have a duty and responsibility to speak out and up for those who cannot or do not know they can. These veterans have found a way to hold onto what they see is honorable in their identity as a veteran, and are fighting for their values.

In this chapter, findings of this study were reported in three major sections, titled "General Findings,” and "The Peace Movement \& Getting Involved.” The following chapter will present a discussion of the key findings of the study, as well as information regarding the implications, limitations, and potential future research areas appropriate to this study. 


\section{CHAPTER 5: Discussion}

The discussion chapter of this study is organized into three sections. The first section, addresses how the findings answer the research questions. The second section demonstrates how the research is related to the three main literatures in Chapter Two Military Socialization, Social Movement Theory, and Identity Theory, follows this. The next section provides a discussion of the implications of this study, followed by its limitations and suggestions for future research.

\section{Research Questions}

The set of six research questions address multiple aspects of veterans' understanding of the peace movement, the participation of veterans in the peace movement, and what it means to be a veteran for peace. What the research uncovered were differences in responses to all the research questions, not just based on relative levels of movement support/membership or combat exposure, but also differences based on service type (i.e. enlisted vs. officer). Along with these differences, there were also variations in the level of identification with, and feelings about, the legitimacy of "veteran in the peace movement," both among and between veterans of all types, in all categories.

Research Question \#1: How does a veteran understand the current peace movement?

First, it must be noted that veterans as a group do not share a common understanding of the peace movement. There are clear differences between the three types of veteran. Type I veterans' responses communicated a fear about what the peace 
movement implies about the veterans’ patriotism and loyalty, as well as threats it may pose to national security. Type II veterans, on the other hand, were more likely to recognize and accept the peace movement, but doubted that the movement could create change in the political landscape. For both of these veteran types, changing the political landscape seemed to be the most pressing reason for involvement. Type III veterans expressed faith in the movement's potential, and found that it aligned with their personal and political beliefs, though they also were discouraged with the slow progress of the peace movement.

Research Question \#2: Which, if any, parts of the current peace movement does a veteran find to be in line with his or her own values?

All of the veterans in this study agreed, "peace is a good thing." However, as in all areas of this study, where the veteran peace movement fit into their personal values varied by type of veteran. Type I veterans felt the peace movement is potentially unpatriotic, so the movement held nothing for them personally. These veterans trusted the government to know what's right, or felt they didn't have the information they need to comfortably question U.S. policies. Some of them implied that being part of the peace movement was tantamount to betraying their country, and, because they saw themselves as patriots, participation in the movement was unacceptable. Further, they expressed the fear that the peace movement would open the U.S. to another terrorist attack.

While Type II veterans questioned both what the government is doing and the direction this country is headed, they also expressed doubts that they had anything of value to add to the movement, and whether peace was even feasible. Similar to the Type 
I veterans, Type II veterans' responses conveyed the underlying feeling that people are inherently violent and peace is just not realistic.

Finally, the Type III veterans believe that the work they do as part of the veteran peace movement is for the good of the service and the country. These veterans openly discussed changing - radically if needed - the political landscape, and the importance of giving support to other veterans. For Type III veterans, peace movement participation was seen to be a continuation of their work in the service, but this time in something they 'believe in and choose to do,' rather than are 'ordered to do and then swallow.' Membership in the veterans' peace movement serves as both an extension and an expression of themselves.

Research Question \#3: What do veterans believe it means to be a veteran for peace?

All of the veterans in this study recognized "protesting" as part of what is means to be a veteran for peace. The Type I and Type II veterans generally mentioned only "protest actions” - e.g. marching, rallying, and demonstrating - when discussing the meaning of the role, veteran for peace. What was unique in the responses to this question among the Type III veterans was the move to understanding the veteran for peace role as more than just "taking action." In addition, Type III veterans used the veteran for peace role to create an identity -- a category of self in terms of that role -- that was then used as both a lens for seeing the world, as well as a script for directing action that encouraged a broader set of role-related behaviors. All of the Type III veterans have engaged in proactive action because their perception of being a veteran for peace included a much broader range of role-related actions. For Type III veterans, role-consistent behaviors could be as 
simple as tabling at a county fair, or as aggressive as enacting a patrol during the holiday shopping season; as mundane as participating in a national conference, or as extraordinary as interrupting a House debate and being arrested. For Type III veterans the bottom line is that they will be heard, and they will keep bringing their message back to the larger public again and again in order to achieve their goals.

Research Question \#4: How do veterans come to identify with the current peace movement?

While all veterans recognized the peace movement, not all veterans were aware of the veteran peace movement, and only Type III veterans identified with it. The common link between these veterans was the presence of a "trigger.” Many of the Type III veterans reported different forms of "during service” trauma. For some, the trigger was an event that brought back memories of traumatic experiences suffered during their service. These traumas were always there. While some of the veterans immediately sought out a way to cope with service-related memories/feelings and stumbled upon the veteran peace movement, others turned to self-medication using drugs and/or alcohol in efforts to escape those memories/feelings. Still others were only made aware of how deeply their service experiences affected them over a period of time as the memories and events associated with that trauma slowly revealed themselves. For still other veterans, that trigger was the culmination of introspection that came from years of personal study or political activism for another cause, such as the Democratic Party. For these veterans, the trigger is not about the events that led them to movement participation as trauma suffered during service, but is instead, a reaction to feelings of abuse by the military and 
government, not necessarily in terms of trauma suffered during service. This could be thought of as results in a form of "post-service" trauma. This trauma differs from the previous discussion of "during-service-related" trauma in the degree of emotional and mental damage, but has the same effect in directing the veteran to take action. Finally, those who suffered the during service trauma are more radical in their political activism, in general, than those who came to the veteran peace movement as a result of post-service trauma.

Research Question \#5: How do veterans take a stand against the current peace movement?

No one in the study took a stand against the veteran peace movement. Rather, the Type I veterans engaged in a sort of passive resistance to the movement. This resistance displayed itself in a subtle refusal to accept the legitimacy of the role "a veteran in the peace movement” (while still acknowledging that some veterans do take part) in the peace movement, and in declarations that movement., Type I veterans declared that veterans being part of the peace movement was "wrong-sided" and seemed to imply the two roles - "veteran" and "peace movement member" - were mutually exclusive.

Research Question \#6: “What do veterans feel is gained by involvement in the peace movement?

Almost all of the veterans in this study agreed that veterans have something to offer the movement. This was one area where the three veterans Types displayed the most agreement. The shared across-type responses included camaraderie, healing, helping other veterans, and making others aware of the realities and ugliness of war. 
Type II veterans, and some of the Type IIIs, added additional aspects including, continuing to behave honorably, finding a political voice, having a level of influence that civilians do not have.

The next section of this chapter relates back to the literature and is divided into Military Socialization, Identity Theories, and Social Movement Theory.

\section{Military Socialization}

The findings of this research inform several different areas in the literature on Military Socialization including:

- how individuals are socialized into the military (Franke 1997, 1999, 2000, 2001)

- the relationship between recency of service and political attitudes towards the military (Jennings \& Markus 1977), and

- the effects of length of service on political attitudes towards the military (Jennings \& Markus 1977).

The current research builds upon the earlier Military Socialization literature in several areas including exploring differences in socialization experiences between officers and enlisted personnel, and the relationship between an individual's feelings about their service experiences and their support of and membership in the veteran peace movement appeared to be related.

\section{Socializing soldiers}

The existing literature on military socialization (Franke 1997, 1999, 2000, 2001) focuses on how the military trains service members to be soldiers even as the details of 
what it means to be a "soldier" change. For example, Franke (2000) discusses the different roles veterans can be trained to perform, and suggests that as the role the U.S. military plays in the world changes, so too, will the versions of "soldier" (e.g. soldier as warrior or soldier as peacekeeper) available to service members also changes. For the veterans in this study, the version of the role "soldier" they used as a standard to guide their actions varied depending upon the campaign and when they served. For example, Bob, who was a non-combatant during the Cold War era, stated, he was "a Cold Warrior, and supposedly a tip of the spear deterrent against the Soviets.” This is not a warrior version that is available to service members today, as the Cold War is over. Today's veterans would talk about either being a peacekeeper in Bosnia, or a warrior-soldier in the Iraq II or Afghanistan Wars. It is important to note that these are not just differences in campaigns, but differences in what it means to be a soldier.

These individuals were socialized to internalize clearly different versions of the soldier role. Interestingly, there is an aspect of military socialization that is not discussed in the current literature: regardless of the version of soldier being used, what does it mean to be a “combat veteran?” In this study, however, this phenomenon was seen quite clearly addressed in the comments of veterans like Ben, who felt that he was a combatant, although the actual assignment had been one of peacekeeper during the Bosnian War. Or, Barry, who was clearly in a combat situation, but interpreted his experience it as "not real” combat war, due to preconceived notions of what it meant to be at war.

Another underexplored aspect of the Military Socialization literature has to do with differences in socialization experiences between officers and enlisted personnel. All 
of Franke’s (1997, 1999, 2000, 2001) research focuses on the socialization of officers. However, veterans' first-hand experiences confirm that officers and enlisted are socialized differently - enlisted are sent to several weeks of bootcamp, officers attend officer training school. Enlisted personnel are trained in a variety of "grunt work" tasks, while officers are trained in various leadership tasks. Another contribution of the current study to the existing military socialization literature is the recognition that while there may be differences in how officers and enlisted personnel are socialized, the effects of these differences are difficult to separate from issues of length and recency of service.

A third segment of the Military Socialization literature examines the relationships among veterans' political views towards the military, the recency of military service, and length of that service (Jennings \& Markus 1977). The current research addresses several limitations of the earlier work by broadening the pool of veterans interviewed for this research. For example, the previous research was entirely focused on Vietnam veterans, and it also fails to address differences between enlisted and officer service members, between men and women, and does not by discuss how recency and length of service interact with rank in regards to political attitudes, operationalized in this case as peace movement participation.

Recency of service and political attitudes towards the military

This current research supports the argument that the recency of a veteran's military experience influences a veteran's political views. In this study, all of the veterans who came to peace movement did so after some time had passed from when they left the service. All of them who joined the movement discussed doing so after 
taking time, or having time, to reflect on their service. All of the veterans also spoke of service, and after having done some form of personal introspection about what they had been asked to do, what they believed in, and whom they believed they were both as veterans and as citizens of the U.S. This introspection might have taken the form of personal study, therapy, or a combination of both. Interestingly, the form of the introspection appears to be less important than the introspection itself. Those who questioned their service experiences the most, who sought out and found others who felt as they did, were the ones most likely to not only support the peace movement, but to be a part of it. And, the further away these veterans got from their service, the closer they appeared to be in beginning this introspection and then moving toward supporting and joining the peace movement.

Finally, it appears that, again, even recency of service is mitigated by whether the service member was an officer or an enlisted person. As time passed, the enlisted participants were more likely to be accepting of the movement, and to be part of it, and they were also likely to even report becoming more politically radical. Officers, on the other hand, were less likely to reflect back on their service and question what they were asked to do.

\section{Length of service and political attitudes towards the military}

Length of service also appears to have a very strong influence on level of support of and membership in the peace movement. While there seems to be little relationship between length of service and support of veterans in the peace movement, there is a connection between length of service and membership in the peace movement. Veterans 
who served six years or less were more likely to be members of the veterans' peace movement than others. Some of the Type III veterans who were the most outspoken activists had put in less than two years of service. They were Vietnam veterans, and as noted earlier, all of them were not only supporters, but also members of the veterans' peace movement.

Interestingly, veterans who served over twenty years were very unlikely to be members, though it is difficult to say whether this is due to length of service or rank, as all of the 20-year veterans were officers. Their lack of membership in the peace movement may be due to feelings of loyalty that are inextricably linked to military benefits that include medical, dental, monthly salary, and several other "perks" of retirement after honorable service. It is also feasible that the difference in movement membership is a result of military acculturation - the longer a service member is in the military, the more deeply she internalizes the beliefs, customs, and behaviors of a "good" officer, and the harder it is to question or challenge them. It is apparent that officers saw the military as a career more than the enlisted members.

Gender and attitudes towards the military

The current research contributes to a final underexplored area of the Military Socialization literature by examining gender differences in level of movement support and membership. Findings of this study revealed that men were more likely than women to support the peace movement, and to support other veterans who are members of it. There are a couple of possible explanations for this. The first is that the number of female veterans interviewed was much smaller than that of the men, so it may simply be 
the result of under representation. The second option is that the men in the study were more likely to encounter direct combat situations than the women were. While it is true that women in the military face combat realities with greater frequency than they were even fifteen years ago, few, if any, saw or were involved in real-time combat operations or activities. Finally, several of the men were Vietnam era veterans, but none of the women were. As a result, the historical realities of these veterans vary a great deal. Campaign and attitudes towards the military

The current research also found that differences in level of peace movement support and membership were tied to differences in the campaign during which veterans served. Veterans who were involved in Vietnam and Iraq II were far more likely to be supportive of the peace movement, and to be members, than veterans from Kosovo, Iraq I, or Afghanistan. It is quite possible that part of this is a result of differences in public perception about the campaigns. In general, the American public supported the Kosovo campaign. Iraq I was a short war that, to many, was surreal and “didn’t count.” After 9/11, many Americans were in support of going into Afghanistan to eliminate the Taliban and find Osama bin Laden. However, the American public has consistently been split when the conflicts in discussion are Vietnam and Iraq II. When citizens question the validity of a conflict, the service members in them do the same. This means that larger questions regarding service in general, and the place of a veteran in society in particular, cannot be avoided because the veteran is tied to her conflict the same way that a citizen is tied to her country. In addition, the relative level of post-service trauma and depression that is often experienced are also consequences of being part of one campaign, but not 
another. These factors cannot help influencing how veterans' feel about their service in the conflicts, or their choices in determining how to "do" veteran as they move forward after leaving the service.

\section{Identity Theories}

The findings of this research inform several different areas in the Identity theories literature including:

- how shared self-meanings develop through interaction (Mead 1934),

- how social identities form based on an "in-group”/“out group” distinction and vary in terms of inclusiveness (Brewer 1991),

- how identities are organized based on relative importance or salience (McCall \& Simmons 1966) and how social networks impact salience (Burke \& Reitzes 1991),

- how available role standards impact role enactment (Burke 1991; Collier 2004),

- how variation in role type impacts social action (Callero 2004), and

- how degree of role identification affects role usage (Callero 2004).

Mead

Ultimately, the entire theoretical foundation for this thesis rests upon the work of George Herbert Mead. Mead saw the self as exclusively social in that shared selfmeanings come about as a result of social interaction with other people (Mead 1934). According to Mead, we only understand ourselves in relation to other people. In this study veterans discussed how their understandings about "what it meant to be a soldier" developed through their experiences in the service. Additional support for the idea that 
shared self-meanings arises from interactions with others can be found in Type III veterans' discussions of learning what it meant to be a veteran for peace. Bernie expressed this clearly, when he related the following:

"I got involved in the peace movement through VVAW action in Washington in 1971 on the mall. Activities like that... I was just totally ecstatic that my feelings about the war were legitimized... That really helped steer almost the whole decade of the '70s, knowing that I wasn't alone in how I felt... Emotionally I needed that. So, that was my initial involvement in that with vets."

Roles can also be used to define one's self and others, as well as operating

schemas to perceive and think about the world and acting by serving as guides that direct role-appropriate action (Mead 1934; Callero 2004; Stryker 2000). The three most obvious dimensions of role meaning discussed by the Type III veterans in this study were:

- Fixing something that is broken in the U.S.

"If we don't, if we're not actually stopping the war and preventing the U.S. from being evil and engaging in future wars then none of this, none of this really matters... We may help a few people, which I think we do, but... none of it really matters unless we win. That's really the only thing that matters... Having some symbolic victory, or coming up with a reform, even ending the war in Iraq or Afghanistan is insignificant if we're just going to do this again [and] we continue to have these satellite wars everywhere." - Sam

\section{- Bearing witness for others}

"The overwhelming obsession to bear witness. To speak for the dead. And to point my fingers at the perpetrators. Those who are responsible for the wars. I speak for the countries we invade. I speak for the civilian populations who are being killed with our tax dollars. That's what I do. That's the reason I get up in the morning. The reason why I'm here.” Mark

- Making a difference. 
"The more you get involved in it, the more you see the work that needs to be done... There's just so much work to be done! It's just not hard to see where there's a need." - Lauren

These elements are part of Type III veterans' shared understanding of the veteran for peace role.

\section{Social Identity Theory}

Social Identity theory proposes that an individual has both a personal identity, and a set of social identities understood as "categorizations of the self into more inclusive social units that depersonalize the self-concept, where "I" becomes “we” (Brewer 1991, p. 476). The boundaries of these "more inclusive social units" serve as the distinction between the "in-group" - the group the person is a member of - and an “out-group” of others. Social identity theory views an individual's actions as a result of group membership. When an individual self-categorizes on a group level, she takes on a "prototype" for that group as the standard by which she judges the effectiveness of her actions. In addition, this theory points out that there are different levels of social identities, and these identities vary in inclusiveness (Brewer 1991, p. 476).

This research informs the Social Identity literature by identifying several different criteria that veterans used in distinguishing in-group level self-categorizations from other out-group ones. Non-combatants were more likely to differentiate themselves from combatants than vice versa. Indeed, one veteran indicated that her non-combat status was the reason she was not involved in the movement. Another veteran implied that perhaps she would have different opinions regarding the peace movement, and veteran involvement in it, if she had been in, or witnessed, combat during her service years. 
Aside from the clear in-group/out-group classification of Type I, Type, II, and Type II veterans, within the Type III veterans, there was a further breakdown. The Type III veteran might consider himself to be part of the peace movement, and a peace movement activist, but might consider other peace activists (those who were too radical, not radical enough, too old, too young, etc.) to be so different as to be an out-group. This indicates that even within a movement, there are perceived out-groups and ingroups.

\section{Inclusiveness}

In an earlier section of this thesis, veterans who claimed the veteran for peace identity for themselves, but identified with their own local chapter rather than the national organization, were discussed. This identification with the smaller group, and declarations of difference from the larger group, is a prime example of self-representation using the model of Brewer's model of optimal distinctiveness (1991). Even though these veterans acknowledged a form of membership in the larger national organization, they preferred to self-categorize as a veteran for peace on the less-inclusive chapter level. While these veterans acknowledge themselves as veterans for peace, they differentiate themselves and the members of their chapter as "more radical" or "less comfortable" than "those other veterans” affiliated with the national organization.

\section{Identity Theory}

The current research impacts the identity theory literature in three areas: salience, commitment, and self-verification of identities.

\section{Salience}


Salience in identity theory is similar to the interactionist concept of prominence because both refer to an identity's relative location in the individual's role-identity hierarchy” (Stryker \& Serpe 1982, p. 206). The more important the identity, the more likely the person is to enact that identity in interactions with others” (Stryker \& Serpe 1982, p. 206). Several factors have been identified as influencing the importance of a given identity within the identity hierarchy, and these are: 1) self-support, 2) othersupport, 3) self-investment, 4) material investment, 5) extrinsic rewards, and 6) intrinsic rewards (McCall \& Simmons 1966, p. 80-81). For Type III veterans into supporting their self-representation as a veteran for peace, and the organizations they are part of also provide a great deal of support. In addition, these veterans made a huge self-investment in the dangers they may have personally faced in combat, the loss of friends during conflicts, the impacts on personal relationships during deployments while they served, and the traumas that may result during or after their service is completed. These heavy levels of self-investment, and the support they receive from others, lead the Type III veterans not only to their involvement into the veterans’ peace movement, but also supports their loyalty to it.

\section{Commitment}

Commitment is defined as the degree to which an individual's interactions with important other people in her life depend upon that individual being a "particular kind of person” or enacting a particular identity (Stryker 2000, p. 207). The relative importance of an identity is dependent on the actor's commitment to the identity (Burke 1991, Stryker 2000). The Type III veterans in this study expressed a belief that together they could get 
politicians to listen to them; that together they have political power. As Jake put it, "People often think that veterans are entitled to things... and Washington sees them as a threat, so they finally react. That's what veterans do, they scare the crap out of politicians because they know that they're poor and trained and armed. And angry. And they want things, and they're persistent.” This persistence, this belief in their own voice, and their devotion to being heard is what accounts for their actions, even to the point of being arrested. Burke’s Model

Burke (1991) examines how individuals decide how to best enact an identity based on a desire for self-verification from others. He explains this process of identity verification through a feedback loop that is continually activated when a particular identity is enacted (1991, p. 837). There are multiple parts of the feedback loop: an internalized role standard, input from others about the person's current state of role enactment, output, a cognitive comparison process, and output, in the form of role related actions (Burke 1991, p. 837). Through the cognitive comparator process, the person compares the internalized role standard with self-referent feedback from others in an effort to minimize the 'gap' between the standard and the enacted behavior, and to gain positive feedback, or limit or eliminate negative feedback from others.

The current research informs the Burke model by illustrating that at different times in history, different standards for soldier are available to different groups of service personnel. And depending upon the role standard internalized, the individual will need to enact slightly different sets of role related behaviors in order to get verification form others for her role enactment. 
As the part the U.S. military plays in the world changes, the versions of "soldier" (e.g. soldier as warrior or soldier as peacekeeper) available to service members also changes. For the veterans in this study, the version of the role "soldier" they used as a standard to guide their actions varied depending upon the campaign and when they served. For example, a Cold Warrior would not be a part of a coalition with soldiers from Russia or former Soviet nations, but today’s peacekeepers and warrior-soldiers can, and often are. Likewise, the rules of engagement for a peacekeeper in a "safe zone" differ a great deal from that of a warrior-soldier who is in an active combat area. These differences in role standards are directly related to the version of soldier called up to guide action.

When there is a disconnect between how an individual sees herself and how others see her an identity discordance can arise causing strong emotions that will need to be resolved via a shift in the understanding and definition of the self. Social stressors can also interrupt the identity process and lead to changes in identity.

The current research continues to inform the Burke model by illustrating how veterans for peace developed a shared role standard that included activism as the result of trying to get a better match between the standard and what they are being asked to do. As long as veterans for peace feel current soldiers are being put in harm's way in conflicts that are not consistent with fundamental U.S. values, the veterans will speak out against these wars because the current service personnel cannot. A common element in the role standards for both soldier and veteran for peace is the idea of "duty." The difference between the Type III veterans and the Type I and Type IIs was that Type IIIs had shifted 
their sense of duty, as a service person, to the country, to a sense of duty to other soldiers in the form of speaking out on their behalf. It is this new sense of duty, and the behaviors it compels, that defines their identity as veterans for peace.

This research informs the Meadian conception of role literature in three areas: reference groups and the existence of multiple versions for same role, types of roles and differences in internalization, and differences in role usage. Callero's discussion of differences in types of roles (2004) and Collier's (2004) suggestion that multiple versions of the same role might exist at the same time are useful in understanding the differences in types of veterans' responses to the peace movement. Depending on the context of a given situation, and the multiple reference groups that an individual might look to for guidance, there is more than one available version of a role. The ability to accurately discern the role required, and to enact the correct version of that role called for, is role mastery (Collier 2004). Also important in understanding veterans and their support or participation in the veterans' peace movement is a discussion of their evaluation and endorsement of the veteran for peace identity and associated role.

The veterans in this study, particularly the Type III member/supporter veterans, illustrated these phenomena quite clearly. These veterans have established toolkits of habits and skills (such as discipline, organization, leadership, familiarity with tactics, and strategy) that they are able to leverage in support of achieving peace movement goals. This can be in the form of rallies, direct action, speaking engagements, or other behaviors. Even Type I and Type II veterans, with very few exceptions, who were not 
members of the peace movement, and did not claim the veteran for peace role, expressed recognition of the various tools that a veteran has to offer for use in the peace movement. In regards to Callero's (1994) discussion of role varying in terms of cultural endorsement and evaluation, Type I veterans acknowledged the existence of the role of veteran for peace for some other veterans, however within their "group" they did not culturally endorse or recognize that role as legitimate. In addition, they evaluated the role negatively, and rejected the associated identity. Type II veterans, on the other hand, culturally endorsed the role as legitimate, but evaluated it with mixed feelings, and rejected the associated identity. Only the Type III veterans culturally endorsed the role as legitimate, favorably evaluated the role, and accepted the associated identity. This research suggests that Type III veterans incorporated elements of "soldier as warrior" and "soldier as peacekeeper" role standards into a new shared veteran identity that could be called "warrior for peace."

With this new understanding of the veteran role, and its corresponding identity, Type III veterans are able to access a script for action that filters their thinking and aids them in categorizing how they will use the resources available to them. For example, veterans for peace are more likely to see their toolkits as being useful in obtaining more benefits, better benefits, for returning veterans, influencing national and military policy, and changing the face of politics in the U.S. than the non-members or the non-supporters. In spite of this shared identity among the veterans' peace movement members, it is important to also mention that this identity is not available to everyone - for example, civilians. As Callero (1994) notes in his discussion of "types of role," all roles are not 
accessible to all individuals. In this study, the veteran for peace identity is only accessible to veterans who have gone through a process of reconciliation. This process led them to seek out a new community (reference group) which provides them access to other veterans "like them." These veterans help each other to feel they are acting in a way that is not only consistent with the values of a veteran, but also provides healing for the individual.

The three Types of veterans in this study also used the role veteran for peace differently. In Callero's (1994) discussion of differences in role use, he notes roles can be used to categorize self and others, for thinking, to guide action, and as a resource to achieve desired outcomes. All the veterans in this study used the role veterans for peace as a tool for categorizing self and others (e.g. "they're veterans for peace and we are not”). However, Type III veterans used the role for a wider set of purposes. First, Type III veterans used the veteran for peace role to create an identity -- a category of self in terms of that role. That identity was then used for "thinking" -- as a lens for seeing the world -- as well as a script for “directing action” that encouraged a broad set of rolerelated behaviors including tabling at a county fair, enacting a patrol during the holiday shopping season, participating in a national conference, or interrupting a House debate.

Perhaps most importantly, Type III veterans used the veteran for peace identity as a resource for “achieving political ends” (Callero 2004) - i.e. getting things done. Like Jake said, veterans are determined and they refuse to be ignored. The veterans’ peace movement was the primary context in which Type III used the role as a resource for achieving political ends. 


\section{Social Movement Theory}

The findings of this research inform several different areas in the literature on Social Movements including:

- $\quad$ why do individuals join social movements (Corrigal-Brown 2008; Polletta \& Jasper 2001)

- the development of activist narratives (Hunt \& Benford 1994)

- how movement participation leads to identity construction (Meithe, 2002; Howard 1994, 2000; Hunt \& Benford, 1994)

Social movement theories indicate that there is an identity development process that takes place for an individual who is part of a social movement. Unfortunately, this literature often fails to address what comes first - the identity with the movement or the participation in it. This study helps to address this, and indicates a tight connection between identity development and social movement support or membership.

Why do veterans join the peace movement?

The Social Movement literature suggests several reasons for why individuals join movements, and how to understand the "why." Stavro (2007) examines the power of collective action to contribute to coalition building based on a shared reality, while KutzFlamenbaum (2007) notes that there are “significant and meaningful divisions” within a movement that can best be uncovered and understood through an in-depth exploration of ideologies of members (p. 21-22). Corrigal-Brown (2008) examines how "individuals can develop different identities in social movements as a result [of] personal political ideology, and the organizational context in which they engage” (p. 4), and Howard 
(1994) states that a person may seek out a social movement in an effort to find a likeminded community.

This research informs the Social Movement literature in the area of "why do individuals join social movements?” by providing a discussion of the intricacies of why individuals join the veterans’ peace movement, such as the differences between “during service” trauma or "post service” trauma as motivators for involvement. This study also provides insight into variations in “radicality,” not just by organizational affiliation, but also by service rank and combat experience.

This research also contributes to the on-going discussion of whether involvement in the movement comes first, followed by identity development, or whether individuals first develop identities as veterans for peace and then seek out and become involved with the movement? Based on this study, the answer is that both patterns are true. Which pattern is "true” depends upon the combination of the veteran and the current political /military events. Some of the veterans in this study already identified with the peace movement and sought it out. Others stumbled on the movement as they sought to navigate their changing political and personal views. There they found a connection with others who felt as they did, and who provided an outlet for action.

The peace movement already existed when these veterans completed their service and began life in the “civilian world.” Yet many of the Type I and Type II veterans didn’t recognize that they might have a place in the peace movement. However, all of the veterans who became movement members indicated that they were looking for a group of veterans who could understand what they were experiencing post-service, and help them 
deal with the emotions arising from realizing that certain service experiences did not align with their current beliefs. When these Type III veterans realized that other veterans were involved in the peace movement, the shared meaning they had developed via their shared experiences led them to seek out and embrace the veteran for peace/social movement activist identity.

The next sections will specifically address social movement participation and identity construction, and how the shared identity developed around a common purpose that spurred action.

\section{Activist Narratives}

Social movement theory describes six types of narratives (Hunt \& Benford 1994, p. 494-501) that movement members engage in when discussing their identification with and involvement in a particular movement. These narratives are classified as

- associational declarations that help to delineate the in-group and out-group

- disillusionment anecdotes that serve as accounts of entry into, or exit out of, a movement

- atrocity tales that illustrate negative experiences and separate the "good guys" from the "bad guys"

- "personal is political" stories that are most often focused on alignment between personal identities and collective identities

- guide narratives that describe becoming aware, active, and committed to the movement 
- war stories that address "becoming committed" to the movement and what that means to the member

In this research, examples of each of these narratives were present in the comments of Type III veterans - those who both support the peace movement and selfidentify as members of the veterans' peace movement. Most of these narratives can only be gathered over the courses of several statements made by the participants. However, Bernie's statement below is an excellent example of an answer that includes all six narratives. Below, he explains his introduction to the veterans' peace movement upon returning from Vietnam:

"I got involved in the peace movement through Vietnam Veterans Against the War (VVAW) action in Washington in 1971 on the Mall. Activities like that, do you know about it, they threw their medals. I was just totally ecstatic that my feelings about the war were legitimized. [personal is political] I had witnessed stuff that I had not been able to access at that time, it took 10 years to be able to access it for the worst parts, [atrocity tales] but I knew that war was wrong, and I knew that what I witnessed was wrong, [disillusionment] and I had a lot of guilt in my mind. That really helped steer almost the whole decade of the '70s, knowing that I wasn't alone in how I felt. I knew I wasn't alone, but, emotionally I needed that. That was my initial involvement in that with vets. That would have been about less than a year after I got out of the military. I was just so against the Vietnam War. Although I still think at that time I believed Vietnam was an aberration, I was beginning to wonder about the history of the United States and war and I had begun studying history and philosophy and biology and other stuff came later. [guide narrative] But I really knew something was wrong with this kind of behavior. Even though I knew it was a pattern in some ways, but still wasn't clear about the overall context of it all. I was really really clear that this is not right. I was not confused about my identity. I was developing a new identity... [becoming committed] But it was all extended back to that I knew something was fundamentally wrong with my society that would allow, that would allow or initiate a war in Vietnam. That would allow the injustices that I was experiencing in the United States. Even though I was a privileged European, Eurocentric, white male, I was very, I was sensitive to what injustices there were in society.” [associational declaration] 
Interestingly, when examining the comments of Type II veterans - those who support the peace movement but who do not self-identify as a veteran for peace, only the “personal is political” stories were observed directly. Type I veterans’ responses were similar to those of the Type II veterans, except that when they recounted their own “personal is political” narratives, they also expressed a belief or feeling that, in spite of these issues, alignment with the peace movement was irreconcilable with the role of veteran. The presence of all six types of narratives in the Type III self-identified veterans for peace comments is consistent with what Hunt and Bedford (1994) would describe as typical of a movement activist. The lack of presence of a complete set of narratives in the comments of the Type I and Type II veterans is also consistent with the same literature. It is only when veterans self-identify with and are involved in the veterans’ peace movement that we would expect to find the more elaborate collection of movement supportive narratives. This clearly indicates an intersection between social movement participation and identity development. This intersection will be discussed in the next section.

\section{Identity Construction}

Hunt and Benford (1994) propose that identity development within a social movement is based on interactions with others. They see movement identities as being constructed, interpreted, and communicated in "identity talk" that is based on groupspecific guidelines. They detail four processes, tied to lived experiences, involved in the construction of a social movement member identity, and participation in a social movement. These four steps are: 
1) Becoming aware, where an individual discover or comes to understand some injustice. This is associated with how the activist comes to frame the issue and to attribute blame.

2) Becoming active, which focuses on the individual's recruitment into and participation in the movement.

3) Becoming committed relates to increased participation in and identification with the movement.

4) Becoming weary and leaving the movement.

This research builds upon and adds to the Hunt and Benford model. In the current study there appears to be an additional step, one that exists either before or in tandem with becoming weary and leaving the movement. Many of the veterans in this study reported that they were "weary." Several of them discussed frustration with the movement, and with the feasibility of peace in this country. In spite of that, even when they believed the peace movement was "dead” they continue to actively participate in the movement. This would indicate that becoming weary and then leaving may not be a single step. If the fourth step is becoming weary, then leaving the movement seems to be an additional, fifth, step - an identity “deconstruction” perhaps, that leads, in this case, a veteran to separate "self” from “movement." Interestingly enough, none of the Type III veterans in this study appear to have any interest in giving up the movement, or in reducing their identification with it. In fact, the more they feel pushed back on, the more determined they appear to be to keep their efforts going.

\section{Major Findings}


This research contributes several useful understandings of veterans, their political views, and their involvement in the peace movement. The first finding of note is that there are three types of veterans based on their views of the veteran for peace role and involvement in the veterans' peace movement - Type I Non-Supporter/Non-Member; Type II Supporter/Non-Member; and Type III Supporter/Member. The process that a veteran goes through to becoming a "Type III” veteran is a complex one. All veterans begin as a Type I, until something begins the 'transformation process.' As a result, before 'buying into' this new way of thinking, a veteran must first resolve if peace action is congruent with patriotism, what the movement means to her, and if she agrees with its ideals. This is often difficult, as in the military, 'peaceniks' are often seen with suspicion and as military-haters. Vietnam era stereotypes of peace activists remain particularly prominent. So, how can one be a patriotic veteran and a member of the peace movement, or peace movement activism?

As a result, she must understand and navigate the often -conflicting stereotypes and ideologies associated with "noble patriotic soldier" and the "military-hating peacenik." How can one be both? Can she be both? Is she still a patriot? Are those the only options? How can she create an identity for herself that may not fit into either of these categories? As part of this, the veteran must also determine if there are others out there "like me" that she can turn to for support. Finally, the veteran, if she decides the movement is for her, must come to understand how to "be" this new person - "Veteran for Peace" - and how to enact this role in her life. \# 
The second major finding of this research identified three distinct elements in the veteran for peace role standard — fixing something broken in the U.S., bearing witness, and making a difference. Veterans are often proud of their service; therefore, they are not likely to wholly disavow it in the name of peace activism. From a symbolic interaction approach (Mead 1934), it is understood that the veteran will act according to the meaning she has given to the peace movement, and members of it, as well as the meaning given to veteran. As the veteran begins this journey of understanding, she seeks out other veterans or peace activists (i.e. a reference group) to determine how she compares to them. She begins to see how these peace movement members are similar to her and how they have themselves already navigated through this process. This is the product of her interactions with others and is part of an interpretive process.

The first element of the veterans for peace identity is a belief that something in the U.S. is broken and needs to be fixed. For Type III veterans, it is the U.S. government that is broken. More specifically, these veterans are concerned with the way the U.S. government 'uses' the military to achieve ends that are seen as imperialistic and dishonorable. They are also angry about the 'throw-away' treatment of veterans returning to the U.S. after fighting 'America’s wars for oil abroad.' Type III veterans believe their country can be 'better,' that veterans deserve better, and that they have the ability, and the right, to 'fix' or change the country and its systems.

The second element of the veteran for peace identity discussed by Type III combatant veterans was the need to bear witness for others, in an effort to make known, and oppose, the actions of a corrupt U.S. government. Several of the Type III veterans 
expressed the belief that there was still the possibility of successfully 'waking up the American people’ if other veterans like them continued the effort.

The third aspect of the veteran for peace identity was seen in Type III discussions of their shared belief that, without their efforts, citizens of this country would be far more likely to be engaged in unquestioning support for the war efforts, and that their activism as veterans for peace is helpful and supportive of veterans, currently active duty personnel, and future service personnel. Type III veterans were clear about not being pacifists, and directly contradicted the view of veterans for peace that many of the Type I veterans suggested - that being an activist is equal to being a complete pacifist who would leave open the door for another terrorist attack rather than fight - by stating that they are ready and more than willing to stand up and fight for what they believe in.

On the other hand, this emerging identity shift might force the discovery of a new social network that consists of like-minded people who also believe peace is patriotic, and this is directly tied to the third major finding: for Type III veterans, because they are able to create an identity as a veteran for peace, being part of the peace movement serves as an extension and expression of themselves.

Upon finding a veterans’ peace movement group, a veteran may find a new 'army' of individuals willing to provide feedback that will serve to make the process easier, or at least clearer. This shift is also likely to alter the veteran's commitment to the use of role behaviors, and while this goes beyond the scope of this research, it can be hypothesized that this is another way that these peace movement veterans can retain their warrior identity. Some of the role-related behaviors of being a warrior (taking initiative, 
duty, loyalty) will still exist, but will be used in a new way, for a new purpose. Instead of being warriors for the military and, by extension, the U.S. government, they are now warriors for peace, fighting for the safe and quick return of their brothers and sisters in arms. This ties into Meadian role theory (Callero 2004; Mead 1934) as it is concerned with how a veteran recognizes that an existing role can be used as a schema to both perceive and think about the world, and she that can create and access more than one version of "veteran" depending on life situations and the reference groups in her life.. \# In this reconciliation struggle, she will discover new legitimate veteran reference groups, and will come to see that there are "other people like me.” This is, in turn, tied to military socialization as it becomes apparent that this new identity allows her to stay true to her soldier-as-warrior role-standard, except that now she is "serving" with other veterans in an effort to adhere to the military codes of "honor, courage, and commitment" as well as "never leave a man behind.” As part of a larger group (veterans in the peace movement), she is better able to achieve these goals; she is able to resist the policies she opposes while still standing up for the troops. She has now successfully created the alternative version of the veteran role she was seeking (Type III). It is then possible to understand how she comes together with other veterans to utilize their collective toolkits and known roles to determine the best courses of action in order to achieve the most realistic group goals, and then act on them.

The fourth major finding of this research is that there are differences in "during service” and "post service” trauma, and a veteran’s identification with and involvement in the veterans' peace movement can be tied back to these traumas. The common link 
between Type III veterans was trauma suffered during or after their service and the presence of a "trigger." Many of the Type III veterans reported different forms of "during service" trauma. These traumas could be the result of something they saw, something that was done to them, or something they were ordered to do. For these veterans, the trigger was an event that brought back memories of these traumatic experiences suffered during their service.

For "post service" trauma veterans, the trigger was the culmination of introspection that came from years of personal study or political activism for another cause, such as the Democratic national political party. For these veterans, the trigger that led them to movement participation was a reaction to feelings of abuse by the military and government as a result of this introspection. It was not necessarily in terms of trauma suffered during service, but looking at the U.S. government's use of the military today, reflecting back on their own service, and finding that they feel betrayed, lied to, or used.

"Post service" and "during service” trauma differ to the degree of emotional and mental damage, but direct veteran action in similar ways. The significant difference between "during service" and "post service" trauma is that those who suffered the "during service” trauma are more radical in their political activism, in general, than those who came to the veteran peace movement as a result of "post service" trauma.

The fifth major finding in this study regards the steps of identity development in a social movement. This research adds to the Hunt and Bedford model by noting that individuals can "become weary" and yet still not decide to leave a social movement. 
In this study there appears to be an intermediate step with becoming weary and leaving the movement. Many Type III veterans in this study reported being weary, and articulated a level of frustration with the movement, and the possibility of peace. However, they continue to participate in the movement, indicating that becoming weary and then leaving may not be a single step.

This suggests an additional step of “identity deconstruction” before a veteran is able to separate her sense of "self” from the "movement." Nevertheless, none of the Type III veterans in this study appear to have any interest in giving up the movement, or in reducing their identification with it. In fact, the more they feel pushed back on, the more determined they appear to be to keep their efforts going. This may be the result of the strong social ties and extended social networks they have developed as a result of their involvement in the veterans’ peace movement.

The final major finding of this research contributes to understanding whether movement involvement precedes identity development, or whether identity development preceded movement participation. The findings of this study suggest that both patterns are true, but are dependent on the veteran and current U.S. political and military affairs. Some of the Type III veterans in this study mentioned that they already identified with the peace movement when they separated from service, and sought it out. On the other hand, others stumbled on the movement as they struggled with their changing political and personal views about their service, about the government, and about U.S. military action. In the veterans' peace movement they found a connection with others who felt as they did, validated their experiences and views, and who provided an outlet for action. 


\section{Implications}

The findings of this study have implications for several different areas. These implications are divided into those for the veteran peace movement, for veteran peace movement members, and for veterans in general.

\section{Implications for the Veteran Peace Movement}

For the movement, what is particularly relevant is the fact that several of the Type I and Type II veterans interviewed did not even know that there was a veterans’ peace movement. Still others did not understand what it was, or what it did, and so were resistant to being a part of it because they feared that the movement was overly passive or was anti-veteran. If the veterans’ peace movement hopes to recruit other veterans, these misconceptions and confusions about the movement must be addressed.

Veterans in the movement were very vocal about their views, and many of them expressed frustration with the lack of media coverage. If the veterans' peace movement wants to expand its membership base, it will need to do a better job of getting the word out via both conventional and less conventional media outlets. In short, both the volume and the quality of the communication from the movement to potential recruits must be improved. Veterans need to be better informed about what veterans’ peace movement organizations do above and beyond protesting war.

To reach out to the Type I and Type II veterans successfully, veterans’ peace movement organizations would do well to highlight the advocacy work that they engage in. It's a simple as framing the issues in such a way that any veteran can find something 
that aligns with deeply held feelings and beliefs about service, duty, and loyalty. All of the veterans in this study expressed a desire and a belief in helping and protecting other veterans, by emphasizing the ways that they do this, organizations like Veterans for Peace, or Iraq Veterans Against the War, might be able to attract more members.

\section{Implications for the Veteran Peace Movement Members}

For movement members there are other issues that need to be addressed.

Primarily, members do not necessarily agree with each other's actions. It might be wise for veterans' peace movement members to focus more fully on common goals and what they have in common, and less on the areas in which their views differ. Movements that splinter over ideological differences often find themselves less successful in achieving their goals. This was a common complaint among the Type III veterans.

Another complaint was not wanting to work within the "bureaucracy” created by political action coalitions. However, Type III veterans also felt that their efforts were miniscule in their impact. If they truly desire to have more influence on the movement, as well as a greater impact on the nation, they will need to find a way to marry their individual desires and efforts with the goals of the movement they claim to be a part of.

\section{Implications for the Veterans}

The findings of this research also have implications for all veterans -- those who have come home, or are already home. Veterans who are seeking out others who might share their views, or provide guidance as they struggle with how to be a veteran who opposes current U.S. policy, need to know about the veterans peace organizations, and what they have to offer. It is also important to recognize that there are consequences for 
a veteran who self-identifies as a veteran for peace, and then seek out and join a veterans peace organization. Other veterans, particularly those who do not recognize the veteran for peace identity as legitimate, may not be accepting of movement members. As a result, influence may be brought to bear in the form of peer pressure, or even confrontation, to bring the "errant veteran" back to the "right way" of being a veteran. While there were no stories of direct physical attacks or confrontations from other veterans in the comments of the Type III veterans, they did acknowledge that they spend quite a bit of time justifying their movement participation, explaining to people who they are, and why they do what they do.

\section{Limitations}

There are several limitations to this study that must be addressed. First and foremost is transferability. The results of this research should only be considered applicable in similar contexts involving a similar group of participants. Because of the nature of this qualitative research project, this study does not claim to be able to adequately address differences in veterans' peace movement participation related to race, gender, campaign, length of service, and rank beyond the current study participants.

Although 27 interviews were conducted, many of the veterans contacted chose to not take part in the study. Most of these were minority veterans. As a result, this study is quite possibly missing some very interesting and useful information that is relevant for understanding the lived military experience of veterans of color. The reticence of these particular veterans may, in itself, be indicative of differences by race, but it cannot be verified without further research. 
Further, this study does not thoroughly address the experiences of women, because the majority of those interviewed were men. The women who did take part in the study seemed to be more resistant to elaborating on their military experiences. This may mean that the specific events or triggers that led a woman to join the movement (such as sexual abuse, discrimination, etc.) were not explored satisfactorily.

Finally, the largest portion of combat veterans were from Vietnam or Iraq II. There were very few veterans from other conflicts that took place in the time between these two wars. Because conflicts like those in Kosovo, Bosnia, Mogadishu are seen in such a different light by both civilians and veterans, the influence of these campaigns remains obscured.

\section{Suggestions for Future Research\#}

The results of this study, along with the previously identified limitations, suggest several areas where future research might prove fruitful. One area might be to look at whether gender of a veteran serves as a proxy for combat. As mentioned earlier, among the limited number of women in the study, most had not seen combat. However, most of the veteran members were male and had seen combat. This begs the question - what is more influential: the gender of the veteran, the combat exposure, or some combination of the two? Exploring this question would expand our understanding of the entire veteran population.

In a similar view, another potential area of exploration would be to focus on the possibility of racial differences in peace movement support and veterans' peace movement membership. Like gender and combat, experiences tied to combat experience 
and the race of the veteran are worth looking at. Historically, minority veterans are more likely to be given the less prestigious positions in the military. As a result, their exposure to combat, and experience in the military, will vary a great deal from that of white veterans.

As suggested in the previous paragraphs, a comparison of campaigns and combat veterans, regardless of race or gender, might also be in order. Being involved in combat - seeing a love one killed, killing another human being, taking care of the wounded, etc. - have an impact on a person. Those impacts vary by individual, as do the responses to that exposure. This line of research would likely provide a window into a better understanding not only of veterans, but also veterans who affiliate with the peace movement, and develop the identity of veteran for peace.

As suggested in previous sections of this chapter, comparisons of officer versus enlisted service type, as well as short-term and long-term military service offer opportunities to more thoroughly explore military socialization and its short-term and long-term impact on the veteran identity. It is sensible to assume that the shorter the time in service, the less ingrained the social conditioning, while the more prestigious the position in the organization, the more devoted to it the individual becomes. However, this cannot be confirmed without further research designed to tease out these subtleties.

\section{Conclusion}

Within the fields of military socialization, social movements, and identity development, researchers have focused how an individual comes to identify with a role, and then enacts that identity in their interactions with others. Unfortunately, none of this 
literature is focused on veterans who have left the service and their subsequent involvement in an organized political group, like the veterans’ peace movement. This qualitative study explores how a veteran will come to identity with and participate in the peace movement. What this study found was that, while experiences and beliefs as a veteran might vary, there is a shared identity that develops among veterans for peace.

This study expands existing research, and explicitly provides insight into the lived experiences of veterans - an area that is extremely under-studied. Not only does this research provide insight into an overlooked population, it opens the door for a study on a population that is becoming increasingly significant in today's U.S. society because of the wars in Iraq, Afghanistan, and the continuing potential for conflicts in several other areas. These soldiers, sailors, marines, and airmen will be coming home, and they will be facing all of the confusions and traumas discussed in this research. The findings in this study, and the implications of it, can be utilized to ease their return and transition back into civilian society.

\footnotetext{
"For other veterans that hear this, and you're kind of on the fence about knowing which way to believe, you know, search your heart. You know what you went through, and you know what you're going through. Ask yourself if you're really supporting these wars and supporting that stuff. And, if so, what are they really doing for the country? What are they really doing for our people? What are they really doing for those people that we're supposed to be liberating? That's another thing, are those people's lives better now that we've gone over there?" - Jack
} 


\section{RESOURCES}

Andreas, Joel, Addicted to War: Why the U.S. Can't Kick Militarism www.additctedtowar.com, pulled Jan. 2010

Anonymous. 2007. “Massive Antiwar March Planned for DC Sept. 15.” New York Beacon. 14 (29):14

Arai, Tatsushi. 2005. “Creativity for Peace: Exploring Unexplored Pathways to Conflict Resolution.” The Humanities and Social Sciences. 16(5):934-ABaker, Wayne E., Faulkner, Robert R. 1991.”Role as Resource in the Hollywood Film Industry.” The American Journal of Sociology. 97(2): 279-309

Barringer, Mark. 1998. “The Anti-War Movement in the United States” from http://www.english.illinois.edu/maps/vietnam/antiwar.html.

Benford, Robert D., Scott A. Hunt. 1994. "Identity Talk in the Peace and Justice Movement.” Journal of Contemporary Ethnography. 22:488

Bernd, Simon, Roman Troschel, Dorit Dahne. 2008. “Identity affirmation and social movement support.”.European Journal of Social Psychology. 38:935-946

Berg, Bruce L. 2007. Qualitative Research Methods for the Social Sciences. $6^{\text {th }}$ ed. Boston, MA: Allyn and Bacon.

Blumer, Herbert. 1962. "Society as Symbolic Interaction." in Arnold M. Rose. Human Behavior and Social Process: An Interactionist Approach. Houghton-Mifflin. Reprinted in Blumer (1969).

Blumer, Herbert. 1969. Symbolic Interactionism: Perspective and Method. Berkeley: University of California Press. 
Brewer, Marilyn B. 1991. "The Social Self: On Being the Same and Different at the Same Time". Personality and Social Psychology Bulletin. 17(5):475-482

Brewer, Marilyn B., Sherry K. Schneider. 1999. "Social Identity and social dilemmas: A double-edged sword." Social Identity Theory. Abrams and Hogg (Eds.). 169-186

Brown, Jerry, Rinaldo Brutoco.1997. Profiles in Power: The Anti-nuclear movement and the Dawn of the Solar Age. Twayne Publishers.

Burke, Peter J. 1991. “Identity Processes and Social Stress.” American Sociological Review. 56:836-849

Burke, Peter J., Donald C. Reitzes. 1991. “An Identity Theory Approach to Commitment.” Social Psychology Quarterly. 54(3):239-251

Cast, Alicia D., Jan E. Stets, Peter J. Burke. 1999. "Does the Self Conform to the View of Others?” Social Psychology Quarterly. 62(1):68-82

Callero, Peter L. 1986. "Toward a Meadian Conceptualization of role." The Sociological Quarterly. 27(3):343-358

Callero, Peter L. 1994. “From Role-Playing to Role-Using: Understanding Role as Resource.” Social Psychology Quarterly. 57(3):235-243

Collier, Peter J. 2001. “A Differentiated Model of Role Identity Acquisition.” Symbolic Interaction. 24(2):217-235

Collier, Peter J., David L. Morgan. 2004. “Role Mastery as Cultural Capital” Paper presented at the 102nd Annual American Sociological Association Meetings New York City, NY. August, 2007 
Collier, Peter J., David L. Morgan. 2007. “’Is that paper really due today?”: Differences in First-Generation and Traditional College Students' Understandings of Faculty Expectations.” Higher Education. 55(4):425-446

Corrigall-Brown, C. J. 2008. "We Are Not All Activists: The Development and Consequences of Identity in Social Movement Contexts" Paper presented at the annual meeting of the American Sociological Association Annual Meeting, from http://www.allacademic.com/meta/p239630_index.html

Creed, W. E. Douglas, Maureen A. Scully, John R. Austin. 2002. “Clothes Make the Person? The Tailoring of Legitimating Accounts and the Social Construction of Identity.” Organization Science. 13(5):475-496

Davis, Kenneth C. 2004. Don't Know Much About History (Revised ed.). New York: Perennial.

Dubet, François. 2004. "Between a Defence of Society and a Politics of the Subject: The Specificity of Today’s Social Movements.” Current Sociology. 52:693

Dudley, Harold M. 1932. "The Election of 1864." Mississippi Valley Historical Review. 18(4):500-518

Fink, Bob. 2010. "Vietnam -- A View From the Walls: A History of the Vietnam AntiWar Movement” from http://www.greenwych.ca/vietnam.htm

Fisher, Ronald J. 1992. “The Potential for Peacebuilding Forging a Bridge from Peacekeeping to Peacemaking.” Peace \& Change. 18(3):247-266

Franke, Volker. 1997. “Warriors for Peace: The Next Generation of U.S. Military Leaders.” Armed Forces \& Society. 24(1):33-57 
Franke, Volker. 1999.Preparing for Peace: Military Identity, Value Orientations, and Professional Military Education. Westport, CT: Praeger Publishers.

Franke, Volker. 2000. "Duty, Honor, Country: The Social Identity of West Point Cadets.” Armed Forces \& Society. 26(2):175-202

Franke, Volker. 2001. "Generation X and the Military: A Comparison of Attitudes and Values Between West Point Cadets and College Students.” Journal of Political and Military Sociology. 29(1):92-119

Joseph A. Fry. 1966. "From Open Door to World Systems: Economic Interpretations of Late-Nineteenth-Century American Foreign Relations," Pacific Historical Review 65, pp. 277-303

Greenberg, David. 2003. "Slate: Advice and Dissent - How Anti-Aar Protest Movements Have Made the U.S. Stronger,” from http://www.slate.com/id/2080735, posted March 26, 2003

Hickey, Donald R. (1990). The War of 1812: A Forgotten Conflict. University of Illinois Press.

Highleyman, Liz. 2004. "Peace Activism and GLBT Rights.” Gay \& Lesbian Review Worldwide. 11(5):22-25

Hoey, John B. 2000. "Federalist Opposition to the War of 1812. The Early America Review, from http://www.earlyamerica.com/review/winter2000/.

Hogg, Michael A., Dominic Abrams. 1988. Social Identifications, London: Routledge, pp. 6-29 
Hogg, Michael A., Deborah J. Terry, Katherine M. White. 1995. “A Tale of Two Theories: A Critical Comparison of Identity Theory With Social Identity Theory.” Social Psychology Quarterly. 58(4):255-269

Howard, Judith A. 1994. "From Changing Selves toward Changing Society." The SelfSociety Dynamic. Callero and Howard (eds.). pp. 209-227

Howard, Judith A. 2000. “Social Psychology of Identities.” Annual Review of Sociology. Vol. 26: 367-393

Eyerman, Ron, Andrew Jamison. 1989. The Making of the New Environmental Consciousness: A Comparative Study of the Environmental Movements in Sweden, Denmark and the Netherlands. Philadelphia: Temple University Press

Iraq Veterans Against the War. http://ivaw.org/, 17 Feb 2009

James, William. 1890/1981. Principles of Psychology. Cambridge, MA: Harvard University Press, pp. 280-284

Jay, William. 1849. A Review of the Causes and Consequences of the Mexican War. Boston, MA: Benjamin B. Mussey \& Co.

Jennings, M. Kent, Gregory B. Markus. 1977. “The Effect of Military Service on Political Attitudes: A Panel Study.” The American Political Science Review. 17(1):131-147

Karp, Walter. 2003. The Politics of War: The Story of Two Wars Which Altered Forever the Political Life of the American Republic 1890-1920. Mt. Kisco, NY: Moyer Bell Ltd. 
King, Brayden. 2007. “A Social Movement Perspective of Stakeholder Collective Action and Influence.” Business Society. 47:21

Kutz-Flamenbaum, R. V. 2007. "Ideology, Identity, and Issues: A Broad View of the Contemporary Women's Movement" Paper presented at the annual meeting of the American Sociological Association, from http://www.allacademic.com/meta/p182269_index.html

Leip, Dave. 2009. "1864 Presidential Election - Home States". Dave Leip's Atlas of U.S. Presidential Elections. http://www.uselectionatlas.org/USPRESIDENT/home.php?year=1864\&f=0. Retrieved January 112009.

McCall, George, Jerry Simmons. 1966. Identities and Interactions, New York, NY: Free Press, pp. 61-81

Mead, George H. 1934. Mind, Self, and Society. Chicago, IL: University of Chicago Press in Four Sociological Traditions 1994. R. Collins (ed.). pp. 290-303. Oxford University PressMelucci, Alberto, John Keane, Paul Mier. (eds.) 1989. Nomads of the Present: Social Movements and Individual Needs in Contemporary Society. London: Hutchinson Radius

Miethe, Ingrid. 2002. “Collective Identity and Social Movements: A Comparison between Group Discussion and Narrative Interview.” Paper presented at the International Sociological Association, Brisbane, Australia.

Miller, John Chester.1951. Crisis in Freedom: The Alien and Sedition Acts. Boston, MA: Little Brown \& Co. 
Murdock, Eugene C. 1967. Patriotism Limited 1862-1865: The Civil War Draft and the Bounty System. Kent State University Press

Murdock, Eugene C. 1971. One Million Men: The Civil War Draft in the North. Madison, WI: State Historical Society of Wisconsin

Parsons, Talcott. 1951. The Social System. New York, NY: Free Press, pp. 24-26; 38-39

Parsons, Talcott, E.A. Shils. 1951. Toward a General Theory of Action. Cambridge, MA: Harvard

Peterson, Abby. 1989. “Review Essay: Social Movement Theory.” Acta Sociologica. (32)4:419-426

Peace III, Roger C. 1991. A Just and Lasting Peace: The U.S. Peace Movement from the Cold War to Desert Storm. Chicago, IL: The Noble Press

Pilliavin, Jane A., Jean A. Grube, Peter L. Callero. 2002. "Role as Resource For Action In Public Service.” Journal of Social Issues. (58)4:469-485

Polletta, Francesca, James M. Jasper. 2001. “Collective Identity and Social Movemement.” Annual Review of Sociology. 27:283-305

Polner, Murray, Thomas E.Woods, Jr. 2008. We Who Dared to Say No to War. Philadelphia, PA: Perseus Book Group

Riley, Anna., Peter J. Burke. 1995. “Identities and Self-verification in the Small Group.” Social Psychology Quarterly. (58)2:61-73

Roberts, S.V., M. Daniel. 1990. "Return of the Peace Protests.” U.S. News \& World Report. 109(19) 
Roberts, S.V., K.T. Walsh. 1991. "Not All Quiet on the Western Front.” U.S. News \& World Report. 110(3): 43

Robinson, Dawn T., Lynn Smith-Lovin. 1992. "Selective Interaction as a Strategy for Identity Management: An Affect Control Mode.” Social Psychology Quarterly (55) $1: 1-28$

Robnett, B. 2005. "We Don't Agree: Collective Identity Justification Work in Social Movement Organizations" Paper presented at the annual meeting of the American Sociological Association, from http://www.allacademic.com/meta/p18562_index.html

Romero, Frances. 2009. “A Brief History of Antiwar Movements in the U.S.” Time Magazine. Oct. 07, 2009

Smith, James Morton. 1967. Freedom's Fetters: The Alien and Sedition Laws and American Civil Liberties. Cornell University Press

Starr, Alexandra, Lee Walczak. 2004. “Kerry's War Record: A Double-Edged Sword?” Business Week. 3871:53

Stavro, Elaine. 2007. "Rethinking Identity and Coalitional Politics, Insights from Simone de Beauvoir.” Canadian Journal of Political Science/Revue. 40(2):439-463

Stets, Jan E., Peter J. Burke. 2000. “Identity Theory and Social Identity Theory.” Social Psychology Quarterly. 63(3):224-237

Stromberg, Joseph R. 1998. “The Spanish-American War: The Leap into Overseas Empire.” http://www.independent.org/newsroom/article.asp?id=1344. 
Stryker, Sheldon, Richard T. Serpe. 1982. "Commitment, Identity Salience, and Role Behavior: Theory and Research Example.” In William Ickes \& Eric Knowles (Eds.). Personality, Roles, and Social Behavior, pp. 199-218. New York: Springer-Verlag.

Stryker, Sheldon. 2000. " Identity Competition: Key to Differential Social Movement Participation?" Self, Identity, and Social Movements. 13:21-40

Swidler, Ann. 1986. “Culture in Action: Symbols and Strategies.” American Sociological Review. 51(2):273-286

Tajfel, Henri, John Turner. 1979. "An Integrative Theory of Intergroup Conflict." The Social Psychology of Intergroup Relations, pp. 94-109. Monterey, CA: BrooksCole.

Taylor, Alan. 2004. "The Alien and Sedition Acts" in Julian E. Zelizer, ed. The American Congress, pp. 63-76

Turner, Ralph H. 1978. “The Role and the Person.” The American Journal of Sociology. (84)1:1-

Veterans for Peace. 2010. http://www.veteransforpeace.org/, 17 Feb 2009

Volunteer for Liberty. 2010. www.alba.valb.org, newsletter of the Abraham Lincoln Brigade, February 1941. Volume III, No. 2

Wittner, Lawrence S. Rebels Against War: The American Peace Movement, 1933-1983. Philadelphia: Temple University Press

Wright, James. 2008. “D.C. Religious Leaders Host Peace Festival.” Afro - American Red Star. 116 (52):A.3 
Yale. 2010. www.yale.edu

Yu, Fu-Lai Tony, Diana Sze Man Kwan. 2008. "Social Construction of National Identity: Taiwanese versus Chinese Consciousness.” Social Identities. 14(1):33-52

Zakaria, Fareed. 1999. From Wealth to Power: The Unusual Origins of America's World Role. Princeton: Princeton University Press

Zaroulis, Nancy, Gerald Sullivan. 1984. Who Spoke Up? American Protest Against the War in Vietnam, 1963-1975. New York: Holt, Rinehart and Winston

Zwick, Jim (ed). 1992. Mark Twain's Weapons of Satire: Anti-Imperialist Writings on the Philippine-American War. New York: Syracuse University Press 


\section{APPENDIX A}

INTERVIEW RECRUITMENT POSTER

Are you a veteran?
Are you interested in talking about the peace
movement?
I am a veteran, and a graduate student here at PSU. My
looking for veterans who are no longer actively serving.
wersonal information will be kept confidential. Would you be
willing sit down for an interview and share your thoughts?
If so, please contact me at
Iwegener@pdx.edu or (503) 725-9025




\section{APPENDIX B \\ INTERVIEW COVER LETTER}

\section{Peace, War, \& Principled Action - A Study of Veterans and the Peace Movement}

My name is Laura K. Wegener, and I am a student at Portland State University (PSU). I am beginning a study on U.S. veterans' understandings of the peace movement and their contact with, or involvement in, peace movements, and would like to invite you to participate.

You are being asked to take part because you are a U.S. Veteran. As part of the study, I am interested in your opinions and attitudes about the peace movement, and hope that the information I collect will help us to better understand veterans and the peace movement. If you decide to participate, you will be asked to participate in a one-on-one interview either face-to-face at a location of your choosing, or over the phone, which involves answering questions about your understanding of, and involvement in, the peace movement. It should take approximately 45-60 minutes to complete.

I assure you that any information gathered will be held in the closest confidence. No identifying information will be in the interview transcript and all interview audio tapes and transcripts will be kept in a locked filing cabinet. You may not receive any direct benefit from taking part in this study, but the study may help to increase knowledge that may help others in the future.

Any information that is obtained in connection with this study and that can be linked to you or identify you will be kept confidential. Subject identities will be kept confidential, and you will be given the opportunity to pick a pseudonym for yourself before the interview begins.

Participation is entirely voluntary. Your decision to participate or not will not affect your relationship with the researcher or with PSU in any way. If you decide to take part in the study, you may choose to withdraw at any time without penalty. Please keep a copy of this letter for your records.

If you have concerns or problems about your participation in this study or your rights as a research subject, please contact the Human Subjects Research Review Committee, Office of Research and Sponsored Projects, 600 Unitus Bldg., Portland State University, (503) 725-4288 / 1-877-480-4400. If you have questions about the study itself, contact Laura K. Wegener at 3904 SE $115^{\text {th }}$ Ave., Portland, OR 97266, (503) 761-1686.

Sincerely,

Laura K. Wegener

PSU Sociology Department 


\section{APPENDIX C}

\section{LETTER OF CONSENT}

\section{Peace, War, \& Principled Action - A Study of Veterans and the Peace Movement}

You are invited to participate in a research study conducted by Laura K. Wegener from Portland State University (PSU), Sociology. The researcher focus on US veterans' perception of the peace movement and their contact with, or involvement in, peace movements is aimed at better understanding what brings a veteran to the peace movement, as well as why a veteran would choose more to become part of a peace movement effort. Ms. Wegener is a graduate student at PSU and this study is conducted as a graduation requirement for her master's degree. The study will be conducted under that supervision of Dr. Peter Collier, a faculty member of the Sociology Department at PSU.

If you decide to participate, you will be asked to participate in an audio-recorded interview with Ms. Wegener. These interviews will be conducted once, in-person, and will last approximately 45-60 minutes. If it is not possible for you to meet with Ms. Wegener at a location of your choice, the interviews may also be conducted over the telephone. While participating in this study, it is possible that topics may come up that are emotionally sensitive or may cause emotional discomfort. If at any time you feel uncomfortable, or wish to end the interview, you can simply inform Ms. Wegener, and the interview will cease. You may not receive any direct benefit from taking part in this study, but the study may help to increase knowledge which may help others in the future.

Any information that is obtained in connection with this study and that can be linked to you or identify you will be kept confidential. Finally, Ms. Wegener will make a copy of the transcript available to you after the interview if you should request one.

Your participation is voluntary. You do not have to take part in this study, and it will not affect your relationship with either Ms. Wegener or PSU. You may also withdraw from this study at any time without recrimination.

If you have concerns or problems about your participation in this study or your rights as a research subject, please contact the Human Subjects Research Review Committee, Office of Research and Sponsored Projects, 600 Unitus Bldg., Portland State University, (503) 725-4288 / 1-877-480-4400. If you have questions about the study itself, contact Laura K. Wegener at 3904 SE $115^{\text {th }}$ Ave., Portland, OR 97266, (503) 761-1686.

Your signature indicates that you have read and understand the above information and agree to take part in this study. Please understand that you may withdraw your consent at any time without penalty, and that, by signing, you are not waiving any legal claims, rights or remedies. The researcher will provide you with a copy of this form for your own records.

Signature

Date 


\section{APPENDIX D}

\section{INTERVIEW GUIDE}

\section{INRODUCTORY/RAPPORT BUILDING}

1. What service were you in?

2. How long did you serve?

3. Where did you serve?

4. What type of work did you do?

5. Were you ever overseas? [Probe - When? Where? Combat areas?]

6. Looking back on it now, what are your thoughts about your service? [Probe Miss it? Good times? Bad times?]

7. Are you aware of the current peace movement? [Probe - are you also aware of the veteran peace movement?]

8. What do you think of the peace movement? [Probe - Can you tell me more about what you mean?]

9. Are you involved in either of them? (If involved go to question 10, if not involved go to question 25)

\section{IF INVOLVED}

10. How did you get involved in the peace movement? [Probe - Can you elaborate on that?]

11. Why did you get involved in the peace movement?

12. From whom or what did you get your information on peace movements?

13. Do you feel your involvement in the peace movement is making a difference? [Probe - Why or why not?]

14. What keeps you involved? [Probe - Please elaborate/explain; if still not answered: Probe - Family? Friends? Other reasons?]

15. What did you do when you first started your involvement with the peace movement?

16. What do you do now?

17. Who do you work with when you take these actions?

18. Do you think your story on peace movements is like other activists you know? [Probe - Please elaborate on that.]

19. What do you think veterans have to offer the peace movement? [Can you please tell me more about that?]

20. You mentioned that you [act alone/are involved with an organization], why do you prefer this type of involvement? [Probe: Can you tell me more about that?]

\section{IF IN AN ORGANIZATION}


21. Why did you choose to become involved in this particular group over others that deal with the same issue?

22. Do you think this is a better or more effective organization than others? [Probe Why or why not?]

\section{IF ACT ALONE}

23. Why did you choose not to become involved in an organized, formal organization?

24. What do you see as the benefits and drawbacks to acting alone? [Probe-Can you explain that some more, please?]

\section{IF NOT INVOLVED:}

25. Do you know veterans involved in it?

26. What do you think veterans involved in the movement get from their involvement?

27. What does involvement in peace movement mean to you?

28. What do you think it means to others?

29. What, if anything, do you think veterans have to offer the movement?

30. Why aren't you involved in it?

\section{FINAL QUESTIONS:}

31. Can you suggest others you may know that might be willing to be interviewed? I am looking for all types and levels of involvement or uninvolvement.

32. Is there anything else you'd like to add? 


\section{APPENDIX E}

\section{CODEBOOK}

\section{Peace movement}

110 It is

111 Defective (Dead, complacent, fragmented, etc.)

112 A good idea

113 Outdated

114 Harmful

115 Unrealistic/overly idealistic

116 About the troops

117 A legacy for the next group

116 Too passive

120 Identify with

121 Lost faith in government (lie to, used, betrayed, etc.)

122 War in unjust (based on lies, is due to political/personal agendas, is about oil, etc.)

124 Violence is bad

125 Waste of life for nothing

126 Need to end American imperialism

130 Do not identify with

131 Trust government \& leadership

132 War is just/honorable

133 Peace/goals are unrealistic

134 Presence is humanitarian

140 What is gained

141 Healing

142 Helping others

143 Camaraderie

144 Sense of purpose or value

145 Awareness

246 Social change

200 Getting Involved

210 How got in

211 Recruited

212 Seeking like-minded others

213 Progression from other activism areas

220 Why got in

221 Angry 
222 Betrayed

223 Needed to heal

224 Event trigger

225 Saw that could make difference

230 Where get info

231 Professors

232 Independent research

233 Other veterans

234 Student groups

240 Why stay involved

241 So much to do

242 Enjoy it

243 Urge to speak out

250 What is involvement

251 Marching, tabling, \& rallying

252 Attending meetings

253 Lobbying

254 Educating \& recruiting others

255 Speaking to media \& outreach

256 Direct action (Resisting/refusing deployment, etc.)

260 Why not involved

261 Don't agree with (credible threat, inevitable, etc.)

262 No time (school, other obligations, etc.)

263 Nothing to add or contribute (enough people, not in combat, etc.)

264 Waste of time (pointless, etc.)

265 Moved on

\section{Organization}

310 Why choose this org/group

311 Only one available

312 Aligned with personal goals/beliefs (Non-violent, More radical, etc.)

313 Couldn't do it alone

314 Reach (overseas, etc.)

\section{Why org/group}

321 Strength in numbers

322 Established methods/means (no point in reinventing the wheel, etc.)

323 Get more done

324 Group movements, not individuals, can make change

325 More effective 
330 Bennies of group

331 Camaraderie

332 Presence

333 Vindication

340 Drawbacks of group

341 Bureaucracy

342 Too passivist

400 Alone

410 Why alone

411 Hate bureaucracy

412 More intimate connection

420 Benefits of alone

421 Flexibility of action

422 There are none

423 Tighter focus

430 Drawbacks of alone

431 No voice

432 No support

433 There are none

500 Veterans

510 Vets get

511 Healing

512 Sense of purpose

513 Camaraderie

514 Helps with conscience

515 Protect others

520 Vets offer

521 Perspective

522 Experience

523 Leadership

524 Legitimacy

525 Credibility

526 Voice of sanity

527 Skills with tactics, strategies, guns

528 Nothing 
530 Other

531 Stereotypes of activists

531 Disloyal/betrayal of service (should know better, whiners, etc.)

600 Feelings about the military

610 The Good

611 Good people

612 Good missions

613 Amazing experiences

614 Discipline

615 Honorable/Proud

630 The Bad

631 Lied to

632 Used

633 Turned into joiners/yes-men

634 Most traumatic experience of life

635 Regrettable (negative impact on world, etc.)

640 Ambivalence

641 Come to terms with

642 Best choice at time

643 Would not do again 